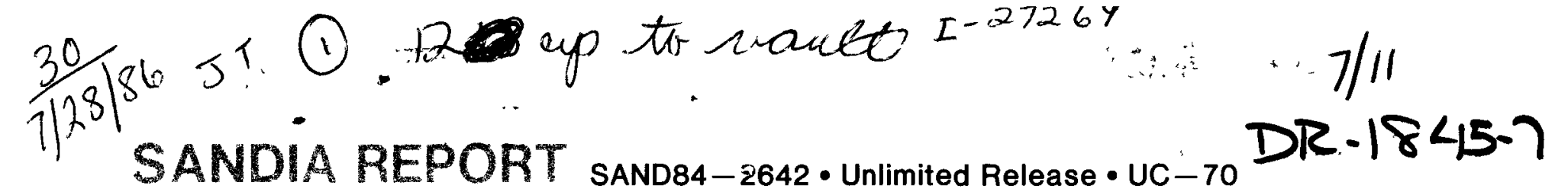

Printed July 1986

\title{
Estimation of Hydrologic Properties of An Unsaturated, Fractured Rock Mass
}

Elmer A. Klavetter, Ralph R. Peters

Prepared by

Sandia National Laboratories

Albuquerque, New Mexico 87185 and Livermore, California 94550

for the United States Department of Energy

under Contract DE-AC04-76DP00789 
Issued by Sandıa National Laboratories, operated for the United States Department of Energy by Sandia Corporation

NOTICE: This report was prepared as an account of work sponsored by an agency of the United States Government Neither the United States Govern ment nor any agency thereof, nor any of their employees, nor any of their contractors, subcontractors, or their employees, makes any warranty, ex press or implied, or assumes any legal liablity or responsibility for the press or implied, or assumes any legal lability or responsibility for the
accuracy, completeness, or usefulness of any information, apparatus, product, or process disclosed, or represents that its use would not infringe privately owned rights Reference herein to any specific commercial product, process, or service by trade name, trademark, manufacturer, or otherwise, does not necessarily constitute or imply its endorsement, recommendation or favoring by the United States Government, any agency thereof or any of or favoring by the United States Government, any agency thereof or any of in do not necessarily state or reflect those of the United States Government, any agency thereof or any of their contractors or subcontractors

\author{
Printed in the United States of America \\ Avallable from \\ National Technical Information Service \\ US Department of Commerce \\ 5285 Port Royal Road \\ Springfield, VA 22161 \\ NTIS price codes \\ Printed copy A0 \\ Microfiche copy A01
}

\title{
DISCLAIMER
}

This report was prepared as an account of work sponsored by an agency of the United States Government. Neither the United States Government nor any agency thereof, nor any of their employees, makes any warranty, express or implied, or assumes any legal liability or responsibility for the accuracy, completeness, or usefulness of any information, apparatus, product, or process disclosed, or represents that its use would not infringe privately owned rights Reference herein to any specific commercial product, process, or service by trade name, trademark, manufacturer, or otherwise does not necessarily constitute or imply its endorsement, recommendation, or favoring by the United States Government or any agency thereof The views and opinions of authors expressed herein do not necessarily state or reflect those of the United States Government or any agency thereof. 


\section{DISCLAIMER}

Portions of this document may be illegible in electronic image products. Images are produced from the best available original document. 

SAND84-2642

Unlimited Release

Printed July 1986

Category UC -70

\title{
MASIT:
}

\section{Estimation of Hydrologic Properties of An Unsaturated, Fractured Rock Mass}

\author{
Elmer A. Klavetter and Ralph R. Peters \\ Nevada Nuclear Waste Storage Investigations Project \\ Sandia National Laboratories \\ Albuquerque, NM 87185 \\ SAND- $-84-2642$ \\ DE86 013379
}

\begin{abstract}
The geologic formations in the unsaturated zone underlying Yucca Mountain, on and adjacent to the Nevada Test Site (NTS), are currently being investigated as a possible host for a radioactive-waste repository; the US Department of Energy (DOE) is carrying out these studies through the Nevada Nuclear Waste Storage Investigations (NNWSI) project. The Yucca Mountain site is unique among those investigated in that the prospective repository horizon lies entirely in the unsaturated zone. The geologic formations underlying Yucca Mountain are made up of nonwelded and welded tuffs. The nonwelded tuffs have both high- and low-conductivity matrix material with a small fracture density. The welded tuffs have a low-conductivity matrix material and are highly fractured. Flow models used to characterize water-movement paths and velocities must deal with the possibility of flow in both the matrix and fractures. Because of the large number of fractures that can exist in the system of interest, it is not generally feasible to model fractures explicitly. It is, therefore, necessary to develop a model describing the hydrologic characteristics of a rock mass containing both matrix and fractures.
\end{abstract}

In this document, two distinctly different approaches are used to develop continuum models to evaluate water movement in a fractured rock mass. Both models provide methods for estimating rockmass hydrologic properties. Comparisons made over a range of different tuff properties show good qualitative and quantitative agreement between estimates of rock-mass hydrologic properties made by the two models.

This document presents a general discussion of (1) the hydrology of Yucca Mountain and the conceptual hydrological model currently being used for the Yucca Mountain site, (2) the development of two models that may be used to estimate the hydrologic properties of a fractured, porous rock mass, and (3) a comparison of the hydrologic properties estimated by these two models. Although the models were developed in response to hydrologic characterization requirements at Yucca Mountain, they can be applied to water movement in any fractured rock mass that satisfies the given assumptions. 


\section{Contents}

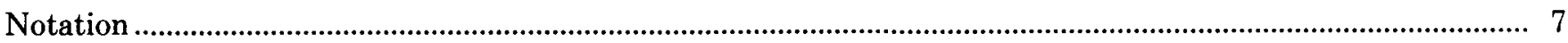

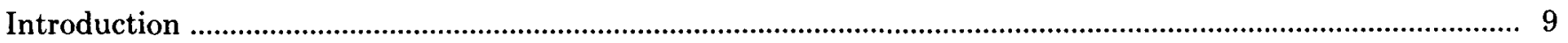

General Discussion of the Yucca Mountain Hydrologic System ....................................................................... 9

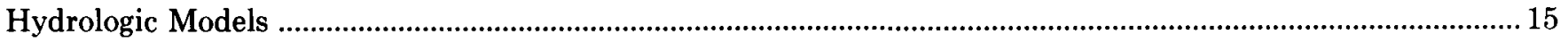

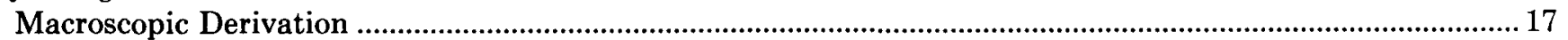

Microscopic Derivation ……………………………………………………………………………………. 27

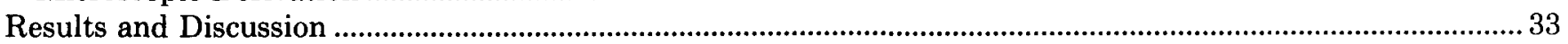

Comparison of the Macroscopic and Microscopic Approaches .......................................................................... 34

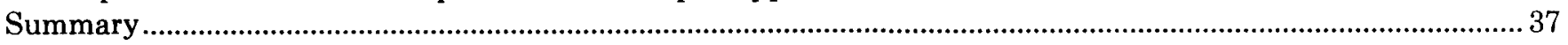

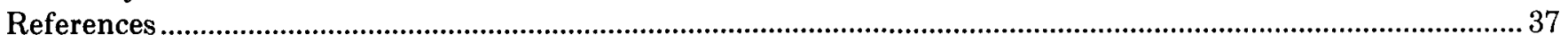

APPENDIX A-Derivation of the Flow Equation ………………………………………………………… 41

APPENDIX B-Comparison of Several Models of Relative Hydraulic Conductivity ........................................ 45

\section{Figures}

1 Location of Yucca Mountain on the Nevada Test Site, Nye County, Nevada ...........................................10

2 Comparison of the Formal Geologic and Functional Stratigraphies in Drillhole USW G-4 …...................12

3 East-West Cross-Section at Yucca Mountain With Conceptual Model of Flow ......................................... 12

4 Conceptual Model of Fluid Flow in a Fracture Plane at Increasing Levels of Saturation..........................14

5 Saturation Curve for Sample G4-6 Taken From Unit TSw2................................................................... 19

6 Representative Matrix Saturation Curves for Hydrologic Units in the Unsaturated Zone ........................20

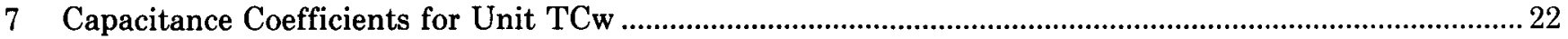

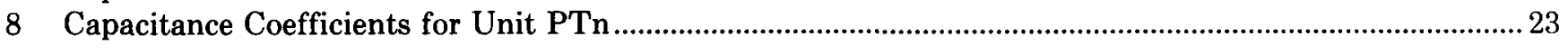

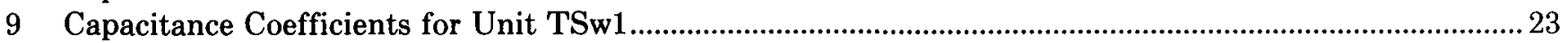

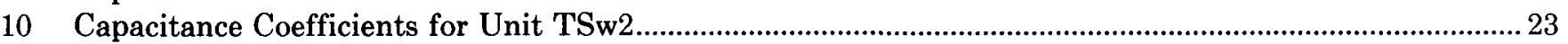

11 Capacitance Coefficients for Unit TSw3

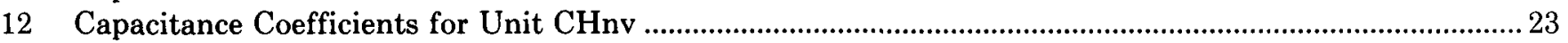

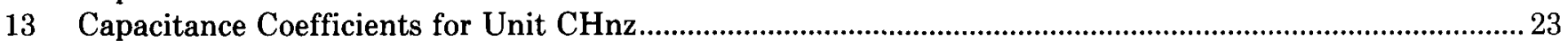

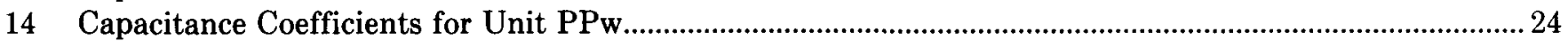

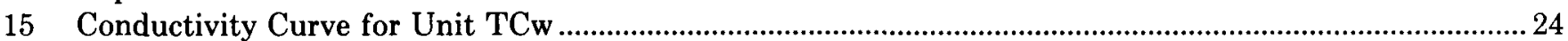

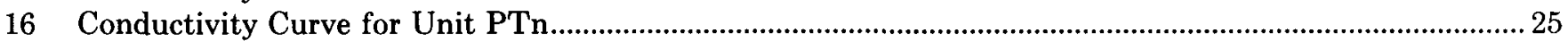

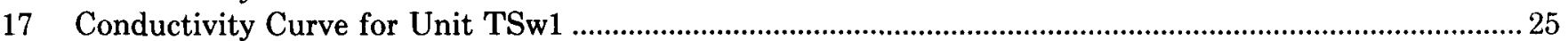

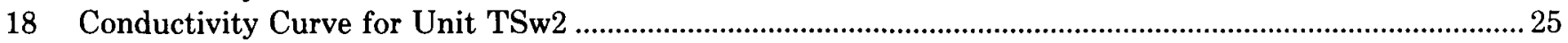

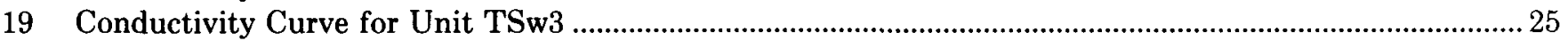

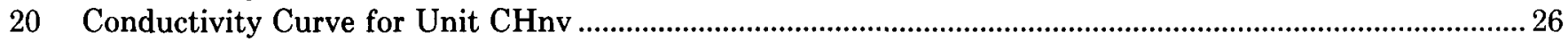

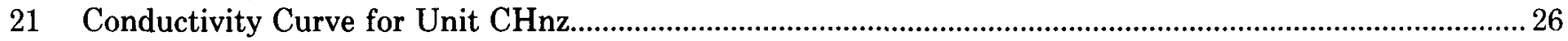

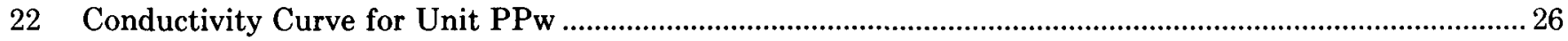

23 Incremental Mercury-Intrusion Volume Versus Pore Diameter for a Matrix Sample From Unit TCw....

24 Incremental Mercury-Intrusion Volume Versus Pore Diameter for a Matrix Sample From Unit TSw2.

25 Incremental Mercury-Intrusion Volume Versus Pore Diameter for a Matrix Sample From

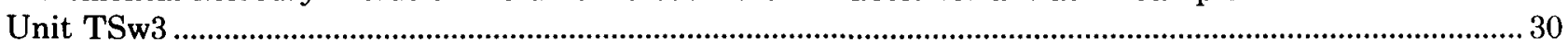

26 Incremental Mercury-Intrusion Volume Versus Pore Diameter for a Matrix Sample From

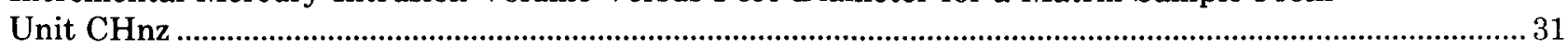

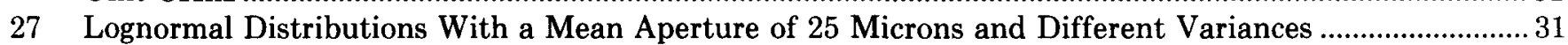

28 Fracture Relative-Hydraulic-Conductivity Curves as Calculated From a Lognormal Distribution of Apertures Using Different Values of the Variance ..................................................................................34

29 Hydraulic Conductivity Comparison for Rock Mass Material of Unit TCw.............................................35

30 Hydraulic Conductivity Comparison for Rock Mass Material of Unit TSw2 ........................................... 35 


\section{Figures (continued)}

31 Hydraulic Conductivity Comparison for Rock Mass Material of Unit TSw3 ..............................................35

32 Hydraulic Conductivity Comparison for Rock Mass Material of Unit CHnz ..............................................35

\section{Tables}

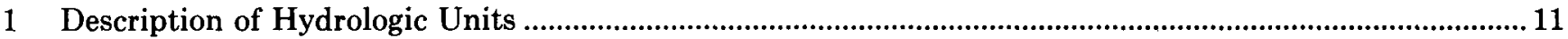

2 Properties Assumed for Unsaturated Zone, Hydrologic Units .....................................................................2 21

3 Property Values Used in Model Comparison ................................................................................................36

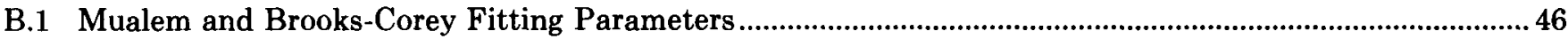




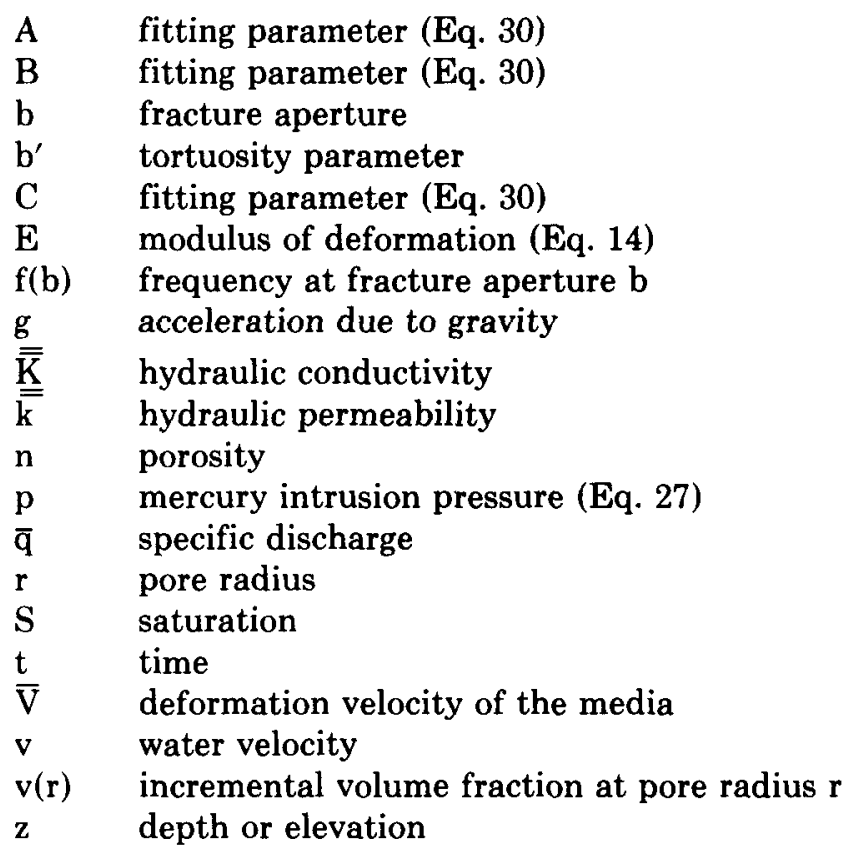

\section{Greek Symbols}

$\alpha \quad$ fitting parameter (Eq. 12)

$\alpha_{\text {1.uth }} \quad$ coefficient of consolidation

$\beta \quad$ fitting parameter (Eq. 12)

$\beta_{1}^{\prime} \quad$ water compressibility

$\epsilon \quad$ Brooks-Corey constant (Eq. B.1)

$\Gamma \quad$ term describing mass transfer between matrix and fractures

$\gamma \quad$ surface tension

$\theta \quad$ volumetric water content

$\lambda \quad$ fitting parameter (Eq. 12)

$\lambda^{\prime} \quad$ fitting parameter (Eq. B.6)

$\nu \quad$ Poisson's Ratio (Eq. 14)

$\xi \quad$ parameter in lognormal distribution (Eq. 25)

$\rho$ density

$\sigma \quad$ parameter in lognormal distribution (Eq. 25)

$\sigma^{\prime} \quad$ stress in rock mass

$\phi \quad$ contact angle

$\chi \quad$ tortuosity distribution function

$\psi \quad$ pressure head

$\omega \quad$ mass transfer coefficient (Eq. 9) 


\section{Notation (continued)}

\section{Subscripts}

b bulk, referring to a rock mass property or bubbling

bulk pertaining to total rock mass

c composite; combining both matrix and fractures

eff effective

f fracture(s)

$\mathrm{Hg}$ mercury

m matrix

$r$ residual

rel relative

s saturated

tot total

w water or wetting 


\section{Estimation of Hydrologic Properties of An Unsaturated, Fractured Rock Mass}

\section{Introduction}

The geologic formations in the unsaturated zone at Yucca Mountain, on and adjacent to the Nevada Test Site (NTS), are currently being investigated as a possible host rock for a radioactive-waste repository; the US Department of Energy (DOE) is carrying out these studies through the Nevada Nuclear Waste Storage Investigations (NNWSI) project. The Yucca Mountain site is unique among those being studied as a site for a repository in that it lies entirely in the unsaturated zone. The geologic formations above the water table are composed of both fractures and porous material. The unsaturated flow that exists in Yucca Mountain has provided the impetus to formulate methods for determining hydrologic parameters for the rock mass. The purpose of this document is to discuss, in general terms, 1) the Yucca Mountain site with emphasis on characteristics that affect the hydrologic system, 2) the conceptual hydrologic model, and 3) the mathematical model of water movement in the unsaturated-zone porous medium. This mathematical model is currently being used in the NNWSI performance assessment systems code TOSPAC (Dudley et al., in preparation).

\section{General Discussion of the Yucca Mountain Hydrologic System}

The location of Yucca Mountain is shown in Figure 1. It lies within the Basin and Range physiographic province that is characterized by generally linear mountain ranges and intervening valleys. Yucca Mountain is a prominent group of north-trending, fault-block ridges. The elevation of northern Yucca Mountain is approximately $1500 \mathrm{~m}$. The ridge of Yucca Mountain is about $300 \mathrm{~m}$ above the surrounding valley floors. Yucca Mountain is made up predominantly of ash-flow and ash-fall tuffs. These tuffs can be organized into formal geologic units or into func- tional stratigraphic units. The major difference between these two methods of organization is that a formal geologic unit may contain two or more layers of rock types, each of which has much different thermal, mechanical, and hydrologic properties, whereas the functional grouping strives to identify units that have a minimum of internal variability of these properties within each unit. Information concerning the two methods of organization may be seen in Table 1 , which describes the functional units in terms of rock type and indicates which portions of the formal geologic units are included within each functional unit. The table also lists the location of both the formal geologic and functional stratigraphic units in drill hole USW G-4. (Drill hole USW G-4 is located near the eastern boundary of the proposed repository; its location along with the preliminary estimate of the proposed repository boundary is shown in Figure 1.) Figure 2 compares the two methods of organization in the form of two scaled bars.

The functional units above the water table can be organized into three basic types of rock in terms of properties affecting the hydrology.

1) Densely to moderately welded tuffs that are highly fractured. These units have low saturatedmatrix conductivities $\left(10^{-11} \mathrm{~m} / \mathrm{s}\right.$ or less for all but one unit) and high saturated-fracturesystem conductivities. (For a unit volume of rock, the total saturated conductivity of the fracture system is probably several orders of magnitude higher than the total saturated conductivity of the matrix.) The units included in this group are $\mathrm{TCw}, \mathrm{TSw} 1, \mathrm{TSw} 2, \mathrm{TSw} 3$ and $\mathrm{PPw}$. Unit PPw is the most porous and has the highest matrix conductivity of any of the units in this group. PPw also is only moderately welded while the others are densely welded.

2) Nonwelded, vitric tuffs that have few fractures. These units have high saturated-matrix conductivities (in the range of $10^{-6}$ to $10^{-8} \mathrm{~m} / \mathrm{s}$ ) and relatively low saturatedfracture-system conductivities. The units included in this group are PTn and CHnv. 
3) Nonwelded, zeolitized tuffs that have few fractures. These units have low saturated-matrix conductivities $\left(10^{-11} \mathrm{~m} / \mathrm{s}\right.$ or less) and low saturated-fracture-system conductivities. The units above the water table included in this group are $\mathrm{CHnz}$ and $\mathrm{CFUn}$.

It appears that organizing tuffs by functional stratigraphic units rather than by formal geologic units will more closely meet the needs of modelers because the functional stratigraphic units have much more uniform properties within a particular unit. These units will be referred to as the hydrologic units in further discussions. A more complete discussion of definition of the hydrologic (functional) units, the methods used to pick their boundaries, etc., may be found in a report by Ortiz et al. (1985). A discussion of the methods used to pick the preliminary boundary and location of the repository is in Mansure and Ortiz (1984). A general introduction to the geology of the region may be found in the Draft Environmental Assessment for the Yucca Mountain Site (DOE, 1984).
Information regarding the hydrology and fracture frequency was drawn from many sources, including reports by Scott et al. (1983), Peters et al. (1984), and Sinnock et al. (1984).

Figure 3 is an east-west cross-section through Yucca Mountain at the location indicated in Figure 1. It is based on information contained in the previously cited report by Ortiz et al. The positions of the hydrologic units are indicated along with the position of the water table and the approximate position of the repository. This area is characterized by very deep water tables ( $\sim 600 \mathrm{~m}$ below the crest of Yucca Mountain in Figure 3) resulting from many factors including very small recharge rates, high transmissivities in the saturated zone, and the low elevation of the discharge points (Montazer and Wilson, 1984; and Winograd and Doty, 1980). Thus, it is possible that a repository may be placed deep undergrond and still be at some distance above the water table. The water travel time from the prospective repository location to the water table could be long, with a long time required to travel along the water table to the accessible environment.

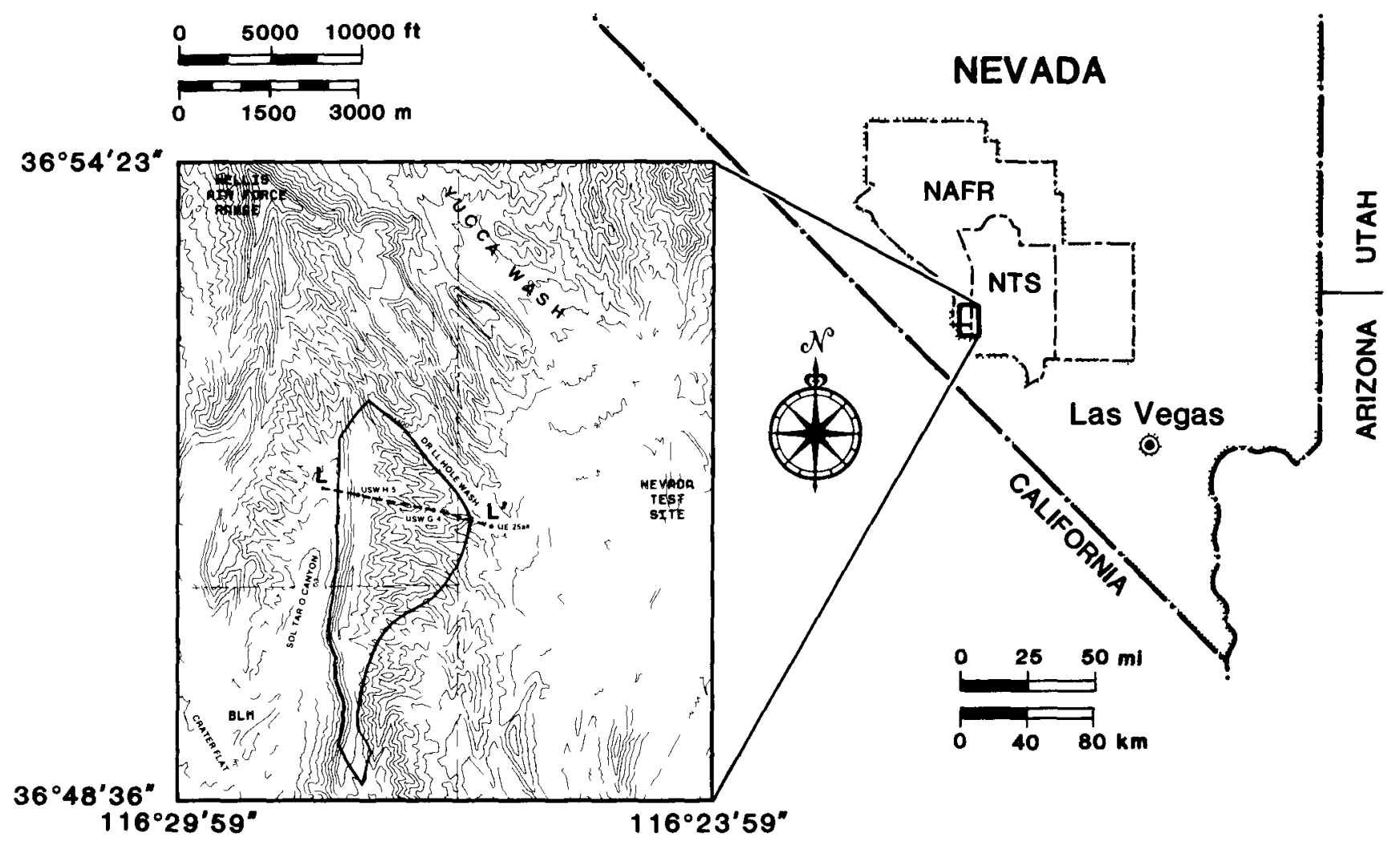

Figure 1. Location of Yucca Mountain on the Nevada Test Site, Nye County, Nevada. Outline Indicates Prelıminary Repository Boundary Cross Section in Figure 3 is Along Line L-L'. 
Table 1. Description of Hydrologic Units

\begin{tabular}{|c|c|c|}
\hline Unit & $\begin{array}{c}\text { G-4 } \\
\text { Depth }^{(8)} \\
(f t)\end{array}$ & $\begin{array}{l}\text { Hydrologic } \\
\text { Unit }\end{array}$ \\
\hline $\mathrm{TCw}$ & $22-118$ & $\begin{array}{l}\text { Tiva Canyon welded } \\
\text { unit }\end{array}$ \\
\hline PTn & $118-243$ & $\begin{array}{l}\text { Paintbrush nonwelded } \\
\text { unit }\end{array}$ \\
\hline TSw1 & $243-670$ & $\begin{array}{l}\text { Topopah Spring welded } \\
\text { unit }\end{array}$ \\
\hline TSw2 & $670-1293$ & $\begin{array}{l}\text { Topopah Spring welded } \\
\text { unit }\end{array}$ \\
\hline TSw3 & $1293-1345$ & $\begin{array}{l}\text { Basal Vitrophyre of the } \\
\text { Topopah Spring welded } \\
\text { unit }\end{array}$ \\
\hline CHn1v & $1345-1360$ & $\begin{array}{l}\text { Vitric Calico Hills non- } \\
\text { welded unit }\end{array}$ \\
\hline $\mathrm{CHn} 2 \mathrm{v}$ & Absent & $\begin{array}{l}\text { Vitric Calico Hills non- } \\
\text { welded unit }\end{array}$ \\
\hline $\mathrm{CHn} 3 \mathrm{v}$ & Absent & $\begin{array}{l}\text { Vitric Calico Hills non- } \\
\text { welded unit }\end{array}$ \\
\hline Chn1z & $1360-1705$ & $\begin{array}{l}\text { Zeolitized Calico Hills } \\
\text { nonwelded unit }\end{array}$ \\
\hline $\mathrm{CHn} 2 \mathrm{z}$ & $1705-1761$ & $\begin{array}{l}\text { Zeolitized Calico Hills } \\
\text { nonwelded unit }\end{array}$ \\
\hline $\mathrm{CHn} 3 \mathrm{z}$ & $1761-1792$ & $\begin{array}{l}\text { Zeolitized Calico Hills } \\
\text { nonwelded unit }\end{array}$ \\
\hline $\mathrm{PPw}$ & $1792-1960$ & Prow Pass welded unit \\
\hline
\end{tabular}

Moderately to densely welded, devitrified ash-flow tuffs in the Tiva Canyon Member of the Paintbrush Tuff.

Partially welded to nonwelded, vitric and occasionally devitrified tuffs of the Tiva Canyon, Yucca Mountain, Pah Canyon, and Topopah Spring Members of the Paintbrush Tuff.

Moderately to densely welded, devitrified zone of the Topopah Spring Member of the Paintbrush Tuff that contains more than approximately $10 \%$ by volume of vugs.

Moderately to densely welded, devitrified zone of the Topopah Spring Member of the Paintbrush Tuff that contains less than approximately $10 \%$ by volume of vugs. This is the potential repository unit.

Basal Vitrophyre of the Topopah Spring Member.

Nonwelded ashflows, bedded and reworked tuffs, vitric and primarily nonzeolitized Topopah Spring Member and/or the Calico Hills.

Basal, bedded and reworked zone of the vitric tuffs and tuffaceous sandstones of the Calico Hills.

Upper vitric zone of the Prow Pass Member of the Crater Flat Tuff.

Nonwelded ashflows, bedded and reworked tuffs, primarily zeolitized, from the Topopah Spring Member and/or the Calico Hills.

Basal, bedded and reworked zone of the zeolitized tuffs and tuffaceous sandstones of the Calico Hills.

Upper zeolitized zone of the Prow Pass Member of the Crater Flat Tuff.

Moderately welded, devitrified zone of the Prow Pass Member of the Crater Flat Tuff.

(a) Information from Ortiz et al. (1985)

(b) The lower case " $v$ " or " $\mathrm{z}$ " in a unit number (e.g., CHn1v) indicates whether the unit is vitric or water-induced zeolitization has occurred. 


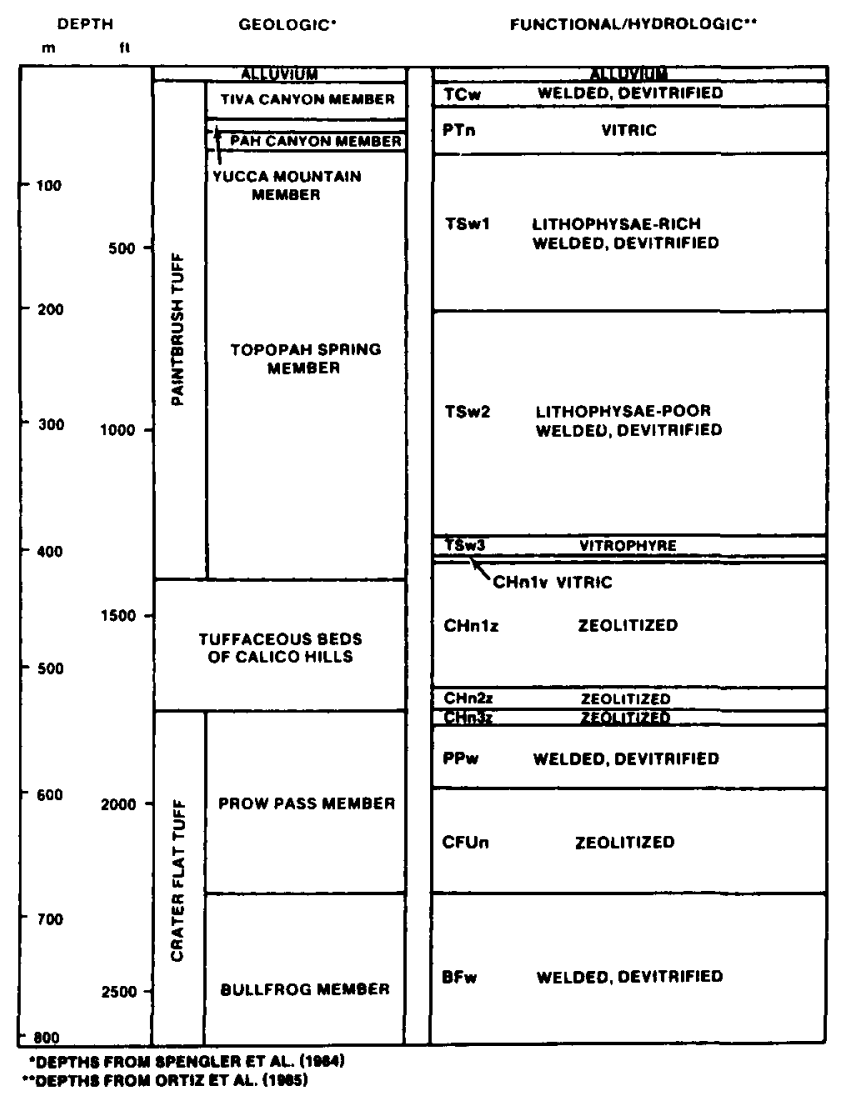

Figure 2. Comparison of the Formal Geologic and Functional Stratigraphies in Drillhole USW G-4

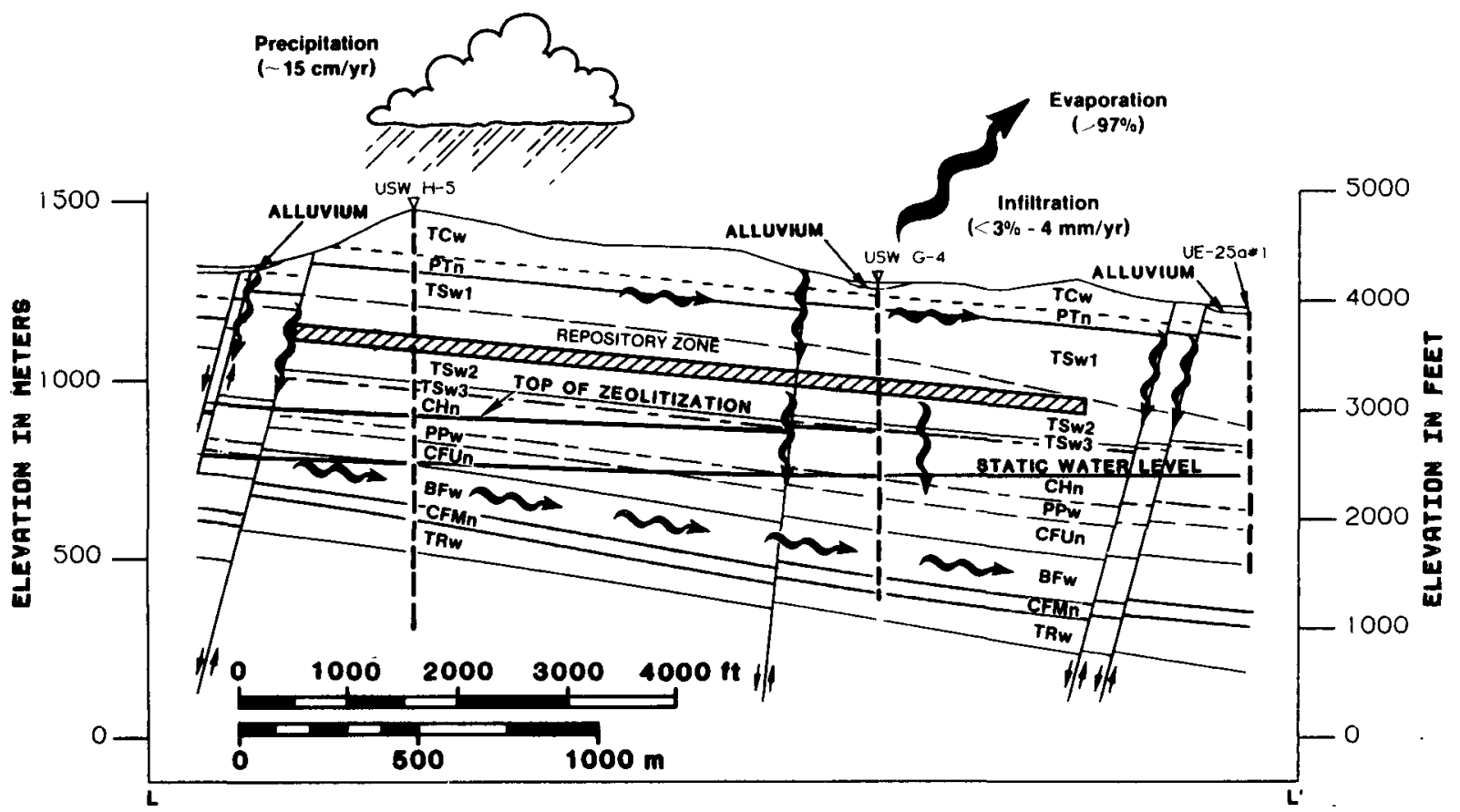

Figure 3. East-West Cross-Section at Yucca Mountain With Conceptual Model of Flow. Cross Section is Along Line L-L' in Figure 1. 
A conceptual model of the hydrologic system at Yucca Mountain is indicated schematically in Figure 3 (DOE, 1984). A small fraction of the annual precipitation infiltrates the surface of the mountain. It then begins moving down through the various units. It is possible that some portion of the total flux may be diverted at interfaces between the hydrologic units, as indicated in Figure 3. The major factors influencing whether there is any diversion of flow are the magnitude of the flux and the contrast in hydraulic conductivities on either side of the interface. If, for example, the flux arriving at an interface is larger than the saturated conductivity of the matrix-fracture system of the lower unit, then water will perch at the interface and some fraction of the total flux will be shed in a generally easterly (down-dip) direction above the boundary between the two units. At lower fluxes, the extreme contrast in hydrologic conductivity between two units (e.g., PTn and TSw1) may also cause water diversion above the boundary between the two units without the need for a perched water table to form at the interface. Calculations and field testing will be required to determine whether it is feasible to divert water in a situation where a perched water table does not form. The conceptual model for the hydrologic system at Yucca Mountain will be important background information used in the development of the conceptual and mathematical models for flow in a fractured, porous medium.

The conceptual model for flow within a fractured, porous medium used by many workers in this field is based on capillary-bundle theory (e.g., Wang and Narasimhan, 1985), which states there is a relationship between pore size and the equilibrium pressure head. Thus, the saturation of a material containing pores of many different sizes is related to the equilibrium pressure head in the material. The following discussion will assume that the average fracture aperture is 25 micrometers and the average pore diameter of the matrix is 0.03 micrometers (Peters et al., 1984). This discussion will also assume that the system is changing very slowly with time, a condition which will be true deep underground in most locations. Figure 4 shows a plan view of a very small section of a hypothetical fracture face at four different saturations. When the matrix is partially saturated, the fracture will be essentially dry because of the higher capillary suction (tension) forces in the matrix pores adjacent to the fracture. A small amount of water may exist in the fracture in regions where a small radius of curvature can be maintained. In Figure 4a, water is contained in regions where the matrix blocks are shown in contact (cross-hatched areas, local aperture $<0.1 \mathrm{mi}$ crometers) and in very thin rings around these regions (not visible in Figure 4a). The conductivity of the fracture in the plane of the fracture is zero because these little islands of fracture water are discontinuous. However, the conductivity across the fracture is not zero; the contact regions for water movement form pipelines to transfer water from one matrix block to the next. For tuffs at Yucca Mountain, the fracture conductivity for flow across the fractures has been estimated to be high compared with the conductivity within the matrix (Wang and Narasimhan, 1985).

As the matrix saturation is increased, the saturation of the fracture will also increase in a highly nonlinear manner. At a higher matrix saturation (and corresponding pressure head) these islands of water may be at the point of coalescing (Figure $4 \mathrm{~b}$ ). At this pressure, the fracture conductivity in the plane of the fracture is still essentially zero while the conductivity for water flow across the fracture has increased. At slightly higher matrix saturations (for the parameters chosen in this example the matrix saturation is of the order of 0.99999), the islands of water in the fracture have coalesced to form sinuous channels (Figure 4c); the fracture conductivity in the plane of the fracture is now nonzero. Finally, at a pressure head approaching zero, the fracture is almost completely saturated (Figure 4d).

The fracture is generally nonplanar. Thus, when there is water movement in the plane of the fracture there will be regions where there is locally high fracture flow and others where the flow is quite small. If the fracture is partially saturated, most of the flow will occur in those regions where the fracture aperture is small. Those regions where the fracture aperture is large carry no water because the aperture in this region is too large to hold any water. This concept is derived from fundamental principles of capillary theory. When the fracture is completely saturated, the situation is completely reversed. Most of the flow in the fracture occurs in those regions where the fracture aperture is large with relatively little flow occurring where the fracture aperture is small because the flow rate is proportional to the cube of aperture (Freeze and Cherry, 1979). 


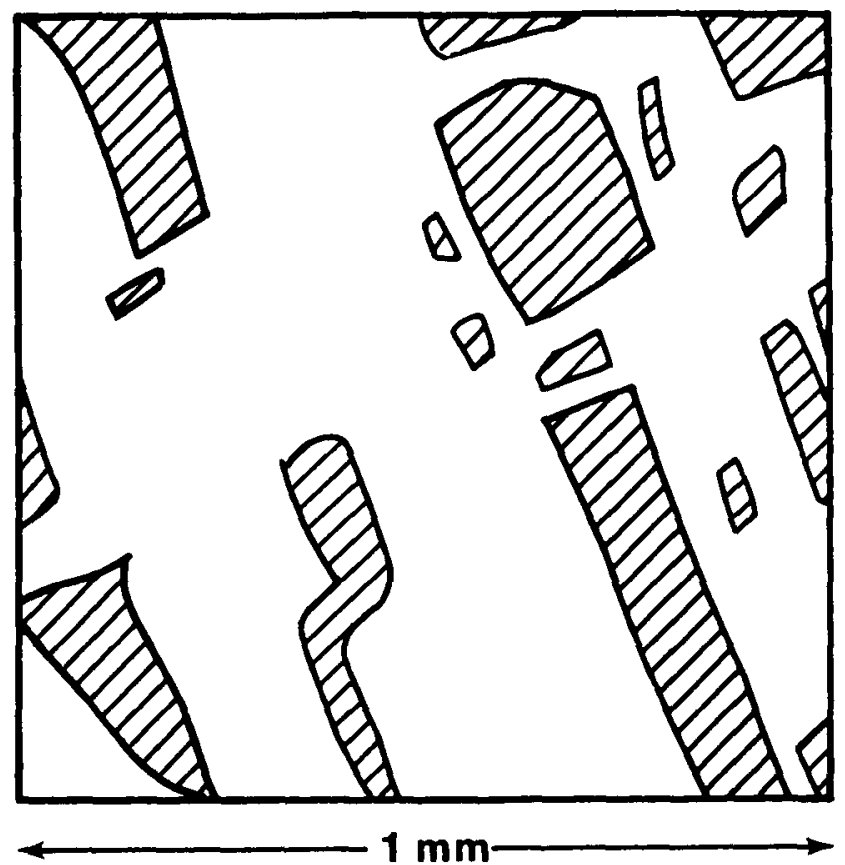

Figure Aa. Pressure head $\simeq-50 \mathrm{~m}$, fracture dry except at contacts (cross-hatch area)

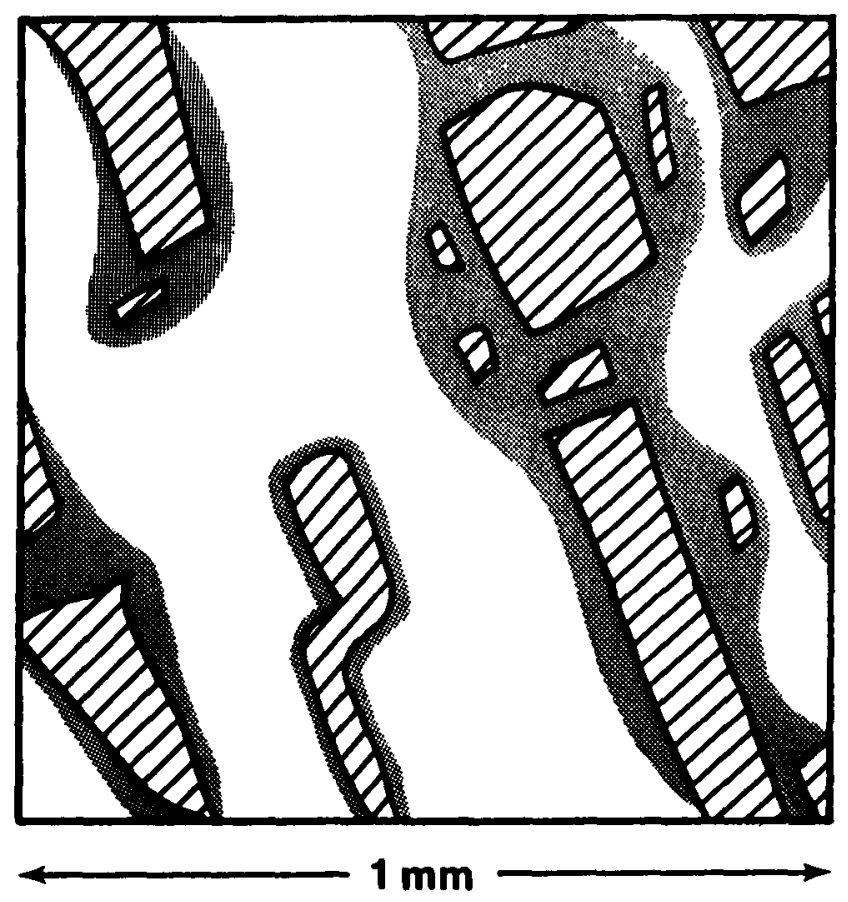

Figure Ac. Pressure $\simeq-0.5 \mathrm{~m}$, sinuous flow in fracture plane

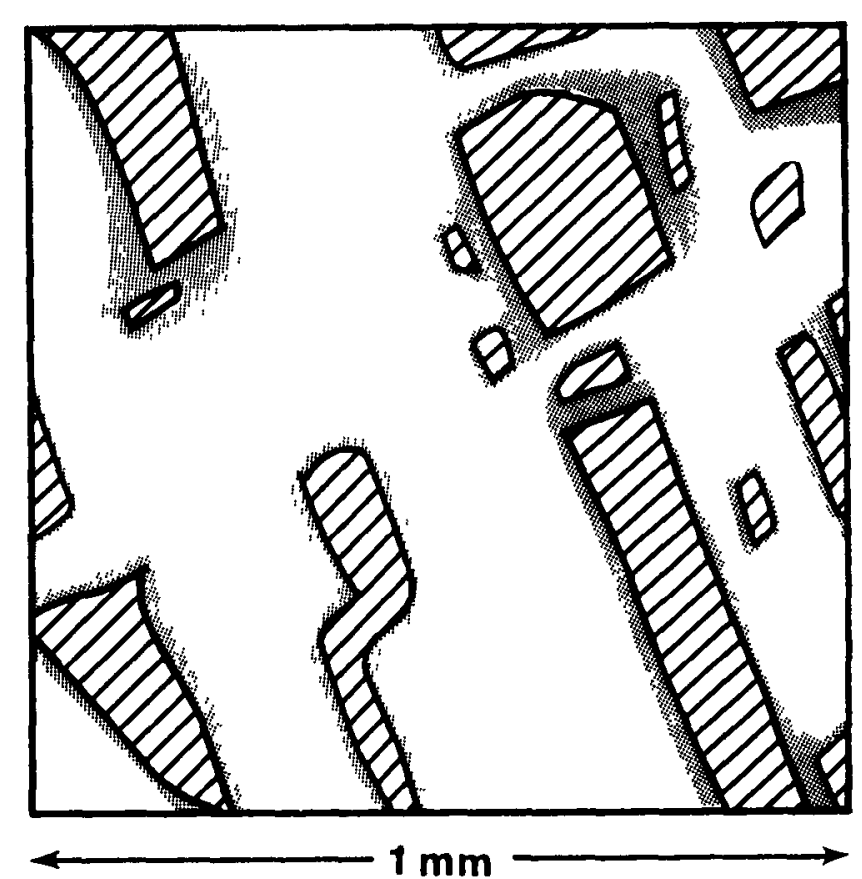

Figure ab. Pressure head $\simeq-5 \mathrm{~m}$, rings around contacts are near coalescence

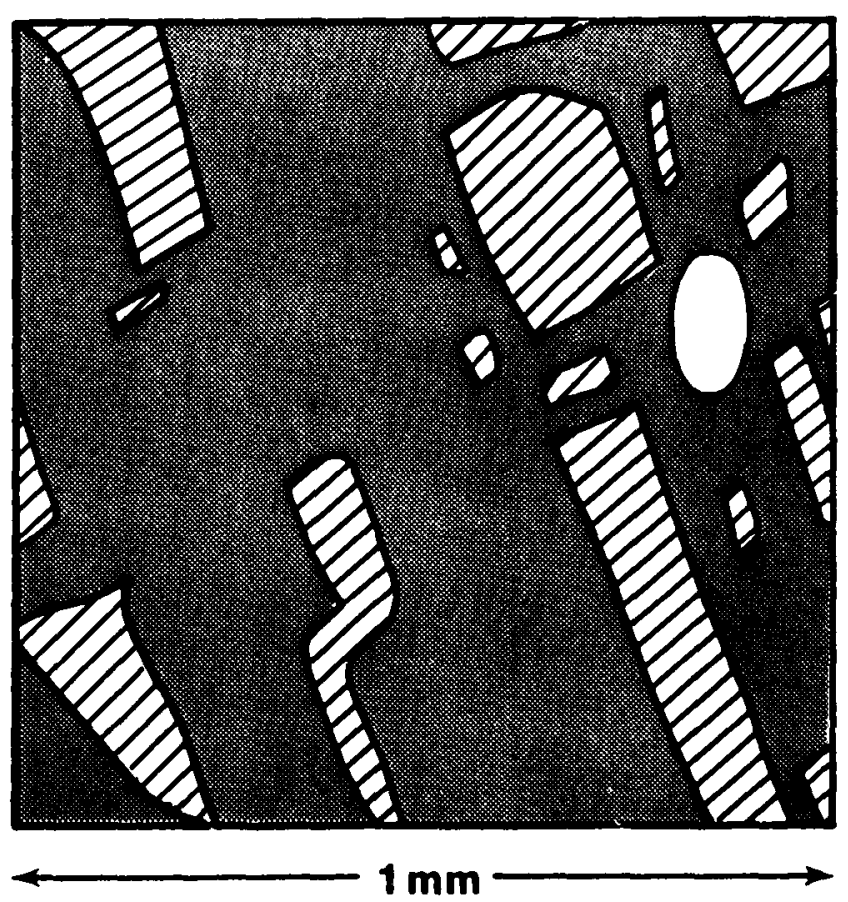

Figure Ad. Fracture near saturation, one "trapped" air bubble

Figure 4. Conceptual Model of Fluid Flow in a Fracture Plane at Increasing Levels of Saturation

14 
The conceptual model of flow in fractures used in this paper is based on the previous discussion. The major points are summarized below.

1) The fracture conductivity for water movement across the fracture is probably much larger than the adjacent matrix conductivity. Thus, flow across the fracture is controlled by the adjacent matrix conductivity. The fracture conductivity across the fracture can be replaced by the matrix conductivity in flow calculations.

2) The average fracture conductivity for water movement in the plane of the fracture is a highly nonlinear function of fracture saturation or pressure head. If the flux is less then the saturated conductivity of the matrix, then the water will tend to flow only in the matrix. If the flux is greater than the saturated conductivity of the matrix, then the matrix will saturate, and the fractures will also carry water.

The manner in which the water flows in a hydrologic unit depends on other boundary conditions besides the flux. For example, in the capillary fringe area near the water table, the matrix is always saturated because of the capillary forces of the small pores in the matrix; thus, in this capillary fringe area some water will be in the highly conductive fractures no matter how small the downward flux is. A lengthy discussion of many different mechanisms for water movement in the unsaturated zone may be found in the report by Montazer and Wilson (1984).

\section{Hydrologic Models}

The purpose of the previous section was to indicate the general setting of Yucca Mountain and to describe the conceptual hydrologic flow model. In this section, geologic and hydrologic information is used to choose appropriate mathematical models for calculations concerning the entire Yucca Mountain site. There are currently many hydrologic codes available (e.g., NETFLO - Intera, 1982; NWFT/DVM - Campbell et al., 1981; TRUST - Reisenauer et al., 1982; SAGUARO - Eaton et al., 1983; TOSPAC - Dudley et al., in preparation; NORIA - Bixler, 1985).

However, those that have tried to simulate an unsaturated, layered system where the water flow may occur in fractures as well as the matrix have generally had numerical stability problems (e.g., Bixler and Eaton, in preparation). The purpose of the following sections is to discuss the mathematical models available, including the one chosen for TOSPAC. This model may be used by other hydrologic codes.

The derivation of the equation for water flow in a partially saturated, porous medium is given in many papers (e.g., Reeves and Duguid, 1975; Freeze and Cherry, 1979; and Narasimhan, 1982). It generally begins with the expression for the conservation of fluid mass in the absence of either sources or sinks:

$\frac{\partial(\rho \theta)}{\partial \mathrm{t}}+\nabla \cdot(\rho \overline{\mathrm{q}})+\nabla \cdot(\rho \theta \overline{\mathrm{V}})=0$,

where $\rho$ is the density of water, $\theta$ is the volumetric water content (water volume per unit volume of media), $t$ is the time, $\bar{q}$ is the specific discharge (volume of water flowing per unit time through a unit crosssectional area normal to the direction of flow), and $\bar{V}$ is the deformation velocity of the medium containing the water. The first term in Eq. 1 arises from temporal changes in water content within the elemental volume, the second term from movement of water relative to the medium, and the third term from the movement of the medium itself (e.g., because of compaction). The flow in the system is assumed to be Darcian; therefore, the specific discharge is given by

$\overline{\mathrm{q}}=-\overline{\overline{\mathrm{K}}}(\psi) \cdot \nabla(\psi+\mathrm{z})$,

where $\overline{\overline{\mathrm{K}}}$ is the hydraulic conductivity tensor, $\psi$ is the pressure head, and $z$ is the elevation above an arbitrarily chosen reference plane (e.g., $\mathrm{z}=0$ at the mean sea level). Substitution of Eq. 2 into Eq. 1 yields the following expression after some rearrangement.

$\frac{\partial(\rho \theta)}{\partial \mathrm{t}}=\nabla \cdot[\rho \overline{\overline{\mathrm{K}}}(\psi) \cdot \nabla(\psi+\mathrm{z})]-\nabla \cdot(\rho \theta \overline{\mathrm{V}})$

If the medium is assumed to be rigid, the last term on the right side is zero and we obtain "Richards' Equation" (Richards, 1931), which is listed below. Richards' equation is typically solved in computer models used to calculate flow in unsaturated media.

$\frac{\partial(\rho \theta)}{\partial \mathrm{t}}=\nabla \cdot[\rho \overline{\overline{\mathrm{K}}}(\psi) \cdot \nabla(\psi+\mathrm{z})]$ 
Equation 4 can be rewritten as follows in Eq. 5 to show the parameters that can be experimentally determined.

$$
\begin{aligned}
\frac{\partial(\rho \theta)}{\partial \mathrm{t}}= & \frac{\partial(\rho \mathrm{nS}(\psi))}{\partial \mathrm{t}}=\rho \mathrm{n} \frac{\partial \mathrm{S}(\psi)}{\partial \mathrm{t}}+\mathrm{nS}(\psi) \frac{\partial \rho}{\partial \mathrm{t}} \\
& +\mathrm{S}(\psi) \rho \frac{\partial \psi}{\partial \mathrm{t}} \\
= & \mathrm{n}\left[\mathrm{S}(\psi) \frac{\partial \rho}{\partial \mathrm{t}}+\rho \frac{\partial \mathrm{S}(\psi)}{\partial \mathrm{t}}\right] \\
= & \mathrm{n} \frac{\partial \psi}{\partial \mathrm{t}}\left[\mathrm{S}(\psi) \frac{\partial \rho}{\partial \psi}+\rho \frac{\partial \mathrm{S}(\psi)}{\partial \psi}\right] \\
= & \nabla \cdot[\rho \overline{\mathrm{K}}(\psi) \cdot \nabla(\psi+\mathrm{z})]
\end{aligned}
$$

The variable $\mathrm{n}$ is the porosity, and $\mathrm{S}$ is the saturation. The term $\frac{\partial \mathrm{n}}{\partial \mathrm{t}}$ is set to zero because the medium is assumed to be rigid. $\overline{\overline{\mathrm{K}}}$ and $\mathrm{S}$ are explicitly shown to be functions of $\psi$ to indicate that the solution to this equation is $\psi(\mathrm{t})$.

If the medium is not assumed to be rigid, then terms involving water storage resulting from the compressibility of the medium must be added to Eq. 5 yielding Eq. 6.

$$
\begin{aligned}
& \rho \frac{\partial \psi}{\partial \mathrm{t}}\left[\mathrm{n} \frac{\partial \mathrm{S}}{\partial \psi}+\beta_{\mathrm{w}} \mathrm{n} \mathrm{S}+\alpha_{\text {bulk }} \mathrm{S}^{2}\right] \\
& =\nabla \cdot[\rho \overline{\overline{\mathrm{K}}} \cdot \nabla(\psi+\mathrm{z})]
\end{aligned}
$$

A discussion of these terms has been given by Reeves and Duguid (1975). $\beta_{u}$ is defined as $\frac{1}{\rho} \frac{\partial \rho}{\partial \psi}$ and is proportional to the compressibility of water. The quantity $\alpha_{\text {lulk }}$ is defined in bulk rock properties as:

$\alpha_{\text {trulk }}=\frac{(1+\nu)(1-2 \nu)}{\mathrm{E}(1-\nu)}$

where $\mathrm{E}$ is the modulus of deformation and $\nu$ is Poisson's Ratio. Eq. 6 is identical in form to that of Reeves and Duguid except the assumption that the relationship between rock mass stress $\left(\sigma^{\prime}\right)$ and the pressure head is $\partial \sigma^{\prime} / \partial \psi=\mathrm{S}$ (see McTigue, Wilson, and Nunziato, (1984)); Reeves and Duguid assume that this ratio is equal to 1.0 .

The determination of some of the experimental parameters used in Eqs. 1 through 6 is fairly straightforward (e.g., that of $\rho$ and the derivative of $\rho$ with respect to $\psi$ ); however, the determination of values for many are difficult (e.g., $\overline{\mathrm{K}}$ ). As previously discussed, some of the hydrologic units are fractured considerably and, depending upon the magnitude of the flux, there may be water movement in both the fractures and the matrix. Equations 1-6 were derived for a porous medium with no regard for the possibility of flow in two different "media" (i.e., fractures and matrix); the derivation contains no information concerning how the coefficients should be evaluated or even what their functional form is.

There are two alternatives for modeling the situation where water movement may occur in both the fractures and the matrix, with neither flow being negligible when compared to the other:

1) Model the fractures explicitly by zoning them into the calculational mesh as a second region that has much different properties from those of the matrix portion.

2) Rederive the flow equation (Eq. 5 or 6 ) for an equivalent porous medium, taking into account the fact that there are two porosity systems (the matrix porosity system and the fracture porosity system).

The option of explicitly zoning in the fractures has been used by a variety of workers. This technique is well suited for "small"-scale problems, such as simulating the results of laboratory or small field-scale experiments. This technique is not suited to large sitescale simulations where there may be more than $10^{10}$ fractures in the calculational region. Also, it would not be physically possible to characterize the geometry of all of the fractures and produce a mesh that would be adequate to identify the relatively small fractures on a site scale. Thus, option 2 must be considered for modeling site-scale problems.

The development of equations describing flow in this equivalent porous medium can be derived either from a "macroscopic" or "microscopic" point of view. A macroscopic model assumes that the fracture and matrix hydrologic properties used are statistically representative of a large volume of rock mass. To derive such a model requires a set of appropriate experimental measurements: separate tests of flow through the matrix and through the fractures. The results of these tests are combined with the assumption of a constitutive equation that describes the water movement characteristics in the system of interest. Then, conductivity and saturation values as a function of pressure head are indirectly determined for both a representative sample of matrix material and a representative set of fractures without requiring any actual knowledge of the physical structure of the system. For both the matrix tests and the fracture 
tests, the volume of rock material tested is treated as a "black box" with the constitutive equation as the transform function and the hydrological properties as the coefficients that have been determined to relate the input and output parameters. For example, in order to indirectly determine values for the hydraulic parameters, the water continuity equation or some equivalent equation (e.g., Eq. 1) may be used as the transform function, with measured values of flow rate and pressure gradient as the input and output parameters. Testing and modeling of the combined matrixfracture system provide the necessary information to link the behavior of the matrix and fractures.

It is also possible to derive the hydrologicproperty values for a rock-mass volume more directly from a microscopic approach, using the actual physical structure of the system of interest, combined with fundamental theoretical considerations of fluid flow in pores of a specific geometry, to determine relative conductivity and saturation values as a function of pressure head. In this manner, the individual hydrologic contributions of every pore size and fracture aperture are considered, rather than inherently taking a "lump-sum" average of the entire system. These values for conductivity as a function of pressure head (or saturation), which are determined independently of the flow equation in which they are to be used, can then be applied to describe the movement of fluid in a fractured, porous media.

The following sections will present both a macroscopic and a microscopic derivation of the equation for water flow in a fractured, porous medium and the evaluation of the coefficients in the flow equation. We show that the results of the two derivations are nearly identical.

Both derivations draw heavily on capillary bundle theory in their evaluation of hydrologic coefficients. A calculation of the rise in height of water in a capillary tube as a function of tube radius indicates that for tubes with a radius of the order of a few millimeters, the fluid rise, due to capillary forces, is the same as the tube radius. Thus, the limit of applicability for capillary bundle theory is tubes having radii of the order of millimeters. This estimate of the limit of applicability indicates the models developed in this paper are not applicable for systems containing fractures with apertures of the order of many millimeters or larger.

\section{Macroscopic Derivation}

Many authors have discussed the dual-porosity approach to modeling fractured, porous media including personnel in the petroleum industry (Warren and Root, 1963; Odeh, 1965; Gringarten and Ramey, 1974) and those involved in hydrogeology (Barenblatt et al.,
1960; Duguid and Lee, 1973). The following derivation draws upon the work just cited, especially that of Duguid and Lee. The fluid continuity equations in a dual-porosity equivalent continuum can be expressed as

$$
\begin{aligned}
& \frac{\partial\left(\rho \mathrm{S}_{\mathrm{m}} \mathrm{n}_{\mathrm{m}}\right)}{\partial \mathrm{t}}+\nabla \cdot\left(\rho \overline{\mathrm{q}}_{\mathrm{m}}\right)+\nabla \cdot\left(\rho \mathrm{S}_{\mathrm{m}} \mathrm{n}_{\mathrm{m}} \overline{\mathrm{V}}\right)+\Gamma=0, \\
& \frac{\partial\left(\rho \mathrm{S}_{\mathrm{f}} \mathrm{n}_{\mathrm{f}}\right)}{\partial \mathrm{t}}+\nabla \cdot\left(\rho \overline{\mathrm{q}}_{\mathrm{f}}\right)+\nabla \cdot\left(\rho \mathrm{S}_{\mathrm{f}} \mathrm{n}_{\mathrm{f}} \overline{\mathrm{V}}\right)-\Gamma=0 .
\end{aligned}
$$

The subscripts " $\mathrm{m}$ " and " $\mathrm{f}$ " refer to the matrix and fractures, respectively. The equations are identical in form to that of Eq. 1 except that they include a term ( $\Gamma)$ for the transfer of fluid from the fracture system to the matrix. Many authors (e.g., Barenblatt, 1960) calculate the transfer of flux between the two systems as

$\Gamma=\omega\left(\psi_{1}-\psi_{\mathrm{m}}\right)$

The value of the transfer coefficient $\omega$ is difficult to determine experimentally, and estimates usually vary over many orders of magnitude (Barenblatt et al., 1960).

Equations 8 and 9 may be added together, yielding a single equation in the two unknowns $\psi_{\mathrm{m}}$ and $\psi_{\mathrm{f}}$ to solve for the flow field in a fractured, porous medium. These two variables are, of course, equal if there is no flow through the media. It is reasonable to assume that as the flow is increased from zero, these two pressure heads may begin to take on increasingly different values. Then, if the flow is held constant, it is reasonable to assume that the pressure heads in the matrix and fractures will eventually equalize. Thus, it is reasonable to assume that the magnitude of the difference in matrix pressure head and fracture pressure head in a particular hydrologic unit depends on both the magnitude and history of the flux. If the flow is large and changing rapidly in time, the difference may be significant. However, the infiltration at the Yucca Mountain site is thought to be less than $1 \mathrm{~mm} /$ year (DOE, 1984; Montazer and Wilson, 1984) and probably changes very slowly with time at the depth of the prospective repository and below. Thus, it appears that the difference in pressure heads may be small for average conditions. However, it may be possible that large localized pulses of water, resulting from intense storms, may travel through the fracture system. In the regions where these pulses occur, the pressure heads in the fractures and the matrix probably will not be equal. The calculations discussed in the following paragraphs investigate the magnitude and 
time history of the flux with regard to the depth a water pulse may penetrate a fractured system. The results of the calculations concerning the flux history are then used as input to calculations to estimate the magnitude of the difference in pressure head between the fractures and the matrix under conditions that are thought to be reasonable at Yucca Mountain.

The results of calculations using explicity zoned fractures are useful in determining whether episodic pulses of water at the surface (e.g., pulses due to large storms) will reach the repository horizon as a sharp pulse (e.g., by moving through the fractures exclusively) or as a very slowly varying pulse (e.g., by moving through the matrix in one or more units). A slowly moving pulse may, in fact, mix with other pulses, resulting in a flux that is constant with respect to time. Work specifically relevant to infiltration pulses at Yucca Mountain has been done by Travis et al. (1984) and by Martinez (in preparation). In Martinez's work the surface was completely saturated for one hour, while in Travis' work a slug of water of the order of $2 \mathrm{~m}$ tall was injected into a 100 -micrometer fracture. Both Travis and Martinez seem to indicate that episodic pulses of water at the surface will not penetrate significant distances into Yucca Mountain if the fracture aperture is less than 100 micrometers (an approximate upper value suggested by Sinnock et al. (1984)). The water injected into the fracture moves quickly into the matrix because of two complementary effects:

1) At the front end of the pulse, a large pressurehead difference exists between the saturated fracture and the partially saturated matrix. (This difference may be of the order of $100 \mathrm{~m}$ ).

2) Because the fracture conductivity ahead of the water pulse is very low (the fracture may be near its residual saturation), flow in the fracture is retarded and the pulse diverted into the matrix. Wang and Narasimhan (1985) indicate that the fracture conductivity for flow within the plane of the fracture may be zero until the nearby matrix material is nearly saturated.

The independent calculations of Martinez and Travis indicate that the penetration distance into fractures contained in low-conductivity, densely welded tuffs similar to those that form an uppermost unit of Yucca Mountain (unit TCw) are of the order of $10 \mathrm{~m}$ or less if the fracture aperture is 100 micrometers or less. Martinez's calculations of the penetration of water into fractures in unit PTn (which is above the prospective repository zone) show much less penetration than into unit $\mathrm{TCw}$ because the matrix of unit PTn is much more conductive.

The velocity of water movement in the matrix is of the order of the percolation rate or the saturated conductivity (whichever is less) divided by the porosity. Thus, the water velocity in the matrix is of the order of ten times the flux, a value which is probably less than several millimeters per year.

Thus, there is some indication that the water flux at depth may be a slowly varying function of time. Wang and Narasimhan (in preparation) have simulated episodic flooding events which concentrate the estimated average annual flux at Yucca Mountain (0.1 $\mathrm{mm} / \mathrm{yr}$ for their calculations) over many years into a time period of 0.2 year. Concentrating the average annual flux of 5000 years into a flood lasting only 0.2 year caused little change in hydrologic conditions (i.e., flux rate, pressure head and matrix saturation) at the depth of the prospective repository and below. Thus, it may be inferred that the difference in pressure head between the fractures and the matrix may be small at depth. It should be noted that episodic pulses of water may penetrate to great depth in regions near large structural features, such as fault zones, or where the fracture apertures are very large so that capillary bundle theory is not applicable. Simulations of these situations have not, to the authors' knowledge, been completed, and there is only informed opinion on this last subject.

Wang and Narasimhan (1985) have simulated the drainage of a fractured, welded-tuff cube of approximately 1.5 cubic meters. This simulation gives an idea of the difference between the fracture and matrix pressure heads under conditions where the flux is a slowly varying function of time. The matrix saturation curve was based on psychrometer test results (Peters et al., 1984) with matrix desaturation occurring over the pressure head range of $-100 \mathrm{~m}$ to $-10,000 \mathrm{~m}$. The matrix saturation curve used is very similar to that shown in Figure 5, which is taken from Peters et al. (1984). The cube has two orthogonal vertical fracture sets and one horizontal set that divide the simulation region up into 75 blocks ( 5 wide $\times 5$ deep $\times 3$ blocks high). The fracture properties and spacings were chosen to be representative of those found in a welded tuff unit at Yucca Mountain. The fracture saturation curve was developed from physical and statistical considerations with the fractures desaturating over the pressure head range of 0.0 to $-0.1 \mathrm{~m}$ which, according to Figure 5, is the region where the matrix saturation deviates very little from 1.00 .

The cube was initially saturated. A step change in the lower boundary's pressure head to $-112 \mathrm{~m}$ initiated the simulation. A pressure head of $-112 \mathrm{~m}$ in the matrix block corresponds to a saturation of $80 \%$. Throughout the simulation the pressure head at a point in the middle of the center block was identical to the pressure head at a point in the adjacent fracture that had the same elevation as the first point. The 
pressure head in both the fractures and the matrix blocks varied only in the vertical direction, which was the direction of flow.

The pressure heads in the matrix and the fractures were identical because of the contrast in their saturation curves. According to Figure 5, over the pressure-head range where the fractures were desaturating ( 0.0 to $-0.1 \mathrm{~m}$ of pressure head), the matrix maintained essentially constant saturation $(S \sim 1.0)$, and over the pressure head range where the matrix was desaturating the fractures were at nearly constant saturation (the fracture residual saturation). Therefore, during the time period when the fractures were draining, only a very small amount of water was required to drain from the matrix to maintain pressure equilibrium with the fractures. After the fractures were drained, their pressure head matched that of the matrix, because only minuscule amounts of water had to be drained from the fractures so that the pressure head in the fractures matched that of the matrix. In the problem of saturating the block slowly, the results would be identical to the drainage problem. These results indicate that the contrast in fracture and matrix properties, under conditions of slowly varying flux (either decreasing or increasing flux), constrains the pressure head in the fractures and the matrix to be nearly identical.

In summary, calculations by Travis and by Martinez indicate that periodic injections of water into the surface above the main body of the repository region are not likely to penetrate the fractures to great depth and so the flux at depth is probably a slowly varying function of time (Wang and Narasimhan, in preparation). Calculations by Wang and Narasimhan (1985) indicate that in a drainage situation (or probably its equivalent, slow saturation) the fractures and matrix, along a direction perpendicular to flow, have nearly identical pressure heads. Thus, except near the surface (where the fracture aperture is large) and near large-scale features (e.g., fault zones), it is reasonable to assume that the pressure head in the fracture system equals that in the matrix.

Summing Eq. 8 and 9 yields

$$
\begin{aligned}
& \frac{\partial\left[\rho\left(\mathrm{S}_{\mathrm{m}} \mathrm{n}_{\mathrm{m}}+\mathrm{S}_{\mathrm{f}} \mathrm{n}_{\mathrm{f}}\right)\right]}{\partial \mathrm{t}}+\nabla \cdot \rho\left(\overline{\mathrm{q}}_{\mathrm{m}}+\overline{\mathrm{q}}_{\mathrm{f}}\right) \\
& +\nabla \cdot\left[\rho \overline{\mathrm{V}}\left(\mathrm{S}_{\mathrm{m}} \mathrm{n}_{\mathrm{m}}+\mathrm{S}_{\mathrm{f}} \mathrm{n}_{\mathrm{f}}\right)\right]=0 .
\end{aligned}
$$

Setting $\psi_{\mathrm{m}}$ equal to $\psi_{\mathrm{f}}$ and calling this pressure head simply $\psi$ enables a simpler evaluation of the terms in Eq. 11. Equation 11 may be expanded to begin evaluating the terms.

$$
\begin{aligned}
& \rho \frac{\partial \psi}{\partial \mathrm{t}}\left\{\left[\mathrm{n}_{\mathrm{m}} \frac{\partial \mathrm{S}_{\mathrm{m}}}{\partial \psi}+\mathrm{n}_{\mathrm{f}} \frac{\partial \mathrm{S}_{\mathrm{f}}}{\partial \psi}\right]+\frac{1}{\rho} \frac{\partial \rho}{\partial \psi}\left(\mathrm{S}_{\mathrm{m}} \mathrm{n}_{\mathrm{m}}+\mathrm{S}_{\mathrm{f}} \mathrm{n}_{\mathrm{f}}\right)\right\} \\
& +\rho\left[\mathrm{S}_{\mathrm{m}} \frac{\partial \mathrm{n}_{\mathrm{m}}}{\partial \mathrm{t}}+\mathrm{S}_{\mathrm{f}} \frac{\partial \mathrm{n}_{\mathrm{f}}}{\partial \mathrm{t}}\right]+\nabla \cdot \rho\left(\overline{\mathrm{q}}_{\mathrm{m}}+\overline{\mathrm{q}}_{\mathrm{f}}\right) \\
& +\rho\left[\mathrm{S}_{\mathrm{m}} \mathrm{n}_{\mathrm{m}}+\mathrm{S}_{\mathrm{f}} \mathrm{n}_{\mathrm{f}}\right] \nabla \cdot \overline{\mathrm{V}} \\
& +\overline{\mathrm{V}} \cdot \nabla\left[\rho\left(\mathrm{S}_{\mathrm{m}} \mathrm{n}_{\mathrm{m}}+\mathrm{S}_{\mathrm{f}} \mathrm{n}_{\mathrm{f}}\right)\right]=0
\end{aligned}
$$

The discussion of the evaluation of the terms in Eq. 12 will proceed from left to right. The first set of terms (terms containing $n \partial S / \partial \psi$ ) represent the storage of water in the unit volume via a change in saturation of the matrix and the fracture system. The matrix saturation and its partial derivative with respect to pressure can be experimentally determined in a variety of ways, including porosimetry tests using injection of mercury into the matrix and, more directly, using thermocouple psychrometer tests. A comparison of these two methods and the results of extensive tests of matrix material may be found in the report by Peters et al. (1984). An example (taken from that report) of typical data resulting from psychrometer testing of matrix samples from Unit TSw2 is shown in Figure 5 . The data from these tests may be fitted by a variety of functions, including those proposed by Haverkamp et al. (1977) and van Genuchten (1978). Peters et al. found that either of the two functions yielded adequate fits if the data were well behaved and complete. However, the function developed by van Genuchten is analytically integrable in the equations used to calculate the unsaturated conductivity. Thus, it was chosen to fit all of the data in the report by Peters et al., and it also will be used in the rest of this paper.

$\mathrm{S}(\psi)=\left(\mathrm{S}_{\mathrm{s}}-\mathrm{S}_{\mathrm{r}}\right)\left[\frac{1}{1+|\alpha \psi|^{\beta}}\right]^{\lambda}+\mathrm{S}_{\mathrm{r}}$

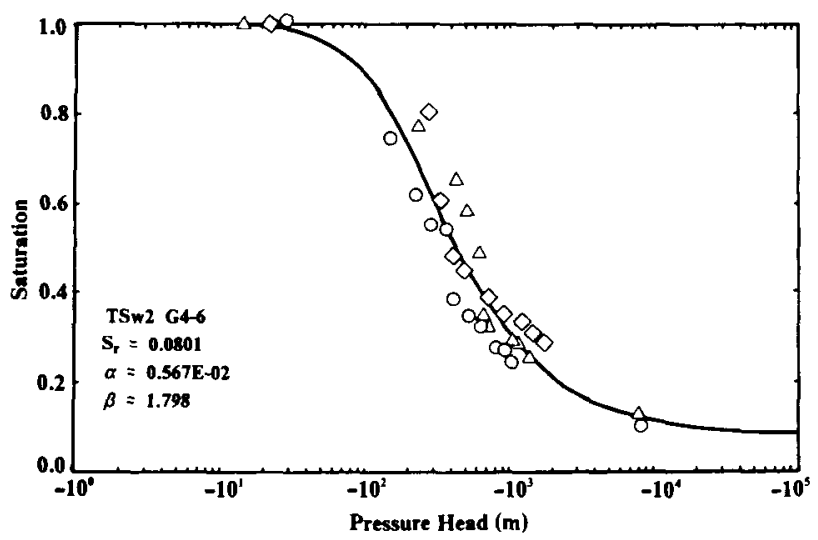

Figure 5. Saturation Curve for Sample G4-6 Taken From Unit TSw2 
The subscripts " $\mathrm{s}$ " and " $\mathrm{r}$ " refer, respectively, to the state of saturation at the saturated state $(\sim 1)$ and at the residual saturation. The fitting parameters $\alpha$ and $\beta$, respectively, influence the break point and the slope of the part of the curve where the saturation is changing rapidly. The parameter $\lambda$ is defined as $1-1 / \beta$. The equation is valid for pressure-head $(\psi)$ values less than zero. The material is completely saturated for all pressure heads greater than zero.

Representative matrix saturation curves for units above the water table are shown in Figure 6, which is reproduced from the report by Peters et al. (1984). This figure indicates that there are significant differences in the shape of the matrix saturation curve for the hydrologic units found above the water table at Yucca Mountain. Table 2 contains information concerning the fitting parameters used to construct these saturation curves as well as other information needed for hydrologic calculations. The information listed for physical properties (e.g., matrix porosity) may not be exactly the same as the designated NNWSI reference property values, but is used here since the physicalproperty and hydrologic-property data are specific to the samples listed.

Information regarding fracture saturation characteristics is much more scarce. Wang and Narasimhan (1985) have used statistical concepts to develop equations describing the saturation curve for fractures in a densely welded tuff. Their fracture saturation curve is similar to that of a coarse sand such as that shown in the text by Freeze and Cherry (1979, p. 42). Plans are being made to experimentally measure the saturation curves of fractured core. (Klavetter, Peters, and Schwartz, in preparation.)

The second term in Eq. 12 (terms containing 1/ $\partial \rho / \partial \psi)$ represents the storage of water in the unit volume due to the compressibility of water.

The third set of terms in Eq. 12 (terms containing $\mathrm{S} \partial \mathrm{n} / \partial \mathrm{t}$ ) represents the storage of water in the unit volume due to the net expansion of the matrix pores and the fracture apertures.

The fourth term (terms containing $\bar{q}$ ) represents the net change in flux of water that is withdrawn from the unit volume. The final two terms (terms containing $\bar{V}$ ) represent the movement of water out of the unit volume due to movement of the rock mass (e.g., dilation).

The information and assumptions listed below as statements 1 to 6 were used in order to rewrite Eq. 12 in terms of one variable, $\psi$, the pressure head. The result is Eq. 14 which may be solved for the pressure head field, subject to the boundary conditions, material properties, etc.

1) The continuity equation for the matrix grain mass.

2) The three-dimensional bulk-rock-consolidation equation with the assumption that the displacement is vertical (see Reeves and Duguid (1975) for further discussion).

3) The assumption that a unit change in the quantity "total saturation times pressure head" at a point causes a unit change in the local stress field (see McTigue, Wilson, and Nunziato (1984)).

4) Darcy's equation for fluid flow.

5) Identical pressure heads in the fractures and the matrix (previously discussed and used, but listed here for completeness).

6) The conventional assumption that the total head is defined as the sum of the pressure head and the elevation above some reference surface.

A more complete discussion of the derivation of Eq. 14 is given in Appendix A.

$$
\begin{aligned}
& \rho \frac{\partial \psi}{\partial \mathrm{t}}\left\{\left(\mathrm{n}_{\mathrm{m}} \frac{\partial \mathrm{S}_{\mathrm{m}}}{\partial \psi}+\mathrm{n}_{\mathrm{f}} \frac{\partial \mathrm{S}_{\mathrm{f}}}{\partial \psi}\right)+\beta_{\mathrm{u}}\left(\mathrm{S}_{\mathrm{m}} \mathrm{n}_{\mathrm{m}}+\mathrm{S}_{\mathrm{f}} \mathrm{n}_{\mathrm{f}}\right)\right. \\
& +\alpha_{\mathrm{l}, \mathrm{llk}}\left(\frac{\left(\mathrm{S}_{\mathrm{m}} \mathrm{n}_{\mathrm{m}}+\mathrm{S}_{\mathrm{f}} \mathrm{n}_{\mathrm{f}}\right)}{\mathrm{n}_{\mathrm{m}}+\mathrm{n}_{\mathrm{f}}}\right)\left(\mathrm{S}_{\mathrm{m}}-\mathrm{n}_{\mathrm{f}}\left(\mathrm{S}_{\mathrm{m}}-\mathrm{S}_{\mathrm{f}}\right)\right) \\
& \left.-\frac{\partial \mathrm{n}_{\mathrm{f}}}{\partial \sigma}\left(\frac{\left(\mathrm{S}_{\mathrm{m}} \mathrm{n}_{\mathrm{m}}+\mathrm{S}_{\mathrm{f}} \mathrm{n}_{\mathrm{f}}\right)}{\mathrm{n}_{\mathrm{m}}+\mathrm{n}_{\mathrm{f}}}\right)\left(\mathrm{S}_{\mathrm{m}}-\mathrm{S}_{\mathrm{f}}\right)\right\} \\
& =\nabla \cdot\left[\rho\left(\overline{\overline{\mathrm{K}}}_{\mathrm{mb}}+\overline{\bar{K}}_{\mathrm{fb}}\right) \cdot \nabla(\psi+\mathrm{z})\right]
\end{aligned}
$$

The term $\partial \mathrm{n}_{\mathrm{f}} / \partial \sigma^{\prime}$ (giving the change in fracture porosity with stress) can be determined by experimentally measuring the closure of a fracture with increased stress (e.g., Peters et al., 1984).

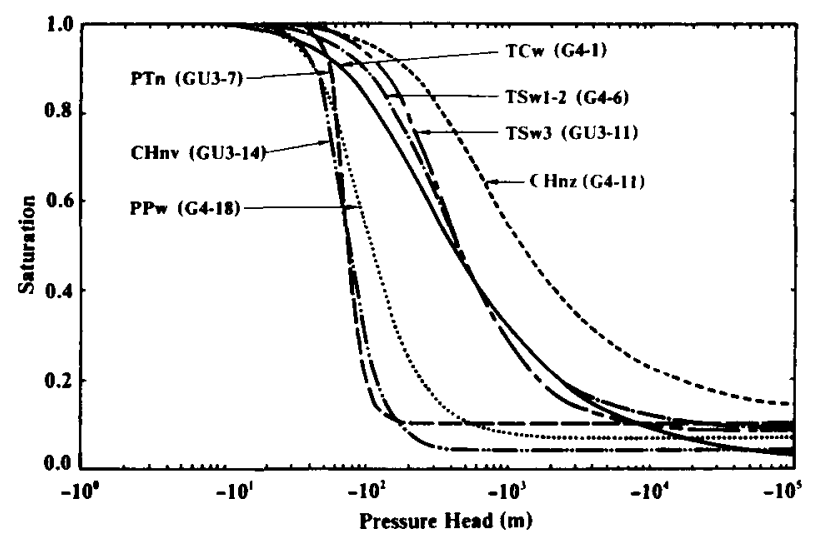

Figure 6. Representative Matrix Saturation Curves for Hydrologic Units in the Unsaturated Zone 
Table 2. Properties Assumed for Unsaturated Zone, Hydrologic Units

\begin{tabular}{|c|c|c|c|c|c|c|c|}
\hline \multicolumn{8}{|c|}{ Matrix Properties" } \\
\hline Unit & $\begin{array}{c}\text { Sample } \\
\text { Code }\end{array}$ & $\begin{array}{l}\text { Grain } \\
\text { Density } \\
\left(\mathrm{g} / \mathrm{cm}^{3}\right)\end{array}$ & $\begin{array}{c}\text { Porosity } \\
\left\{\mathbf{n}_{\mathrm{m}}\right\}\end{array}$ & $\begin{array}{c}\text { Hydraulic }^{\mathrm{b}} \\
\text { Conductivity } \\
\left\{\mathrm{K}_{\mathrm{m}, \mathrm{b}}\right\}(\mathrm{m} / \mathrm{s})\end{array}$ & $S_{r}$ & $\begin{array}{c}\alpha \\
\left(10^{-2} / \mathrm{m}\right)\end{array}$ & $\beta$ \\
\hline $\mathrm{TCw}$ & G4-1 & 2.49 & 0.08 & $9.7 \times 10^{-12}$ & 0.002 & 0.821 & 1.558 \\
\hline PTn & GU3-7 & 2.35 & 0.40 & $3.9 \times 10^{-07}$ & 0.100 & 1.50 & 6.872 \\
\hline TSw1 & G4-6 & 2.58 & 0.11 & $1.9 \times 10^{-11}$ & 0.080 & 0.567 & 1.798 \\
\hline TSw2 & G4-6 & 2.58 & 0.11 & $1.9 \times 10^{-11}$ & 0.080 & 0.567 & 1.798 \\
\hline TSw3 & GU3-11 & 2.38 & 0.07 & $1.5 \times 10^{-12}$ & 0.080 & 0.441 & 2.058 \\
\hline $\mathrm{CHnv}$ & GU3-14 & 2.37 & 0.46 & $2.7 \times 10^{-07}$ & 0.041 & 1.60 & 3.872 \\
\hline $\mathrm{CHnz}$ & G4-11 & 2.23 & 0.28 & $2.0 \times 10^{-11}$ & 0.110 & 0.308 & 1.602 \\
\hline $\mathbf{P P w}$ & G4-18 & 2.59 & 0.24 & $4.5 \times 10^{-09}$ & 0.066 & 1.41 & 2.639 \\
\hline
\end{tabular}

Fracture Properties ${ }^{\mathfrak{c}}$

\begin{tabular}{|c|c|c|c|c|c|c|c|c|}
\hline Unit & $\begin{array}{c}\text { Sample } \\
\text { Code }\end{array}$ & $\begin{array}{l}\text { Horizontal } \\
\text { Stress }^{\mathrm{d}} \\
\text { (bars) }\end{array}$ & $\begin{array}{l}\text { Fracture } \\
\text { Aperture } \\
\text { (microns) }\end{array}$ & $\begin{array}{c}\text { Fracture } \\
\text { Conductivity } \\
\left(10^{-5} \mathrm{~m} / \mathrm{s}\right)\end{array}$ & $\begin{array}{l}\text { Fracture } \\
\text { Density } \\
\left(\text { No. } / \mathrm{m}^{3}\right) \\
\end{array}$ & $\begin{array}{l}\text { Fracture } \\
\text { Porosity } \\
\left\{n_{f}\right\}\left(10^{-5}\right) \\
\end{array}$ & $\begin{array}{c}\text { Fracture } \\
\text { Compressibility } \\
\left\{\partial \mathrm{n}_{\mathrm{f}} / \partial \sigma^{\prime}\right\}\left(10^{-8} / \mathrm{m}\right)\end{array}$ & $\begin{array}{c}\text { Bulk Frac. } \\
\text { Conductivity } \\
\left\{\mathbf{K}_{f, b}\right\}\left(10^{-9} \mathbf{m} / \mathrm{s}\right\}\end{array}$ \\
\hline $\mathrm{TCw}$ & G4-2F & 1.1 & 6.74 & 3.8 & 20 & 14. & 132. & 5.3 \\
\hline PTn & G4-3F & 3.3 & 27.0 & 61. & 1 & 2.7 & 19. & 16. \\
\hline TSw1 & G4-2F & 9.5 & 5.13 & 2.2 & 8 & 4.1 & 5.6 & 0.90 \\
\hline TSw2 & G4-2F & 21.9 & 4.55 & 1.7 & 40 & 18. & 12. & 3.1 \\
\hline TSw3 & G4-2F & 29.9 & 4.34 & 1.6 & 10 & 4.3 & 2.1 & 0.69 \\
\hline CHnv & G4-4F & 34.3 & 15.5 & 20. & 3 & 4.6 & 2.8 & 9.2 \\
\hline $\mathrm{CHnz}$ & G4-4F & 34.3 & 15.5 & 20. & 3 & 4.6 & 2.8 & 9.2 \\
\hline PPw & G4-2F & 39.2 & 4.16 & 1.4 & 3 & 1.3 & .5 & 0.64 \\
\hline
\end{tabular}

Fracture saturation coefficients are $S_{r}=0.0395, \alpha=1.2851 / \mathrm{m}$, and $\beta=4.23$

\begin{tabular}{|c|c|c|c|c|c|c|c|c|}
\hline Unit & $\mathrm{TCw}$ & PTn & TSw1 & TSw2 & TSw3 & $\mathrm{CHnv}$ & $\mathrm{CHnz}$ & PPw \\
\hline $\begin{array}{l}\text { Coefficient of } \\
\text { consolidation } \\
\left\{\alpha_{\text {bulk }}^{\prime}\right\}\left(10^{-i} / \mathbf{m}\right)\end{array}$ & 6.2 & 82. & 12. & 5.8 & 5.8 & 39. & 26. & 17. \\
\hline
\end{tabular}

The compressibility of water $\left\{\beta_{\mathrm{w}}^{\prime}\right\}$ is $9.8 \times 10^{-7} / \mathrm{m}$

\footnotetext{
Notes: a) All matrix data in this section are from Peters et al. (1984).

b) The matrix saturated conductivity and the bulk matrix saturated conductivity $\left(K_{m, b}\right)$ are essentially the same because the factor that converts the matrix value to the bulk matrix value $\left(1-n_{f}\right)$ is nearly equal to 1.0

c) Unless noted otherwise, this fracture information is from Peters et al. (1984).

d) Horizontal stress assumed to be one-third the overburden weight, evaluated at average unit depth in USW G-4.

e) Based on the report by Scott et al. (1983).

f) Calculated as fracture volume (aperture times 1 square meter) times number of fractures per cubic meter.

g) This value of " $K_{t, b}$ " was obtained by multiplying the fracture conductivity by the fracture porosity.

h) Based on the report by Nimick et al. (1984).
} 
The subscripts " $m, b$ " and "f,b" on the conductivity variable $\mathrm{K}$ indicate that the matrix and fracture conductivities are bulk values for a unit volume of the fractured, porous media. These values may be estimated as the conductivity of the material times its relative volume in bulk material.

This functional dependence of the hydraulic conductivity on pressure head is very difficult to measure, especially when the matrix saturated conductivity may be less than $10^{-11} \mathrm{~m} / \mathrm{s}$. There are some methods being explored which may show promise (e.g., matrix testing methods described by Johnson et al. (1959)), and methods for fractures by Klavetter et al. (in preparation). However, for low conductivity tuffs, work in this area is currently in the exploratory stage. For the present, the hydraulic conductivity will be calculated. A variety of methods is available (e.g., Brooks and Corey, 1966; Burdine, 1953; Mualem, 1976 ), and at present there is no indication whether any one of these is superior to the others for predicting the unsaturated hydraulic conductivity for a hard rock such as tuff or even whether any of these do an adequate job of prediction. Mualem's method is currently being used because it gives results that are in the middle of those predicted by a variety of other methods. (See Appendix B for a comparison of Mualem's method with other techniques.) This method has also been shown to yield better estimates of the unsaturated conductivity of a variety of unconsolidated materials than the other methods (Maulem, 1976). The hydraulic conductivity as a function of pressure head using the method of Mualem yields the following analytical expression when the saturation-curve fit of van Genuchten (Eq. 13) is used:

$\mathrm{K}(\psi)=\mathrm{K}_{\mathrm{s}}\left[1+|\alpha \psi|^{\beta}\right]^{-\lambda / 2}\left\{1-\left[\frac{|\alpha \psi|^{\beta}}{1+|\alpha \psi|^{\beta}}\right]^{\lambda}\right\}^{2}$.

$\mathrm{K}_{\text {, }}$ is the saturated conductivity, a parameter that can be measured fairly easily (Peters et al., 1984).

For convenience in discussion and labeling of figures, the mathematical terms in the left side of Eq. 14 are named as follows

$$
\begin{array}{lr}
\text { Matrix Sat.: } & \mathrm{n}_{\mathrm{m}} \frac{\partial \mathrm{S}_{m}}{\partial \psi} \\
\text { Fracture Sat.: } & \mathrm{n}_{\mathrm{f}} \frac{\partial \mathrm{S}_{\mathrm{f}}}{\partial \psi}
\end{array}
$$

Water Comp.: $\quad \beta_{\mathrm{w}}\left(\mathrm{S}_{\mathrm{m}} \mathrm{n}_{\mathrm{m}}+\mathrm{S}_{\mathrm{f}} \mathrm{n}_{\mathrm{f}}\right)$
Bulk Rock Comp.: $\alpha_{\text {bulk }}\left[\left(\frac{\left[S_{m} n_{m}+S_{f} n_{f}\right]}{n_{m}+n_{f}}\right)\right.$

$$
\begin{aligned}
& {\left.\left[S_{m}-n_{f}\left(S_{m}-S_{f}\right)\right]\right] } \\
\simeq & \alpha_{\text {bulk }} S_{m}^{2}
\end{aligned}
$$

$$
\text { Fracture Comp.: } \quad \begin{aligned}
\frac{\partial n_{f}}{\partial \sigma}\left[\left(\frac{\left(S_{m} n_{m}+S_{f} n_{f}\right)}{n_{m}+n_{f}}\right)\left(S_{m}-S_{f}\right)\right] \\
\simeq \frac{\partial n_{f}}{\partial \sigma} S_{m}\left(S_{m}-S_{f}\right)
\end{aligned}
$$

The coefficients on the left side of Eq. 14 (referred to as "capacitance coefficients") relate to the storage of water as " $\psi$ " is varied. The first two terms on the left side (named "Matrix Sat." and "Fracture Sat.") corresponds to the storage of water in the unit volume, resulting from saturation of the matrix and the fracture system. The second group (named "Water Comp.") corresponds to the storage of water resulting from the compressibility of water contained in the fractured, porous media. The remainder on the left side ("Bulk Rock Comp." and "Fracture Comp.") represents the storage of water resulting from dilation of the bulk rock. The term on the right side is proportional to the divergence of the total water flux moving through the unit volume.

The capacitance coefficients on the left side of Eq. 14 have a strong functional dependence on the pressure head $\psi$. Each group of terms from Eq. 14 has been plotted in Figures 7 through 14 for the hydrological units at Yucca Mountain. The labels used in the figures are defined above.

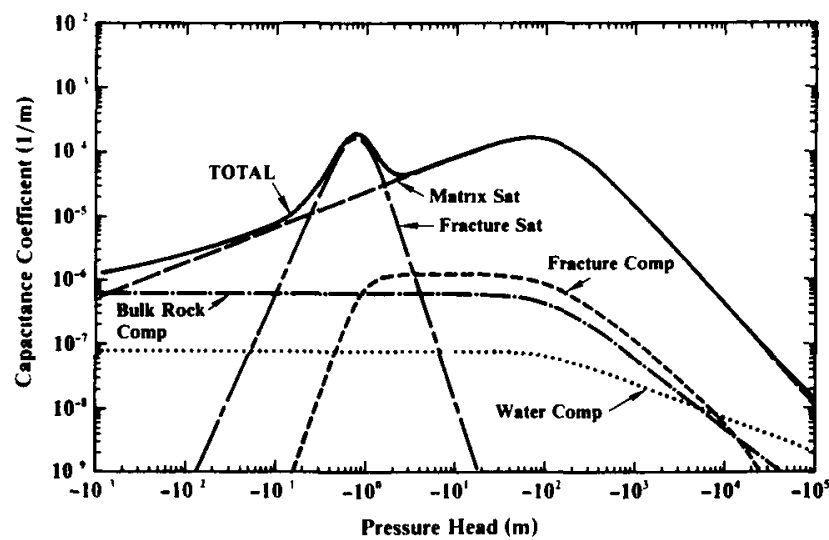

Figure 7. Capacitance Coefficients for Unit TCw 


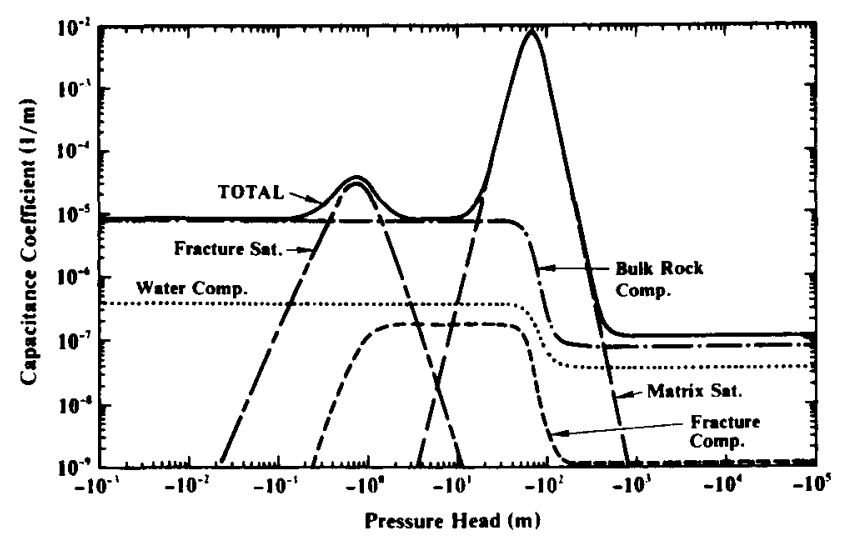

Figure 8. Capacitance Coefficients for Unit PTn

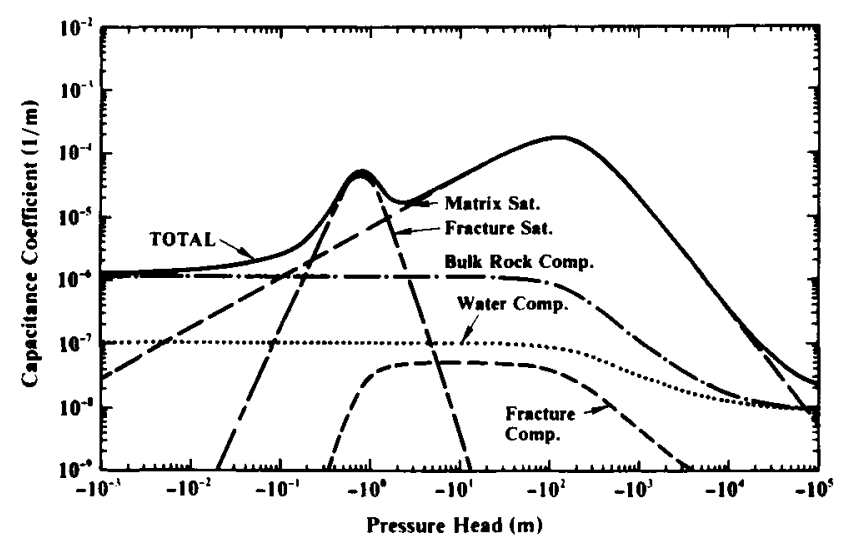

Figure 9. Capacitance Coefficients for Unit TSw1

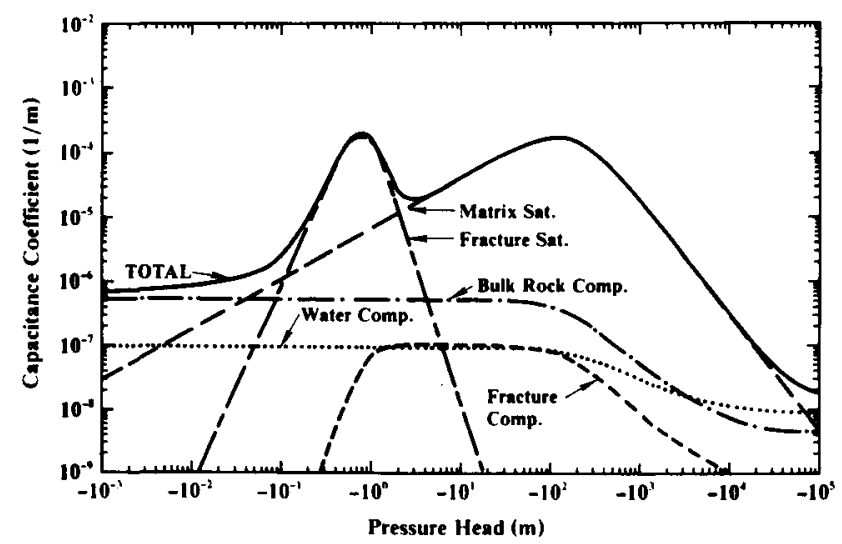

Figure 10. Capacitance Coefficients for Unit TSw2

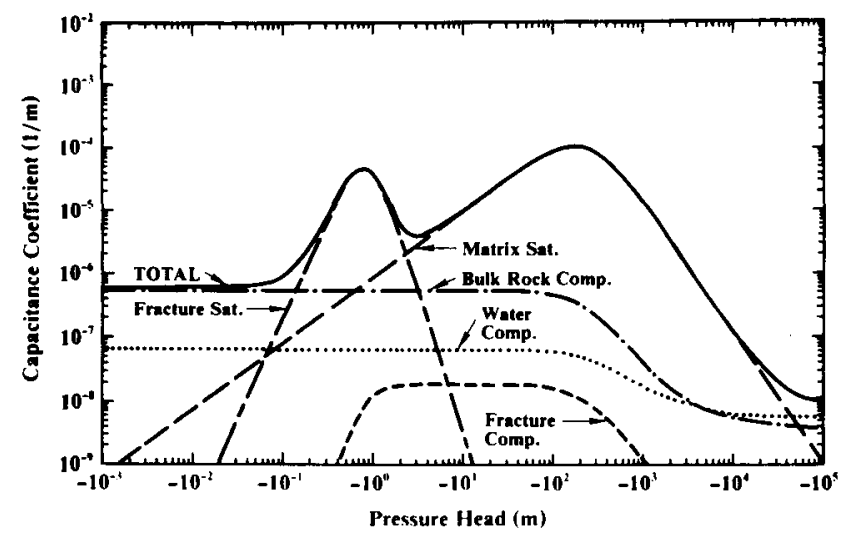

Figure 11. Capacitance Coefficients for Unit TSw3

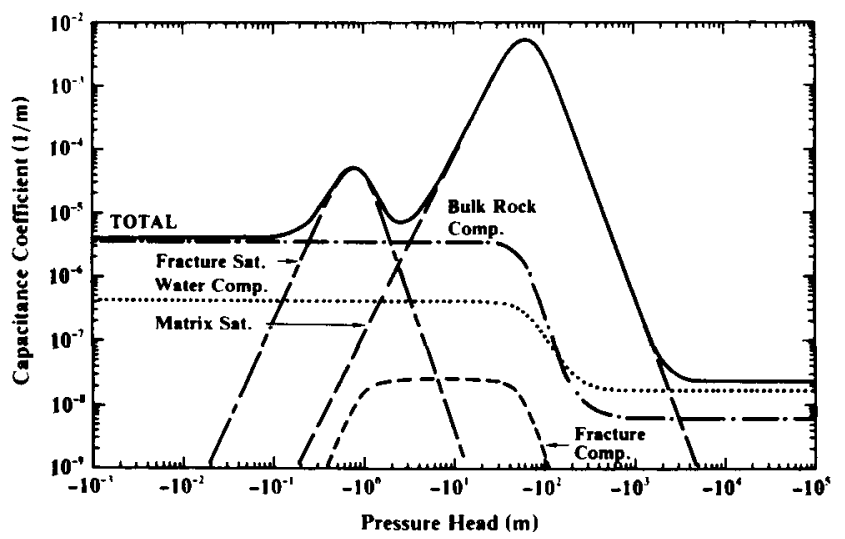

Figure 12. Capacitance Coefficients for Unit CHnv

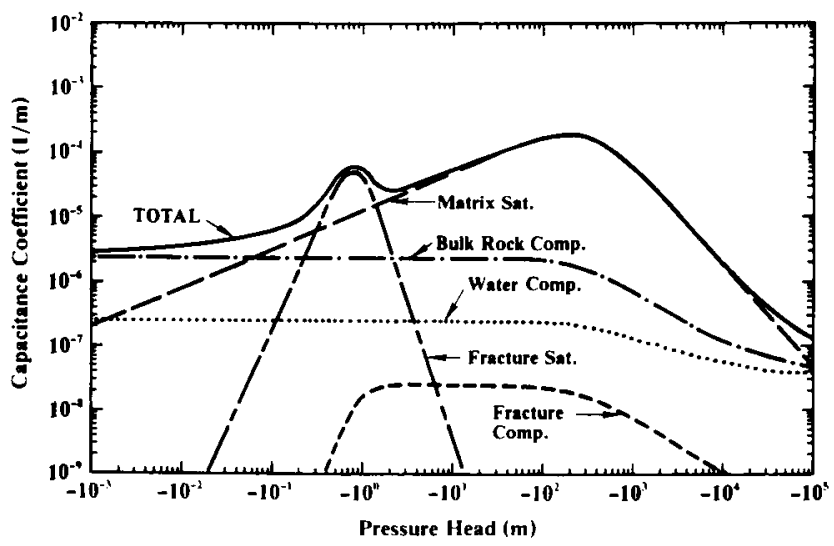

Figure 13. Capacitance Coefficients for Unit $\mathrm{CHnz}$ 


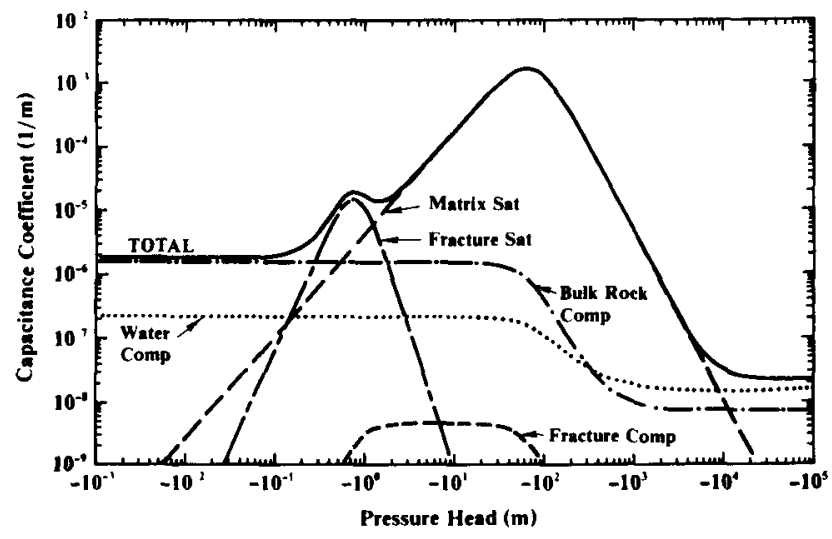

Figure 14. Capacitance Coefficients for Unit PPw

In the compressibility terms "Bulk Rock Comp." and "Fracture Comp.", the terms containing $n_{f}$ were neglected because, under most conditions, $n_{\mathrm{f}}$ is of the order of $10^{-5}$ (see Table 2 and Snow (1970)) and much smaller than $\mathrm{S}_{\mathrm{m}}$ or $\mathrm{S}_{\mathrm{f}}$. The values of the parameters that were used to produce Figures 7 through 14 are listed in Table 2 and are thought to be in the range of values at Yucca Mountain. One should note that the "Fracture Comp." term plotted in Figures 7 through 14 is subtracted from the sum of the other terms.

Inspection of these figures indicates some results that may not be entirely expected. The maximum value of the fracture-saturation coefficient for unit TSw2 is of the same order of magnitude as the maximum value of the matrix-saturation coefficient because the relatively small volume of the fractures is assumed to saturate over a very small change in pressure head. In Figures 7 through 14 it is the largest parameter in the pressure-head region between -0.1 and -1.0 meters. The matrix-saturation coefficient dominates over almost all of the rest of the pressurehead range except where the matrix is saturated or is at its residual saturation; it is generally at least two orders of magnitude larger than the value of the other coefficients. For pressure heads where both the fractures and matrix are totally saturated or both are nearing their residual saturation ( $\psi$ greater than about $-0.01 \mathrm{~m}$ and $\psi$ less than about $-10^{4} \mathrm{~m}$ ), the major coefficients are the water compressibility and bulk rock compressibility (e.g., Figure 8), which account for storage of water resulting from the compressibility of water and from rock-mass deformation. The values for both coefficients near a pressure-head value of zero are probably reasonable. At large negative pressure heads, their values and even the assumptions used in deriving their functional form are in doubt. However, few hydrological problems of interest will be run at pressure heads where both the matrix and the fractures are desaturated.

The terms on the right side of Eq. 14 are also highly variable with the pressure head $\psi$ because of changes in the saturation of the matrix and the fractures. Figures 15 through 22 show the conductivity curves for a unit volume containing only "fracture material," a unit volume of matrix material, and a unit volume containing both materials for each of the hydrologic units. The last line represents the conductivity curve of the fractured, porous media $\left(\overline{\overline{\mathrm{K}}}_{\mathrm{mb}}+\right.$ $\overline{\overline{\mathrm{K}}}_{1,1}$ ) where $\overline{\overline{\mathrm{K}}}_{1 \mathrm{~b}}$ is calculated as the fracture conductivity times the fracture porosity, and $\overline{\mathrm{K}}_{m b}$ is calculated as the matrix conductivity times the quantity one minus the fracture porosity.

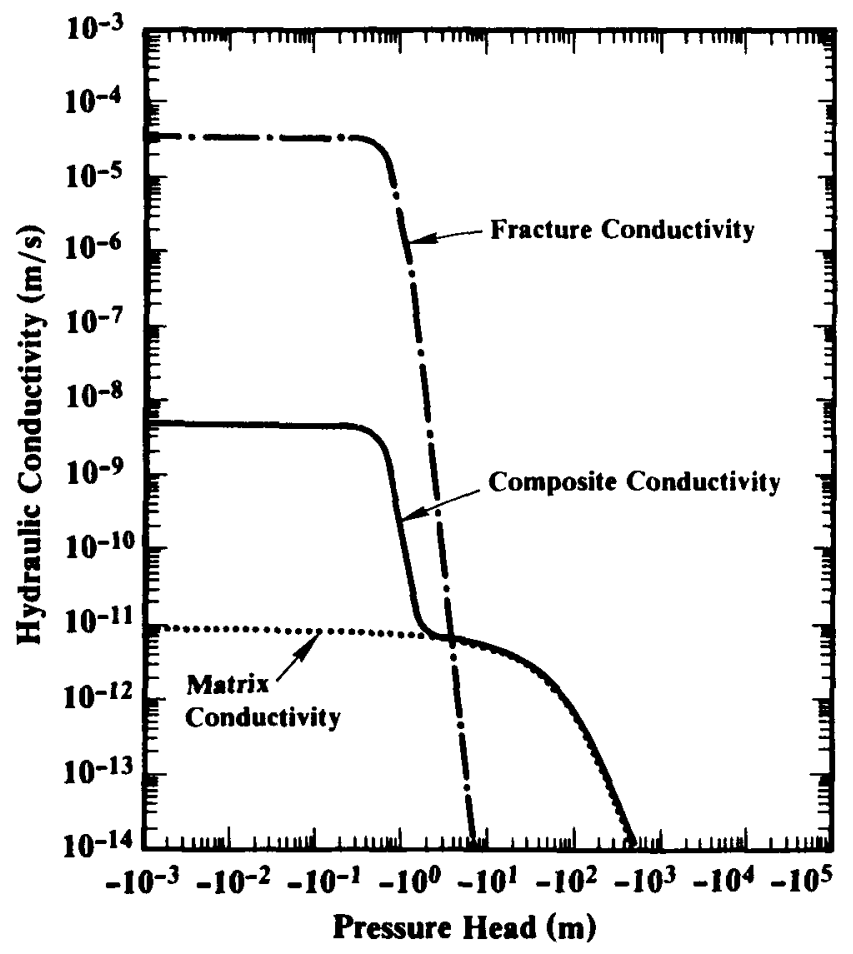

Figure 15. Conductivity Curve for Unit $\mathrm{TCW}$ 


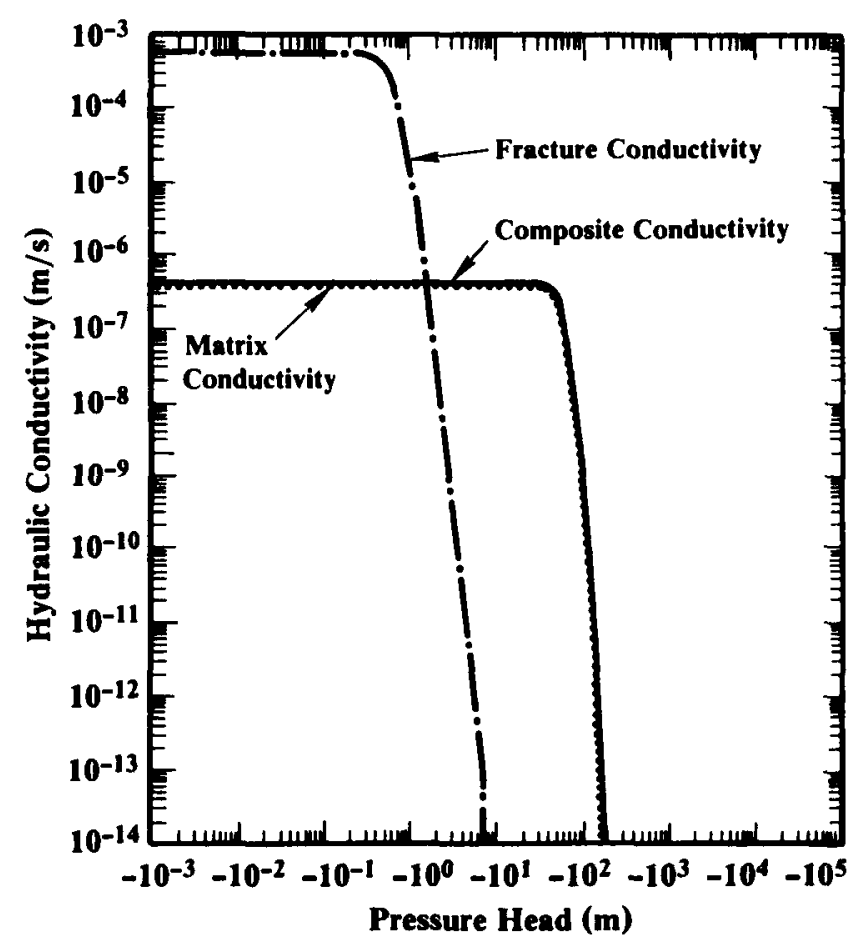

Figure 16. Conductivity Curve for Unit PTn

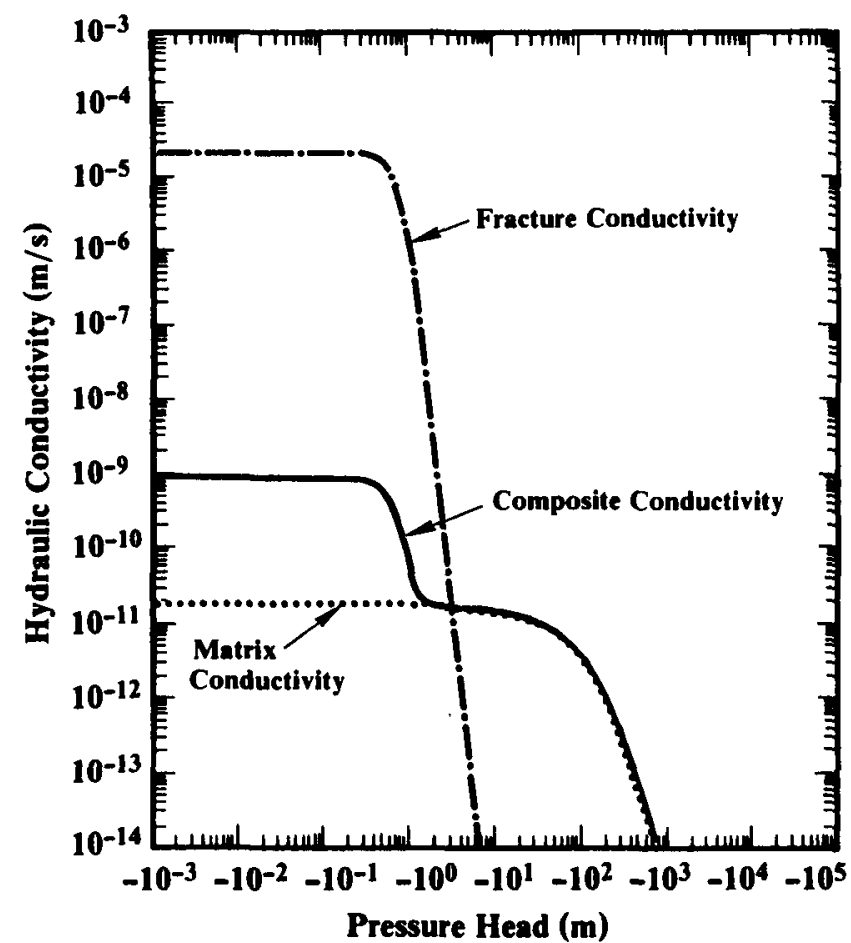

Figure 17. Conductivity Curve for Unit TSw1

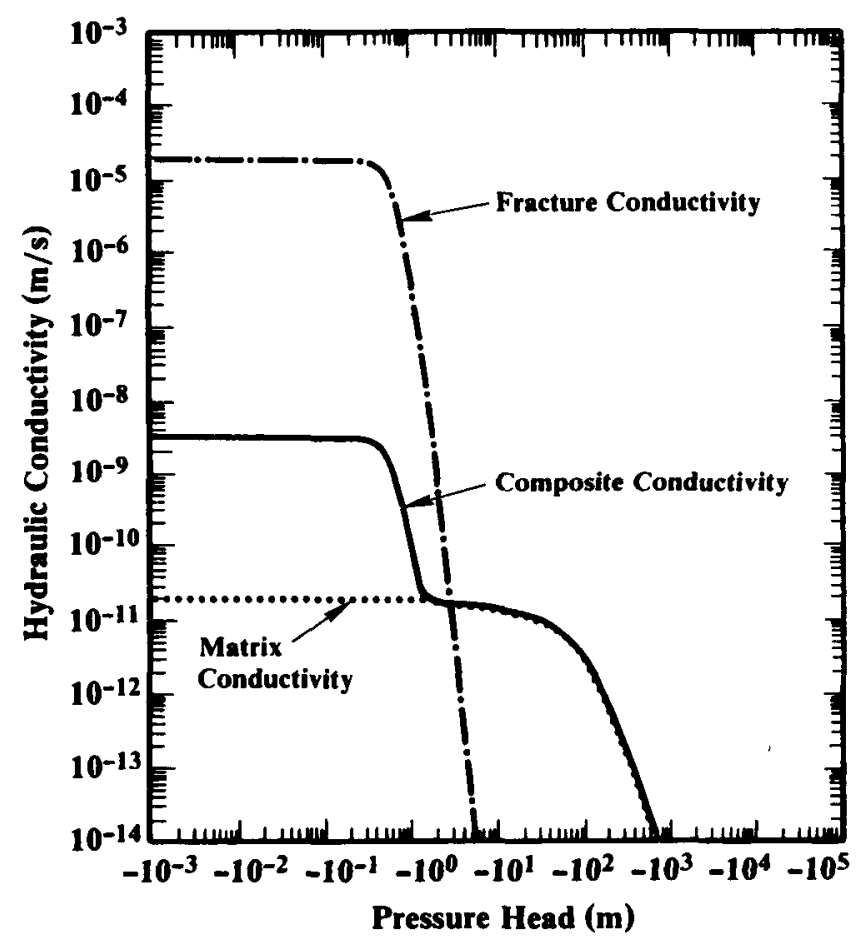

Figure 18. Conductivity Curve for Unit TSw2

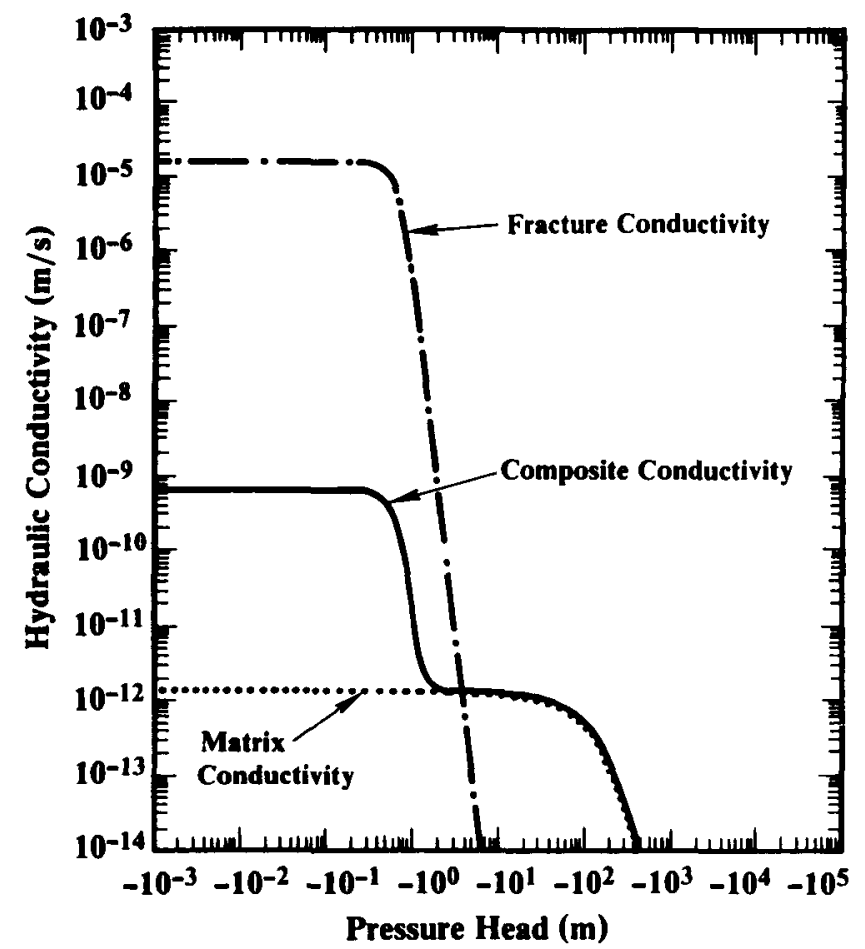

Figure 19. Conductivity Curve for Unit TSw3 


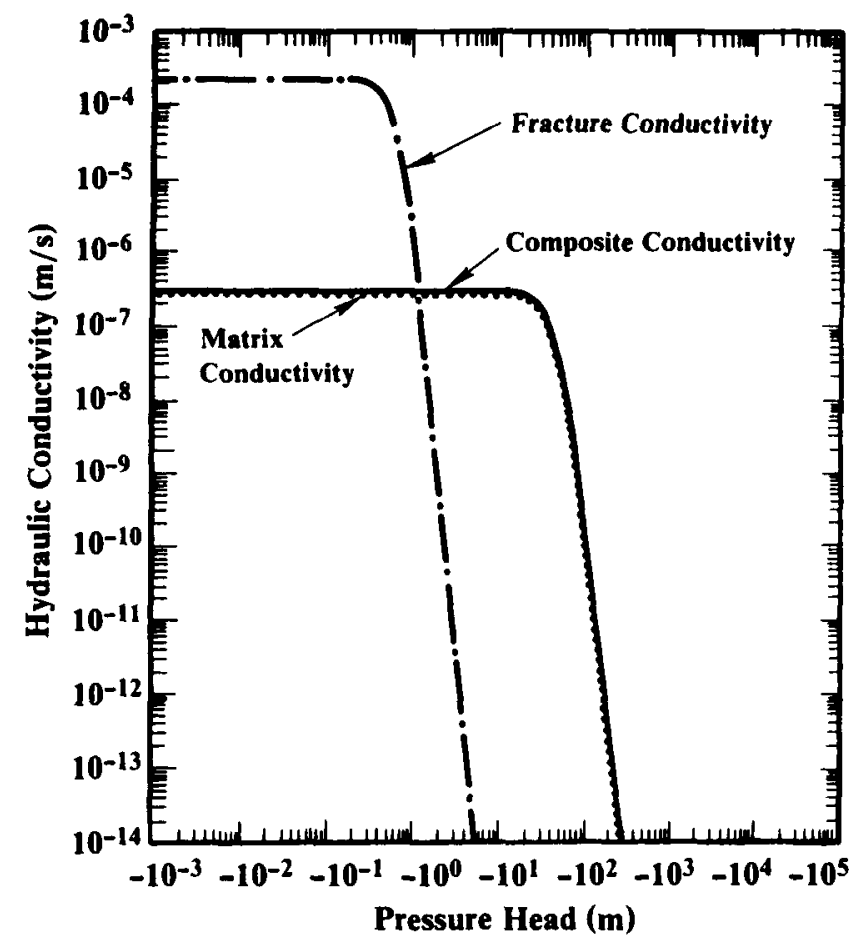

Figure 20. Conductivity Curve for Unit CHnv

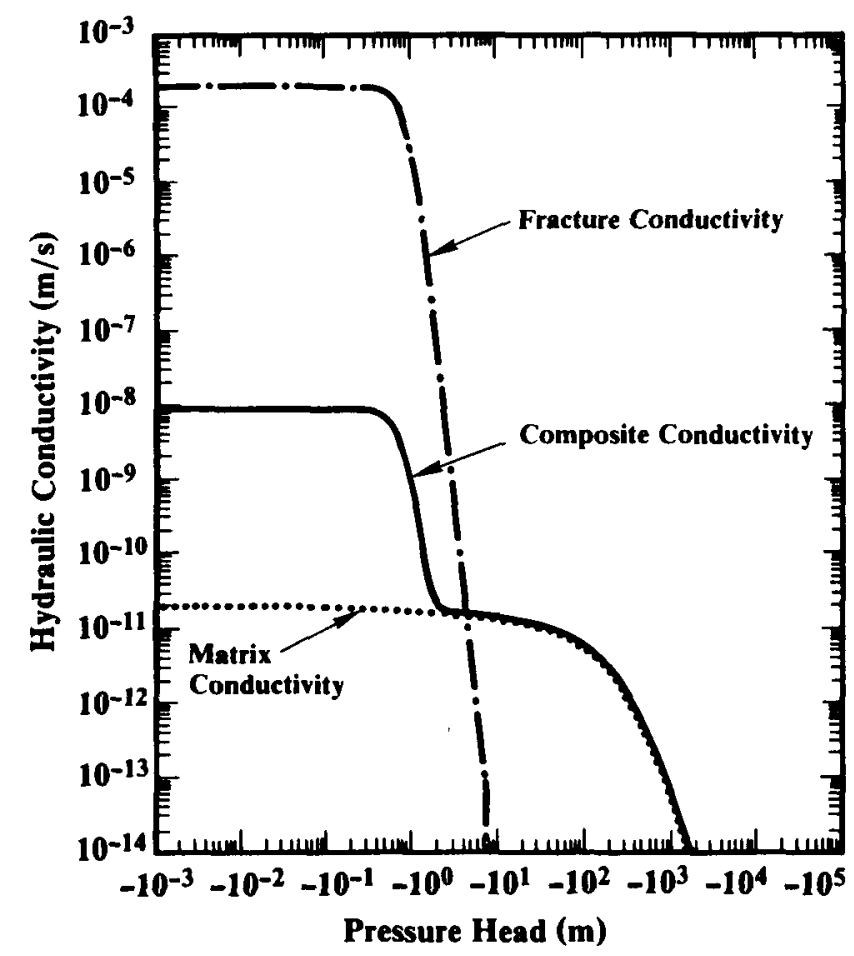

Figure 21. Conductivity Curve for Unit CHnz

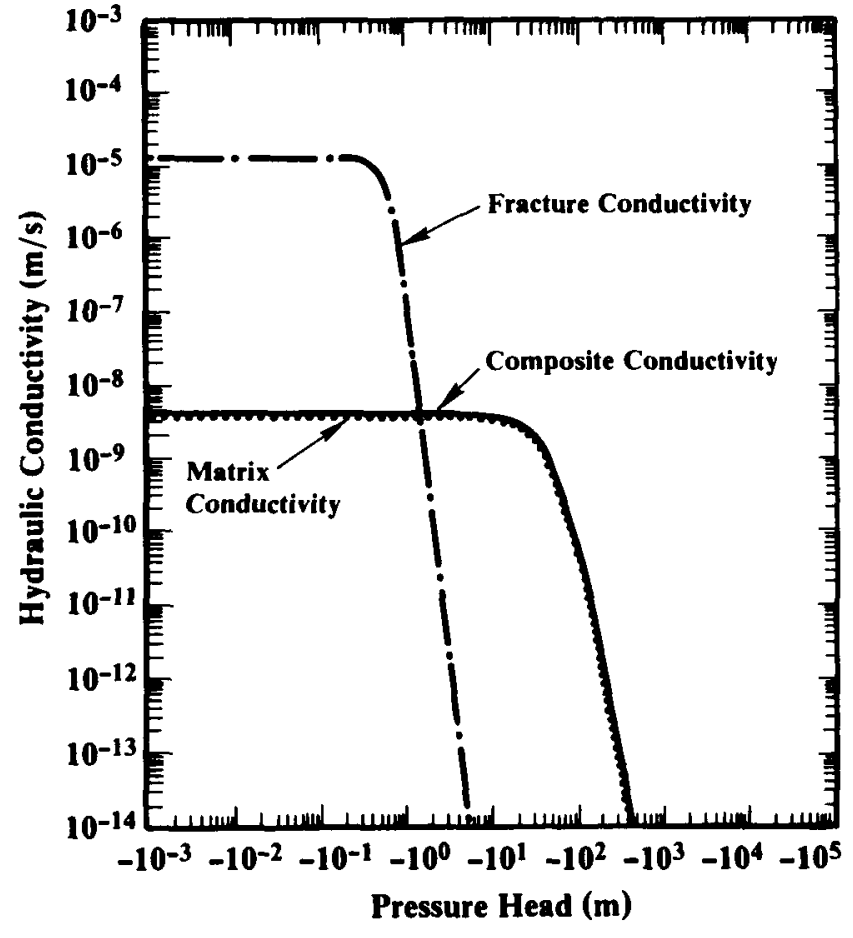

Figure 22. Conductivity Curve for Unit PPw

The total-conductivity curves plotted in Figures 15 through 22 contain either one or two plateaus of fairly constant conductivity with rapidly changing conductivity in the remaining portions of the curve. Curves containing two plateaus result from units that have low matrix conductivity and relatively high fracture conductivity (e.g., units TSw2 and CHnz). Totalconductivity curves for these units are nearly constant at pressure-head values for which the fractures are saturated $(>-1 \mathrm{~m})$ and in the pressure-head range where the fractures are at their residual saturation but the matrix is still saturated (from about $-1 \mathrm{~m}$ to the order of -10 to $-100 \mathrm{~m}$ ). In the regions where the saturation is changing, the conductivity changes very rapidly. Curves containing a single plateau result from units that have relatively low fracture conductivities and relatively high matrix conductivities (PTn, $\mathrm{CHnv}$ and $\mathrm{PPw}$ ). The total conductivity is essentially that of the matrix over the entire range of pressure head; thus, the curve has a much simpler shape. The values of the parameters that were used to produce Figures 15 through 22 are listed in Table 2 and are based upon the best data available for Yucca Mountain.

Equation 14 may be solved numerically for the pressure head with values specified for the material properties (which are discussed above), boundary conditions (e.g., fluxes and pressure heads), and an initial condition. The individual fluxes in the matrix and fractures may then be calculated using an expression 
of the form of Eq. 2. The velocity used in transport equations may be calculated by dividing the flux by the area through which it is flowing.

$$
\begin{aligned}
\overline{\mathrm{v}}_{\mathrm{m}} & =\overline{\mathrm{q}}_{\mathrm{m}} /\left[\mathrm{n}_{\mathrm{m}}\left(\mathrm{S}_{\mathrm{m}}-\mathrm{S}_{\mathrm{m}, \mathrm{r}}\right)\right] \\
& =-\overline{\mathrm{K}}_{\mathrm{mb}} \cdot \nabla(\psi+\mathrm{z}) /\left[\mathrm{n}_{\mathrm{m}}\left(\mathrm{S}_{\mathrm{m}}-\mathrm{S}_{\mathrm{m}, \mathrm{r}}\right)\right] \\
\overline{\mathrm{v}}_{\mathrm{t}} & =\overline{\mathrm{q}}_{\mathrm{f}} /\left[\mathrm{n}_{\mathrm{f}}\left(\mathrm{S}_{\mathrm{f}}-\mathrm{S}_{\mathrm{f}, \mathrm{r}}\right)\right] \\
& =-\overline{\mathrm{K}}_{\mathrm{fb}} \cdot \nabla(\psi+\mathrm{z}) /\left[\mathrm{n}_{\mathrm{f}}\left(\mathrm{S}_{\mathrm{f}}-\mathrm{S}_{\mathrm{f}, \mathrm{r}}\right)\right]
\end{aligned}
$$

$\mathrm{S}_{\mathrm{m},}$ and $\mathrm{S}_{\mathrm{f}, \mathrm{r}}$ are, respectively, the residual saturations of the matrix and the fractures.

The steady-state version of the flow equation is obtained by setting the left side of Eq. 14 to zero. This equation can be integrated to obtain the following form of Darcy's law

$$
-\left[\overline{\overline{\mathrm{K}}}_{\mathrm{mb}}+\overline{\overline{\mathrm{K}}}_{\mathrm{th}}\right] \cdot \nabla(\psi+\mathrm{z})=\overline{\mathrm{q}}_{\mathrm{m}}+\overline{\mathrm{q}}_{\mathrm{f}}=\overline{\mathrm{q}}_{\mathrm{tot}} .
$$

Note that some terms in Eq. 14 and 18 may be summed, yielding Eq. 19 and 20, which are written in terms of a "composite-porosity" material.

$$
\begin{aligned}
& \rho \frac{\partial \psi}{\partial \mathrm{t}}\left[\mathrm{n}_{\mathrm{c}} \frac{\partial \mathrm{S}_{\mathrm{c}}}{\partial \psi}+\beta_{\mathrm{u}} \mathbf{n}_{\mathrm{c}} \mathrm{S}_{\mathrm{c}}+\alpha_{\text {bulk }} \mathbf{S}_{\mathrm{c}}^{2}\right] \\
& =\nabla \cdot\left[\rho \overline{\mathrm{K}}_{\mathrm{c}} \cdot \nabla(\psi+\mathrm{z})\right] \\
& \overline{\mathrm{q}}_{\mathrm{c}}=-\overline{\mathrm{K}}_{\mathrm{c}} \cdot \nabla(\psi+\mathrm{z})
\end{aligned}
$$

The subscript " $c$ " refers to the composite-porosity material that is equivalent to the fractured, porous matrix system in terms of predicting the total fluxes and the pressure-head field. This model is informally referred to as a "composite-porosity" model. (The term containing the partial derivative of the fracture porosity with respect to the stress has been neglected because it has been shown previously in this paper to be small in comparison to the other terms.) The form of Eq. 19 is identical to that of Eq. 6. The coefficients are all defined in terms of quantities that can be experimentally measured.

$$
\begin{aligned}
& \mathrm{n}_{\mathrm{c}} \frac{\partial \mathrm{S}_{\mathrm{c}}}{\partial \psi} \equiv \mathrm{n}_{\mathrm{m}} \frac{\partial \mathrm{S}_{\mathrm{m}}}{\partial \psi}+\mathrm{n}_{\mathrm{f}} \frac{\partial \mathrm{S}_{\mathrm{f}}}{\partial \psi} \\
& \mathrm{n}_{\mathrm{c}} \mathrm{S}_{\mathrm{c}}=\theta_{\mathrm{c}} \equiv \mathrm{S}_{\mathrm{m}} \mathrm{n}_{\mathrm{m}}+\mathrm{S}_{\mathrm{f}} \mathrm{n}_{\mathrm{f}} \\
& \mathrm{S}_{\mathrm{c}} \equiv \theta_{\mathrm{c}} / \mathrm{n}_{\mathrm{c}} \equiv \theta_{\mathrm{c}} /\left(\mathrm{n}_{\mathrm{m}}+\mathrm{n}_{\mathrm{f}}\right)=\mathrm{S}_{\mathrm{m}} \\
& \overline{\mathrm{K}}_{\mathrm{c}} \equiv \overline{\mathrm{K}}_{\mathrm{mb}}+\overline{\mathrm{K}}_{\mathrm{l} b}
\end{aligned}
$$

The definitions of the model terms in Eq. 22, 23, and 24 correspond exactly to the quantities that would be obtained from volume-averaging the properties of the fracture and matrix system. The definition in Eq. 21 differs slightly. The volume-averaged value $n_{c} \partial S_{c} / \partial \psi$ approaches the composite-porosity definition in Eq. 21 as the compressibility of the matrix and fractures becomes small, compared with the derivative of the saturation of the matrix and fractures, a case that is approximately true at Yucca Mountain. (As previously discussed, we may neglect the two terms containing $n_{f}$ in the bulk rock compressibility coefficient.)

With this derivation, a method has been formulated to estimate the hydrologic properties for an unsaturated, fractured porous material. The rock-mass properties as a function of pressure head can be determined by combining the contributions of the matrix and fractures using Eqs. 21 through 24. These parameters can, then, be used in Eq. 19 or 20, as desired, to calculate fluid flow in the composite medium.

The derivation presented above follows that of many other authors, as previously mentioned. Its main difference is the crucial assumption, based on information relevant to Yucca Mountain, that the pressure heads in the fractures and matrix are identical. If this assumption is made initially, Eq. 14 can be derived in an alternative manner assuming that the matrix pore system can be extended to include the "fracture pores." This alternative derivation of Eq. 14 is the subject of the following section.

\section{Microscopic Derivation}

In this section, a different approach from that just presented is used to address the problem of predicting the hydrologic properties for an unsaturated rock mass. The main properties of interest are the hydraulic conductivity and saturation as a function of pressure head. A model will be derived here to predict these properties. Predictions of the models derived by the two approaches will be compared later. A comparison of the concepts behind the two approaches is made in this section, followed by the derivation of a model based upon a microscopic approach predicting the desired hydrologic properties for a system containing both porous rock and fractures.

The theoretical derivation in the previous section produces a model based upon a macroscopic approach that assumes that the fracture and matrix hydrologic properties used are statistically "representative" of a large volume of rock mass. The hydrologic parameters for the fractures and matrix are combined to estimate rock-mass properties for the composite material. In 
Eq. 6 above, which is the equation of motion for a fluid in some porous system (which may contain both matrix and fractures), the hydrological parameters that must be determined are the saturation of the composite rock mass as a function of the pressure head, $S_{c}(\psi)$ and the relative conductivity tensor for composite rock mass, $\overline{\mathrm{K}}_{\mathrm{c}}(\psi)$. (The subscript $\mathrm{c}$ indicates a composite medium that may contain both rock matrix and fractures.) Experimental results from a large number of samples combined with the assumption of a constitutive equation that describes the water movement characteristics in either the matrix system or the fracture system are used to determine a statistically representative set of hydrologic property values for each system. The hydrologic parameter values are, therefore, dependent upon the constitutive equation chosen to describe the flow characteristics. The hydrologic parameters so determined for the fractures and matrix are combined as postulated in the above model to represent the coefficients in the single equation, Eq. 19, for fluid motion in a composite material.

However, a microscopic approach, using the actual physical structure of the system of interest combined with fundamental theory of fluid flow in pores of a specific geometry, can also be used in determining relative conductivity and saturation values as a function of pressure head for the rock mass. In this approach, the contributions of the individual matrix pores and fractures for a volume of rock mass are combined to determine the hydrologic parameters for the composite rock material. Here, the fractures are treated as large "pores." The hydrologic parameters can then be used in the desired constitutive equation to describe flow in a single continuum. The continuum consists of matrix and fractures, with the fractures assumed to be uniformly distributed throughout the rock-mass volume of interest. If the rock is assumed to be rigid, Richards' equation, Eq. 1, may be used to calculate flow in an unsaturated medium. The equation would be written for the rock-mass continuum consisting of matrix and fractures, with hydrologic parameters required for the composite medium. One could also choose to include compressibilities of the water and rock in the constitutive equation for the composite medium. If terms that explicitly include fracture porosity are assumed to be insignificant because of the low magnitude when compared with the matrix porosity, Eq. 6 results. This section of the document will focus on the development of another method by which the necessary hydrologic parameters in Eq. 6 can be estimated for a fractured rock mass.

The previous derivation made the explicit assumption that the fracture and matrix pressure heads along a direction perpendicular to flow were equal;
Eqs. 8 and 9 could then be combined to yield a single equation (Eq. 11) describing flow in a composite rock mass containing both matrix material and fractures. The microscopic approach sums the individual contributions of the matrix and fractures according to capillary bundle theory, implicitly assuming that the pressure heads in the "large fracture pores" and in the small matrix pores are equal along a direction perpendicular to flow. Using basic capillary theory (which predicts permeability characteristics from pore-opening sizes and calculates capillary pressures from a force balance on the liquid-vapor interface), the pore sizes of the matrix determine the contribution of the pores to saturation and relative hydraulic conductivity as a function of pressure head; the fracture aperture sizes determine the individual contribution of the fractures. The individual contributions are weighted by their incremental volume fraction (or porosity) for the representative elemental volume of rock mass. The values for saturation as a function of pressure head and relative hydraulic conductivity as a function of pressure head (or saturation), which are determined independently of the flow equation in which they are to be used, can then be applied in Eq. 19 to describe the movement of fluid in fractured, porous media. Thus, two different methods are available to evaluate the terms $S_{c}(\psi)$ and $K_{c}(\psi)$ in the fluid flow equation for a fractured rock mass.

Composite curves predicted by the two formulations will be compared later for the four stratigraphic units in the list below. All of the units in the list are above the water table at Yucca Mountain. The abbreviations in brackets are unit designations; the value in parentheses corresponds to the sample depth in drill hole USW G-4 on Yucca Mountain from which the matrix hydrologic properties were determined.

1) Tiva Canyon Welded unit [TCw] (43 ft),

2) Topopah Spring Welded unit [TSw2] (1158ft),

3) Basal Vitrophyre of the Topopah Spring Welded unit [TSw3] (1299 ft), and

4) Calico Hills Nonwelded unit [CHnz] (1548ft).

The data on pore-size distribution for tuff matrix samples were obtained from mercury-intrusion tests. A distribution of pore radii is obtained, along with the percent volume of the sample associated with each pore radius. The pore-size distribution of the matrix was inferred from mercury-intrusion measurements taken by Micromeritics Instrumentation Corp. (with a maximum mercury-intrusion pressure of $60,000 \mathrm{psi}$ ); the average, volume-based pore diameter for tuffs was determined to be generally less than 0.1 micrometers. Pore-size distributions for the matrix material for each of the four locations specified above are shown in 
Figures 23 through 26 . A frequency plot of incremental volume versus pore diameter was determined by mercury-intrusion testing for a matrix sample obtained from each of the four depths of drill hole USW G-4 noted above. (Note: Aberrations in pore-size distributions determined by mercury-intrusion testing are not uncommon. For example, the indication of pore volume above 10 micrometers in Figure 24 is considered by Micromeritics to possibly be an artifact of the experimental procedures; it corresponds to only approximately 2 percent of the total volume of mercury injected.) Mercury intrusion data are available for approximately 30 samples taken from various stratigraphic units in Yucca Mountain. For most samples, there is little or no pore volume for pore radii above 1-5 micrometers.

Because no field information is available on the general distribution of fracture aperture in the various stratigraphic units in Yucca Mountain, a lognormal distribution was assumed. Snow (1970) notes that many arguments indicate the suitability of a lognormal distribution for describing fracture-aperture fre- quencies in rock. He has studied joints in granite outcrop and found that mean apertures were distributed approximately lognormally and suggests that apertures are similarly distributed at depth. Sharp (1970) measured apertures in a single fracture in the laboratory. The data showed a lognormal form, with a truncated tail due to the small area available for sampling. The two-parameter lognormal distribution (Aitchison, 1953) is defined by

$$
f(b)=\left[b\left(2 \pi \sigma^{2}\right)^{1 / 2}\right]^{-1} \exp \left[-\left(2 \sigma^{2}\right)^{-1}(\ln b-\xi)^{2}\right],
$$

where $f(b)$ is the frequency of apertures between $b$ and $b+\mathrm{db}, \xi$ is defined by the logarithm of the mean aperture, and $\sigma$ is defined by the variance. Neuzil and Tracy (1981) have indicated a range of parameters that may be appropriate for describing an aperture frequency distribution. Figure 27 shows examples of lognormal aperture distributions for several different values of the variance and a constant value of 25 micrometers for the mean aperture.

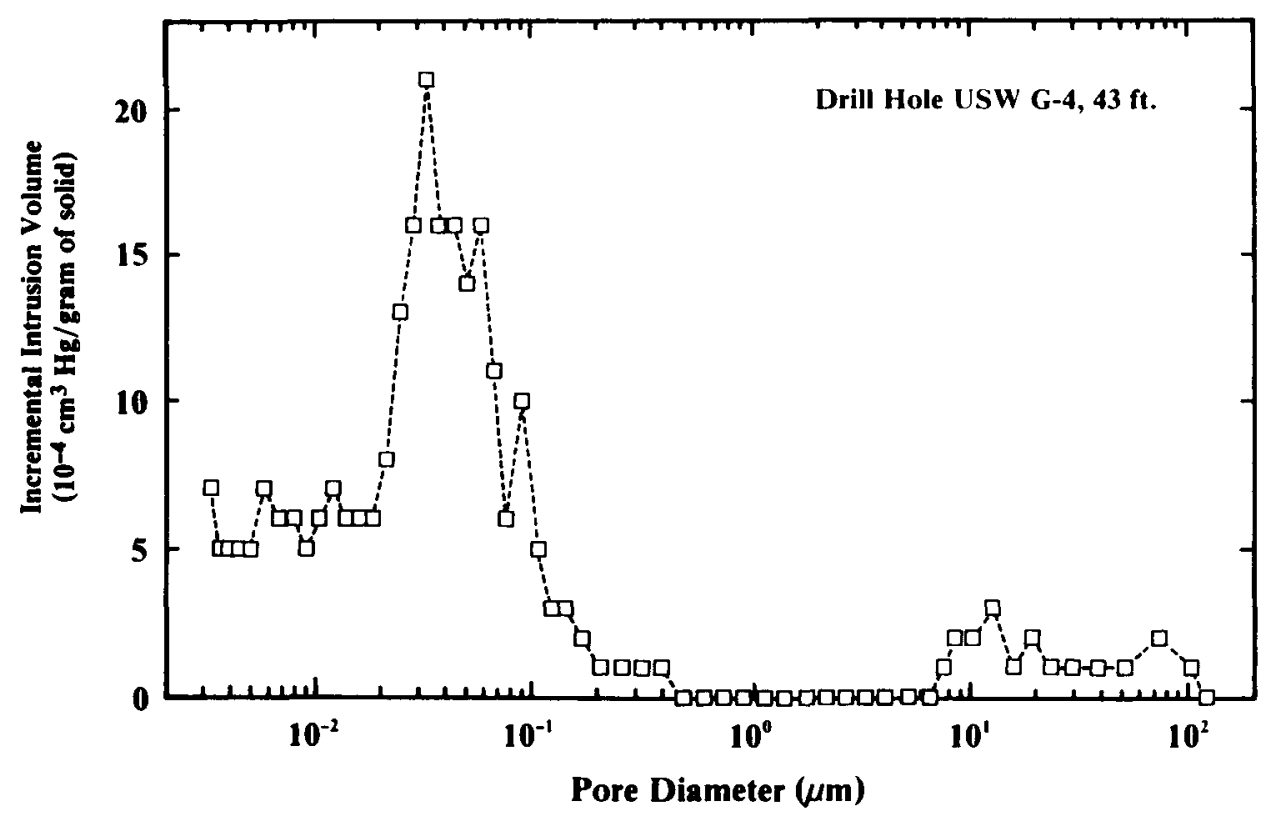

Figure 23. Incremental Mercury-Intrusion Volume Versus Pore Diameter for a Matrix Sample From Unit TCw 


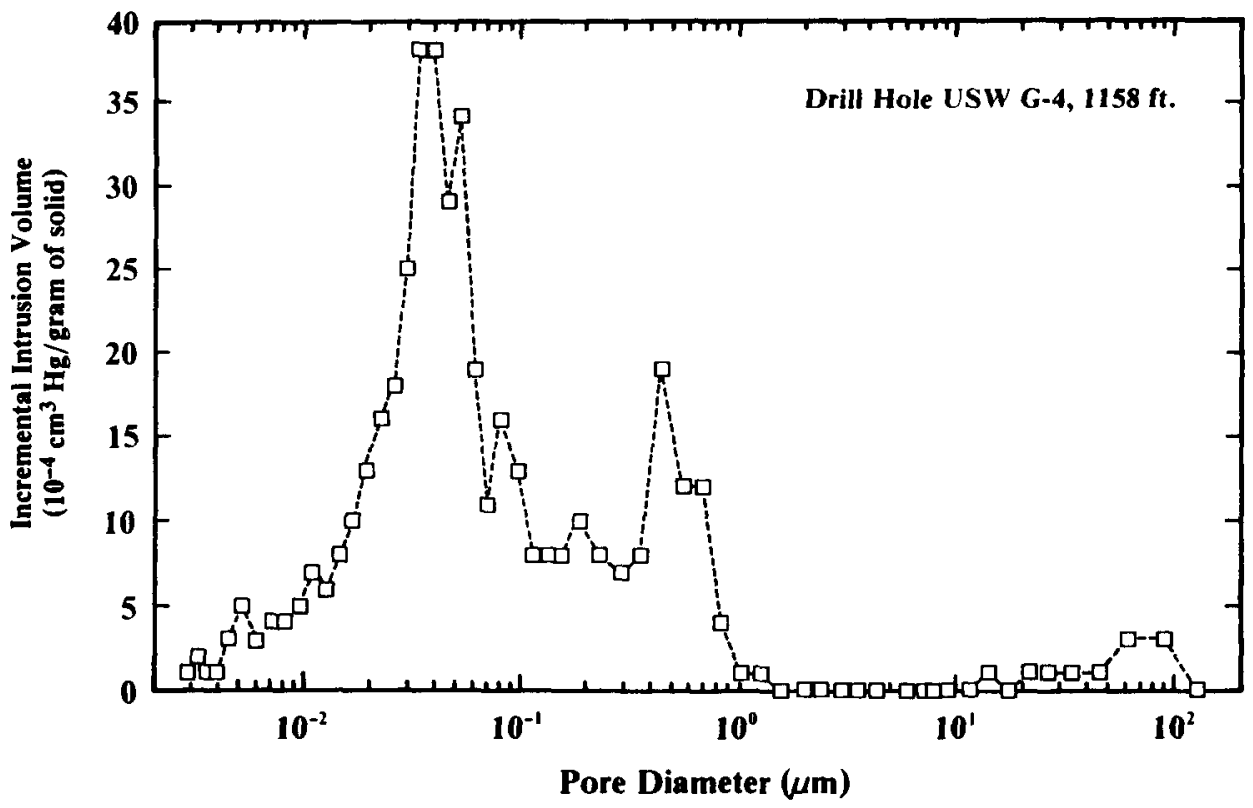

Figure 24. Incremental Mercury-Intrusion Volume Versus Pore Diameter for a Matrix Sample From Unit TSw2

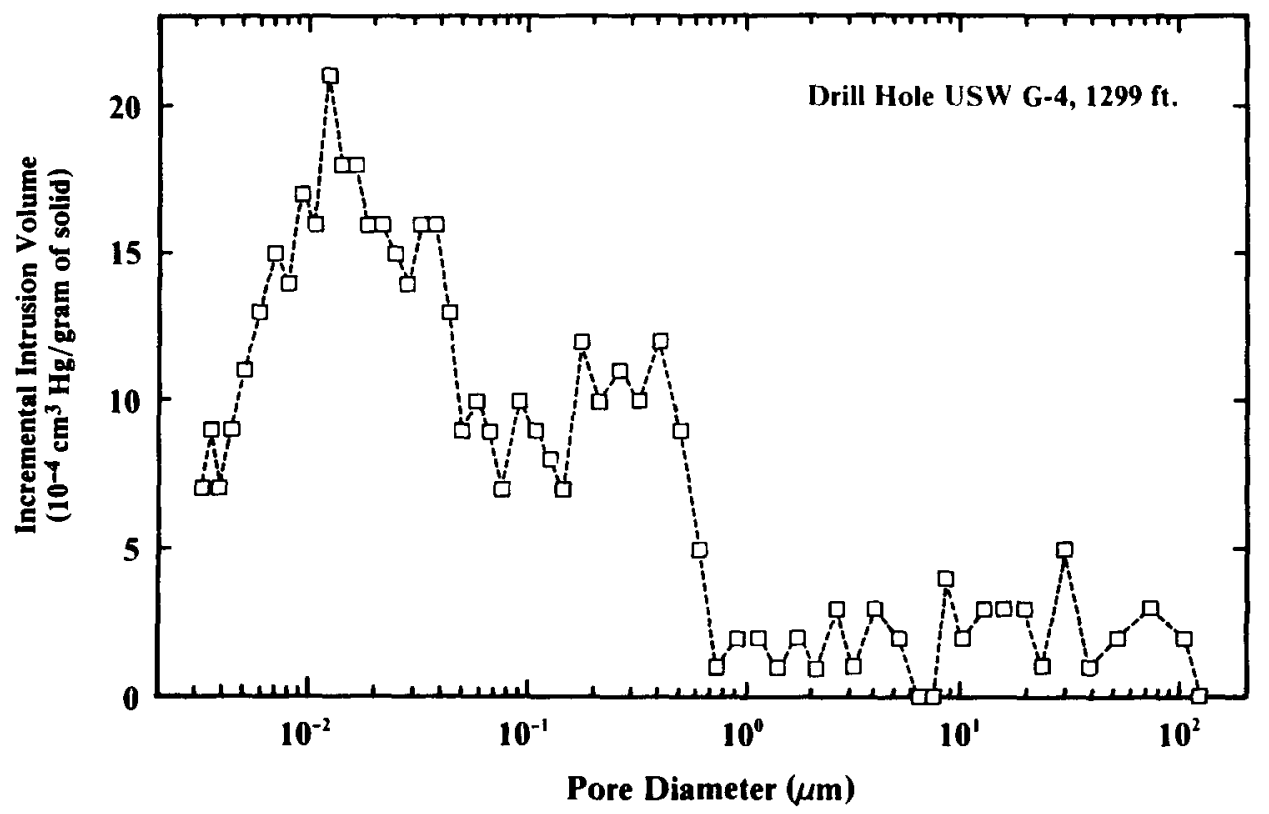

Figure 25. Incremental Mercury-Intrusion Volume Versus Pore Diameter for a Matrix Sample From Unit TSw3 


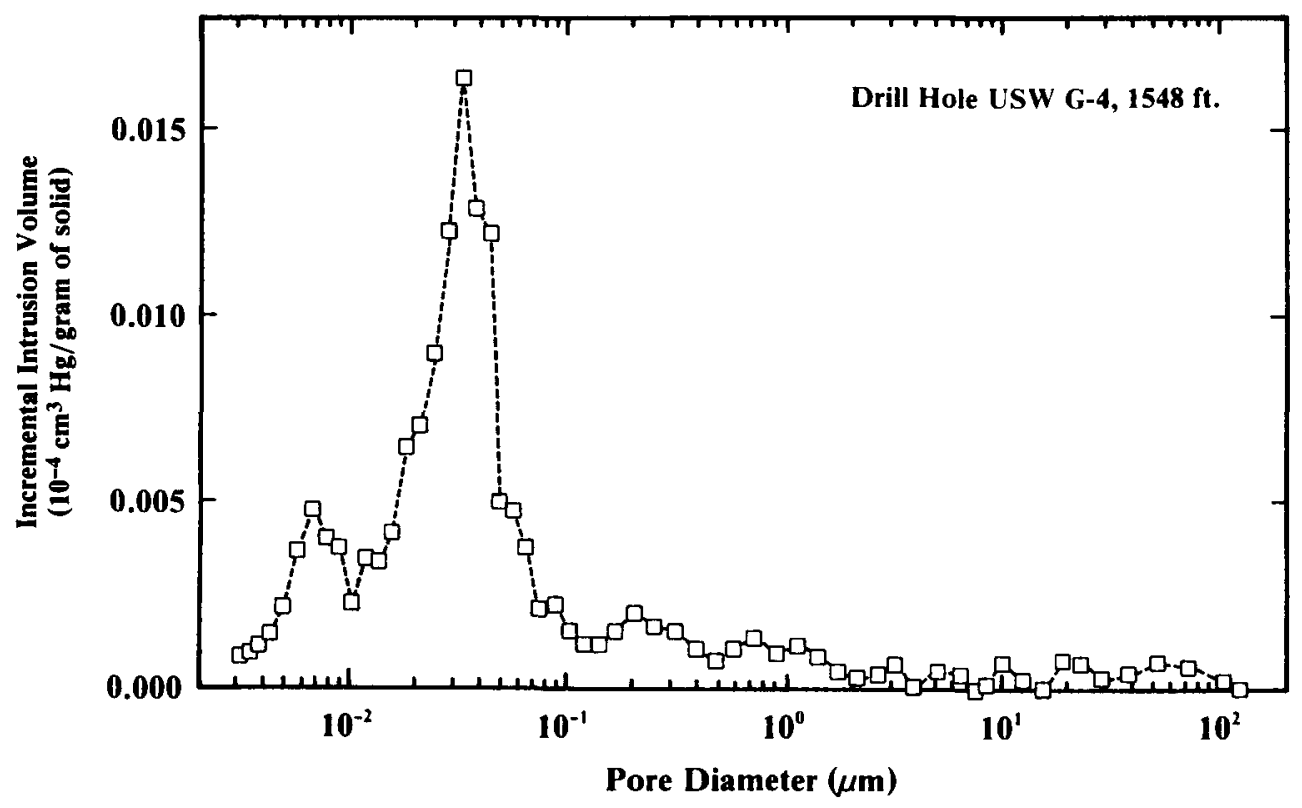

Figure 26. Incremental Mercury-Intrusion Volume Versus Pore Diameter for a Matrix Sample From Unit CHnz

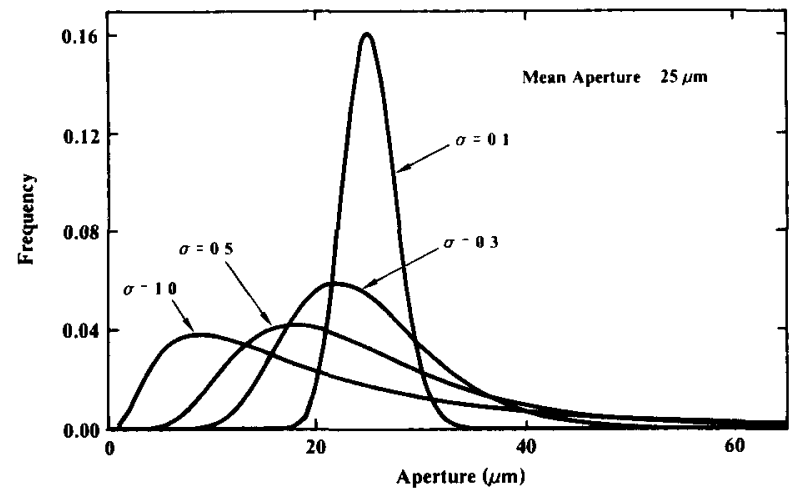

Figure 27. Lognormal Distributions With a Mean Aperture of 25 Microns and Different Variances

For the four comparison cases studied in this section, a fracture aperture value of 25 micrometers was chosen as the mean aperture. The average equivalent hydraulic apertures in Table 2 are in the range of 4-27 micrometers. However, these values take into account the tortuosity of the fractures, both microscopic (surface topology) and macroscopic. (Tortuosity may be simply defined as the ratio of the actual length of the flow path to the straight-line length of the flow path.) Barton et al. (1983) noted that in this range of apertures, the physical aperture dimension is on the order of 2-7 times the equivalent hydraulic aperture. Because the effects of tortuosity of the pores are included in the calculation of the relative conductivity curve for the composite pore-size distribution, the tortuosity effect inherent in the equivalent hydraulic aperture was removed. Thus, an average value of 25 micrometers was used for the mean physical aperture. A variance of 0.3 was arbitrarily chosen, because it seemed to approximate the variance of the fracture relative conductivity curve assumed in the previous approach, and no other information is currently available for the distribution of fracture apertures in the various stratigraphic units at Yucca Mountain. It will be shown later that fracture hydrologic characteristics do not appear to be sensitive to the value of the variance chosen.

The above information on the aperture and pore size distributions is combined with estimates of fracture porosities to yield a rock mass, "pore"-size distribution that includes both the matrix and fracture structural characteristics. For this study, based upon available laboratory and field data for tuff, fracture apertures were assumed to be in the range of $1-100$ micrometers. The individual distributions were linearly weighted with their respective matrix and fracture porosities to create the cumulative, normalized volume distribution as a function of pore diameter (or radius). For example, for a fracture porosity of 10 percent the pores with apertures in the range of 1-100 micrometers will comprise 10 percent of the total rock mass volume. The term "pore" here will refer to either a matrix interstitial opening or a fracture opening. Tortuosity distributions for the resulting pore size distributions were assumed, with the 
tortuosity of a pore decreasing with increasing pore aperture or radius.

The composite, pore-size distribution for the rock mass was used to calculate the saturation values as a function of pressure head based upon capillary-bundle theory (e.g., see Hillel, 1982). The one-dimensional relative hydraulic conductivity values as a function of pressure head were also calculated using capillary theory (Burdine, 1953).

The pressure head (negative suction head) corresponding to a particular pore radius or saturation can be determined from a momentum balance, equating the forces acting upon the fluid interface. (The force up due to surface tension effects is equal to the weight of the fluid down, at equilibrium conditions.) For a circular pore, the pressure head, $\psi$, is given by

$\psi=\frac{2 \gamma \cos \phi}{\rho \mathrm{gr}}$

where $\gamma$ is the surface tension between the solid and fluid, $\phi$ is the contact angle between the solid and fluid, $g$ is the acceleration due to gravity, and $r$ is the pore radius. For the pore sizes corresponding to fracture apertures, the size of the fracture aperture was used in the above equation to calculate pressure head instead of the pore radii, since fracture openings are rectangular rather than circular.

Therefore, a particular pore radius can be calculated from a mercury-intrusion pressure. The volume of mercury intruded at that pressure can be converted to a mercury saturation. The water pressure head corresponding to a particular mercury-intrusion pressure (and pore radius) can be calculated using Eq. 26 for both mercury and water, yielding the equation to convert data on mercury intrusion pressure into equivalent water pressure head.

$\psi_{u}=\frac{-\mathbf{P}_{\mathrm{Hg}_{\mathrm{g}}}}{\rho_{\mathrm{u}} \mathrm{g}} \frac{\gamma_{\mathrm{u}} \cos \phi_{\mathrm{u}}}{\gamma_{\mathrm{H}_{\mathrm{r}}} \cos \phi_{\mathrm{Hg}}}$

The subscripts "w" and "Hg" refer to water and mercury, respectively. The specific values used for surface tension and contact angle values were estimates based upon information contained in a variety of sources (e.g., Hillel, 1982) and are listed below.

$$
\begin{array}{rlrl}
\gamma_{\mathrm{u}} & =0.072 \mathrm{~N} / \mathrm{m} & \phi_{\mathrm{w}} & =15 \text { degrees } \\
\gamma_{\mathrm{I}_{\mathrm{h}}} & =0.484 \mathrm{~N} / \mathrm{m} \quad \phi_{\mathrm{H}_{\mathrm{k}}} & =130 \text { degrees }
\end{array}
$$

The water saturation corresponding to this adjusted water pressure head is 1 minus the mercury saturation at a particular pore radius determined from the intrusion tests. Thus, at zero pressure, no mercury has intruded into the pore volume, the mercury saturation is zero, and the corresponding water saturation is one. At the maximum recorded mercury pressure, corresponding to about $-10,000 \mathrm{~m}$ of water, the mercury content in the pore volume is a maximum and the mercury saturation is assumed to be 100 percent, with a corresponding water saturation of zero.

Although fracture apertures are large in comparison to the pore radii, the fracture system has an extremely low porosity (volume) in comparison to the matrix porosity. Thus, the fracture system has a negligible effect on the saturation-versus-pressure-head curve calculated for the matrix-fracture system. Therefore, saturation as a function of pressure head values for the composite rock mass may be reliably estimated by saturation as a function of pressure head values measured for the matrix alone. The relative hydraulic conductivity curve is much more sensitive to the effects of fractures and is, therefore, more applicable to the comparison of the microscopic model for a composite rock material to the macroscopic model presented in the previous section.

The wetting-phase, relative hydraulic conductivity curve can be calculated using the method of Burdine (1953). Burdine used capillary theory, along with assumptions on the effects of tortuosity of the pores on fluid flow, to formulate an equation to calculate wetting-phase relative hydraulic conductivity as a function of saturation and of pore size. The theoretical permeability of a circular capillary tube is proportional to the square of its radius. The pressure head associated with a particular saturation can again be determined from capillary theory by relating a pore size to its pore entry pressure, as noted by Eq. 26. Burdine's contribution consisted primarily of his treatment of the tortuosity distribution. A simplified formulation of Burdine's equation follows. Both the relative permeability and relative hydraulic conductivity are ratios that go from 0 to 1 and are identical at any chosen saturation. The equation is put in terms of relative hydraulic conductivity for convenience:

$K_{r e l}=\frac{n_{t o t}}{8 k_{s}} \sum_{i=0}^{I_{\text {max }}} \frac{v\left(r_{i}\right) r_{r}^{2}}{\chi_{u}^{2}}$

where $K_{r e l}$ is the wetting-phase, relative hydraulic conductivity (dimensionless), $\mathrm{k}_{\mathrm{s}}$ is the saturated liquid permeability $\left(\mathrm{m}^{2}\right), r$ is the pore entry radius $(\mathrm{m})$, $v(r)$ is the incremental volume fraction $\left(\mathrm{m}^{3} / \mathrm{m}^{3}\right), n_{\text {tot }}$ is the porosity, and $\chi_{k}$ is the tortuosity factor of the wetting phase. 
It should be remembered that capillary theory and the results of this study assume that the liquid is at a steady-state or nearly steady-state condition and that laminar flow prevails throughout the system. Because of the extremely low water fluxes present in Yucca Mountain, it is assumed that the results presented here are applicable.

Burdine suggests that the tortuosity factor for the wetting phase is different from that for the nonwetting phase. Burdine defines the tortuosity factor for the wetting phase as the ratio of a general tortuosity factor for the sample to a tortuosity ratio for the wetting phase. He further postulates this tortuosity ratio for the wetting phase, $\chi_{r, w}$, to be

$\chi_{\mathrm{ru}}=\left(\mathrm{S}_{\mathrm{w}}-\mathrm{S}_{\mathrm{w}, \mathrm{r}}\right) /\left(1-\mathrm{S}_{\mathrm{w}, \mathrm{r}}\right)$,

where $S_{w}$ is the saturation of the wetting phase and $S_{w r}$ is the irreducible, or residual, saturation of the wetting phase.

Rose (1949) and Wheeler (1955), among others, have suggested that the tortuosity factor for a sample is actually represented by a distribution of tortuosity factors, dependent upon the radius of the pore. Both postulated an exponential form for this distribution, in which the tortuosity decreases with increasing pore size. The exponential function suggested by Rose for a sandstone was used here in the absence of any other information. Tortuosity distributions for tuff samples, as for any other real material, must be determined experimentally. The exponential distribution function used by Rose for sandstone is given by (with the pore radius in micrometers)

$\chi\left(\mathbf{r}_{1}\right)=\mathrm{A} \exp \left(-\mathrm{Br}_{1}\right)+\mathrm{C}$.

The parameter $B$ appears to be related to how rapidly the cumulative pore volume changes with pore radius. $\mathrm{C}$ is related to the tortuosity of the larger pores (fractures), or more properly the surface roughness characteristics that give rise to the difference between the physical fracture aperture and the effective, hydraulic aperture. The sum of $A$ plus $C$ is related to the maximum tortuosity of the smallest pore size.

Because the tortuosity factor, or distribution, of the wetting phase, $\chi_{w}$, in Eq. 28 is the ratio of the general tortuosity factor (defined, for example, by Eq. 30) to the tortuosity ratio for the wetting phase (defined by Eq. 29), Eqs. 29 and 30 can be substituted into Eq. 28 to yield the following expression for the wetting-phase, relative conductivity curve

$\mathrm{K}_{\mathrm{rel}}=\frac{\mathrm{n}_{\mathrm{tot}}}{8 \mathrm{k}_{\mathrm{s}}} \sum_{1=0}^{\mathrm{r}_{\max }} \frac{\left(\mathrm{S}_{\mathrm{w}}-\mathrm{S}_{\mathrm{w}, \mathrm{r}}\right)^{2}}{\left(1-\mathrm{S}_{\mathrm{w}, \mathrm{r}}\right)^{2}} \frac{\mathrm{v}\left(\mathrm{r}_{1}\right) \mathrm{r}_{1}{ }^{2}}{\left[\mathrm{~A} \exp \left(-\mathrm{Br} \mathrm{r}_{\mathrm{l}}\right)+\mathrm{C}\right]^{2}}$

The relative hydraulic conductivity, as well as the saturation, can thus be calculated as a function of pressure head for the unsaturated rock mass using only information on the physical characteristics of the porous matrix and the fractures. These characteristics are used, along with the theoretical considerations presented here, to determine the contributions of the pores and the fractures to the overall rock-mass hydrologic properties. These hydrologic properties are used in Eq. 19 or Eq. 20 to describe fluid flow in the fractured, porous media.

\section{Results and Discussion}

Both model approaches calculate hydrologic parameters for an unsaturated, fractured rock mass. These hydrologic parameters are used in a fluid flow equation such as Eqs. 19 or 20. The two approaches use the important assumption that the difference between the pressure head in the matrix and that in the fractures is negligible in a plane perpendicular to flow. Both approaches also assume that representative data are available for the volume of rock mass of interest (i.e., that an REV, representative element of volume, exists). Capillary theory is assumed to apply, which means that laminar flow exists and that fracture apertures are not too large for capillary pressure to have meaning. Additionally, for the microscopic approach, a lognormal aperture distribution is assumed. Justification for this assumption, as well as the rationale for the choice of mean aperture, was given earlier. Figure 28 shows the insensitivity of the fracture relative conductivity curve to the choice of the variance used in the lognormal distribution. 


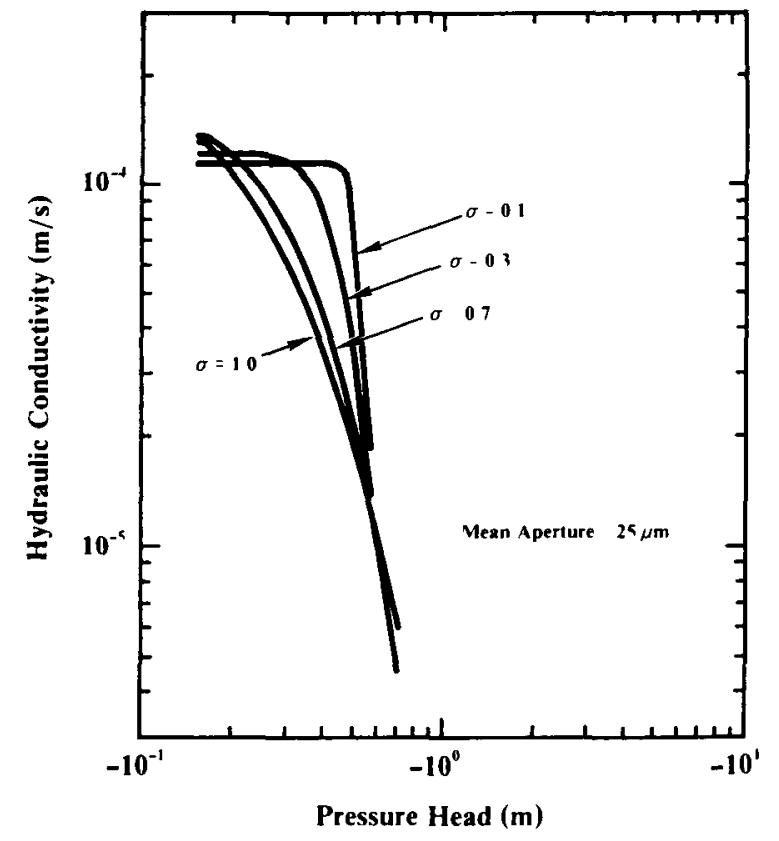

Figure 28. Fracture Relative-Hydraulic-Conductivity Curves as Calculated From a Lognormal Distribution of Apertures Using Different Values of the Variance

\section{Comparison of the Macroscopic and Microscopic Approaches}

A comparison is made here of predictions of the methods derived in the two approaches to calculate the hydrologic parameters used in those equations describing unsaturated flow in a fractured, porous medium. The comparison was made using hydrologic properties and information available from four stratigraphic units above the water table at Yucca Mountain. Depending upon the water flux through each of these fractured units, water may be moving through just the matrix or through both the matrix and fractures.

As stated previously, because of the low fracture porosity considered to exist at Yucca Mountain, the relationship between fracture saturation and pressure head has a negligible effect on the relationship between rock-mass saturation and pressure head. Fracture porosities are generally on the order of $10^{-3}$ to 10 " or less in consolidated rock sytems (Snow, 1970), and the contribution of fractures to the total void volume is not generally significant. Therefore, the composite saturation versus pressure-head curve for a fractured rock mass is essentially identical to the curve for the matrix; the two models are not compared for this parameter.
The composite relative conductivity curves, as calculated using the macroscopic approach to a compositeporosity model (Eq. 24), are compared with the composite relative conductivity curves calculated from Eq. 31, using the pore-size distribution data of the matrix and the assumed lognormal aperture distribution for the fractures. Composite curves predicted by the two formulations were compared for core samples from the following four stratigraphic units. These units are found in the unsaturated zone at Yucca Mountain.

1) Tiva Canyon Welded unit (TCw)

2) Topopah Spring Welded unit, lithophysae poor (TSw2)

3) Basal Vitrophyre of the Topopah Spring Welded unit (TSw3)

4) Calico Hills Nonwelded unit (CHnz)

The relative hydraulic conductivities for the matrix and fractures specified in Eq. 24, using the macroscopic approach, are calculated using Eq. 15 with appropriate values of $\alpha, \beta$, and $\mathrm{K}_{\mathrm{s}}$. The values of the parameters used in Eq. 15 for the four cases specified were taken from Peters et al. (1984) and are listed in Table 3, along with the matrix and fracture porosities. The pore size distributions used for the matrix were shown in Figures 23 through 26. Constant values of 25 micrometers and 0.3 were used in the lognormal aperture distribution for the mean aperture and variance, respectively.

The comparisons of the composite hydraulic conductivity curves for each unit are shown in Figures 29 through 32 . The hydraulic conductivity (equal to the relative hydraulic conductivity times the hydraulic conductivity at saturation) was plotted rather than the relative hydraulic conductivity to indicate the large range of values of the hydraulic conductivity. The curves are not only qualitatively the same, but are, in general, quantitatively similar. The pressure head at which the fracture effects become significant matches well between the two formulation methods. The general shape of those portions of the curves dominated by either fracture (high conductivity) or matrix (low conductivity) characteristics matches very well for the results of the two approaches. Because both methods yield approximately the same relationships for saturation and relative conductivity as a function of pressure head, both models will predict essentially the same flux values at the same conditions. 


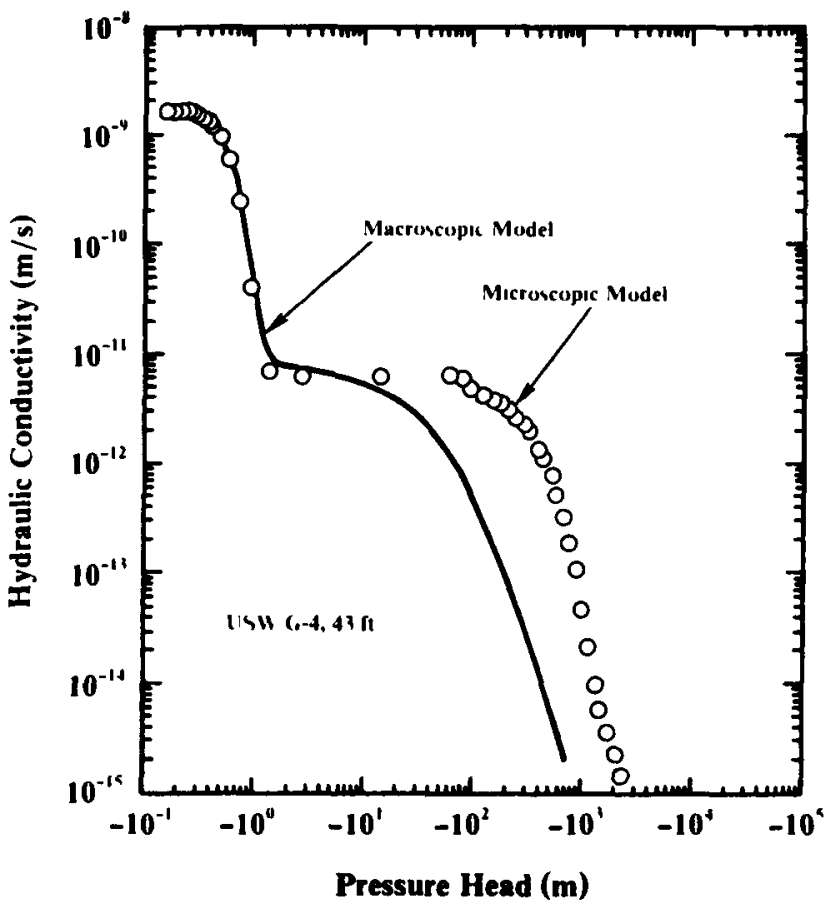

Figure 29. Hydraulic Conductivity Comparison for Rock Mass Material of Unit TCw

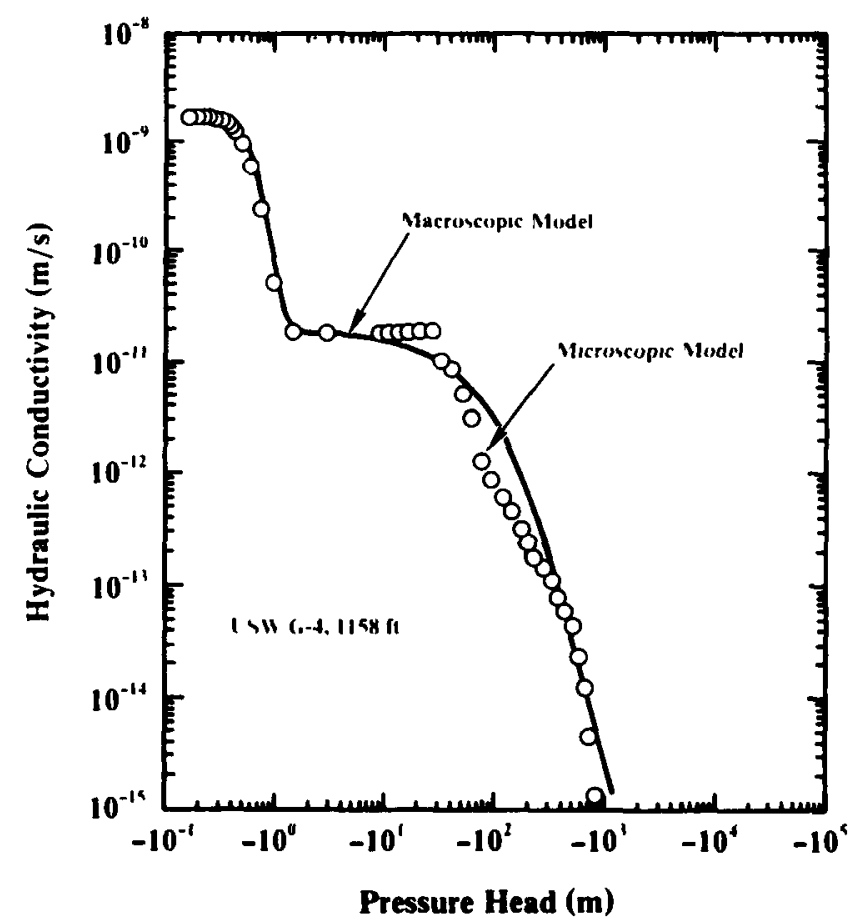

Figure 30. Hydraulic Conductivity Comparison for Rock Mass Material of Unit TSw2

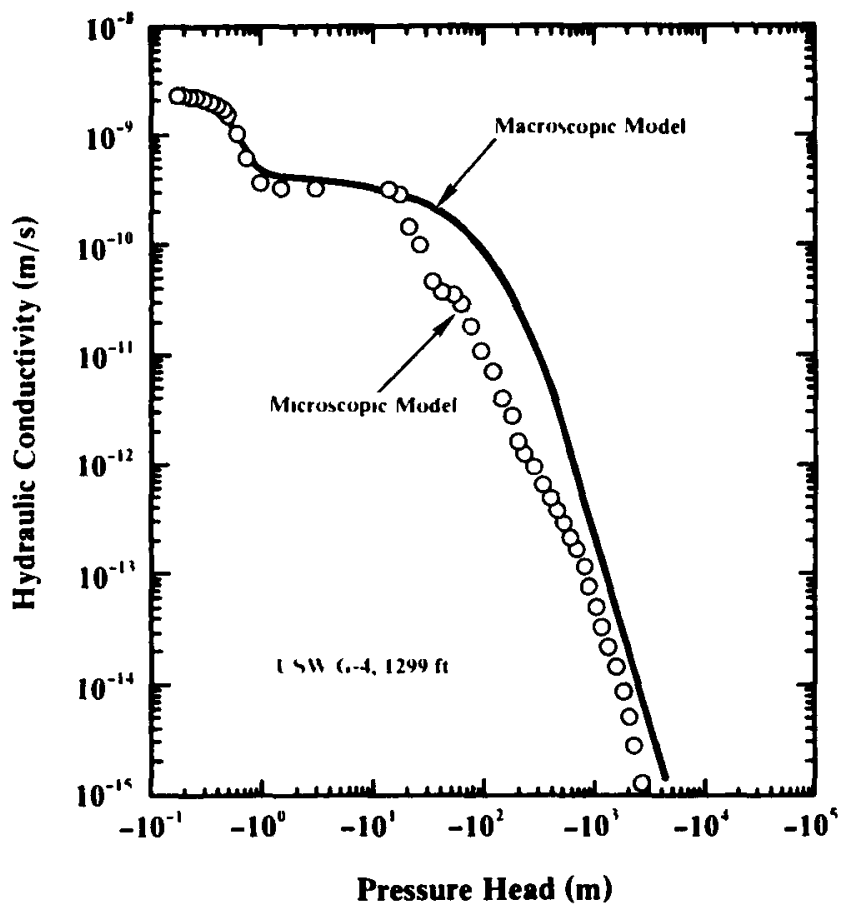

Figure 31. Hydraulic Conductivity Comparison for Rock Mass Material of Unit TSw3

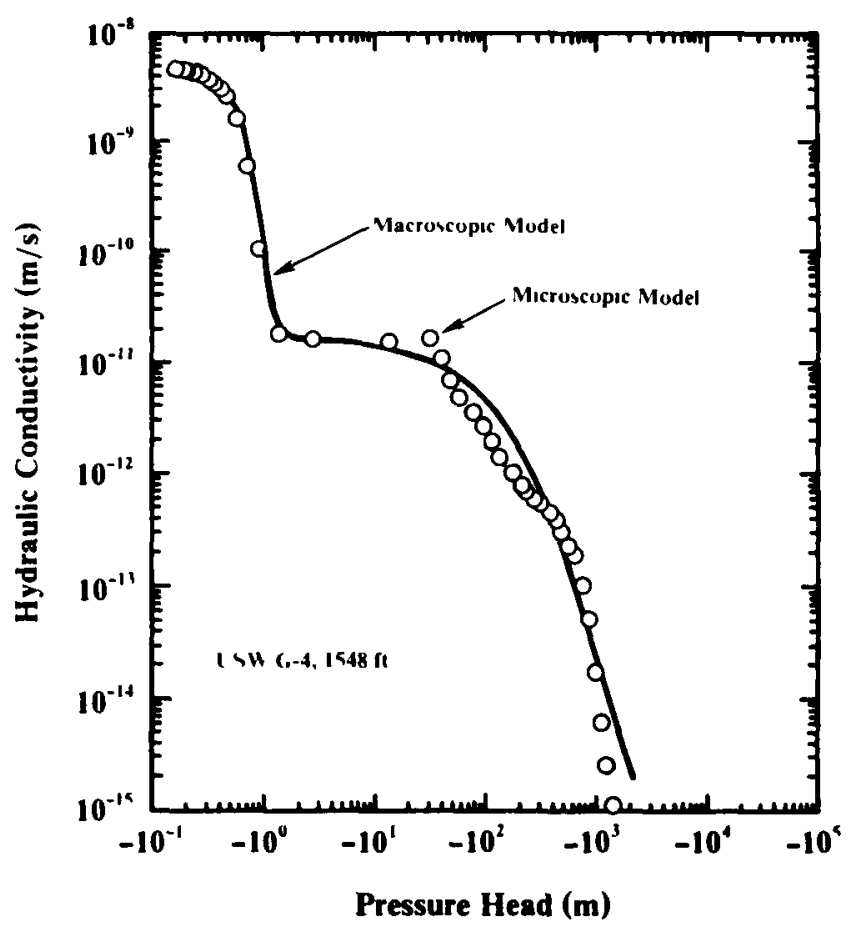

Figure 32. Hydraulic Conductivity Comparison for Rock Mass Material of Unit CHnz 
The good quantitative agreement between the results of the two formulations was aided by adjusting the values of $\mathrm{A}$ and $\mathrm{C}$ in Eq. 30 for the four different samples compared. A constant value of 0.4 was suggested by Rose (1949) for sandstone for the parameter $B$ and was used in the absence of other information. The values of $A$ and $C$ used for the four comparisons are shown in Table 3. Tortuosity factors for porous matrix materials such as sandstones and reaction catalysts are generally in the range of $\sim 1$ to 10 , (Froment and Bischoff, 1979) although the magnitude of the pore sizes and the mean pore radii of tuffs are much smaller than those of sandstones or catalysts and larger tortuosity factors might be expected. However, no definitive interpretations about the tortuosity distributions for tuff should be made from such a small sampling of results because of the complexities involved with the concept of tortuosity. Lumped into the tortuosity are such parameters as pore length distributions, pore shape, and connectivity between pores of different radii. The tortuosity distribution parameters should be experimentally determined for each porous medium of interest. No information is available for tuffs; therefore, parameters were used that provided a reasonable quantitative fit. The purpose of this comparison was not to determine tortuosity parameters but to qualitatively compare the two formulation methods for determining a rock-mass relative hydraulic conductivity curve. The constants A, B, and C used in Eq. 30 affect the magnitude of the calculated relative hydraulic conductivities at any particular saturation or pressure head but have little effect on the shape of the resulting curve. The selection of these tortuosity parameters does not affect the qualitative comparison of the curves.
The good qualitative and quantitative comparison of the two methods for calculation of a relative conductivity curve for a rock mass adds confidence to the validity of the macroscopic model assumptions presented in the first model derivation. The microscopic method presented here for the calculation of the curves is based upon available physical data on the structural characteristics and properties of the matrix and fractures and compares favorably to the macroscopic formulation presented. As more laboratory and field data become available on the distribution of fracture apertures and fracture porosities in the stratigraphic units of Yucca Mountain, these composite relative conductivity curves can be modified to provide a better representation of the physical system. However, the microscopic approach requires a large amount of detail on the structure of both the matrix and the fractures, which can be, and generally is, extremely complicated and difficult to define confidently. Since both methods yield similar results and the first approach does not require this specific structural information, the macroscopic model is being used in current NNWSI performance assessment calculations. To estimate rock-mass properties with this approach, matrix and fracture porosities are required, as well as representative curves for the unsaturated hydrologic properties of the matrix and fractures. When data on fracture spacing are available, they can be used together with the assumed aperture distribution to estimate the fracture porosity. Because of the scarcity of information on the unsaturated hydrologic characteristics of fractures, the method outlined in this report to estimate the characteristic curves for fractures, assuming a lognormal distribution of fracture apertures and using capillary theory, is suggested as a first approximation.

\section{Table 3. Property Values Used in Model Comparison}

\begin{tabular}{|c|c|c|c|c|c|c|c|c|c|c|c|c|}
\hline \multirow{2}{*}{$\begin{array}{l}\text { Sample Depth } \\
\text { Drill Hole in } \\
\text { USW G-4 (ft) }\end{array}$} & \multicolumn{3}{|c|}{$\begin{array}{l}\text { (Fitting Parameters for } \\
\text { Matrix Used in Eq. } 15^{*} \text { ) }\end{array}$} & \multirow[b]{2}{*}{$\mathbf{n}_{\mathrm{m}}$} & \multirow[b]{2}{*}{$n_{f}$} & \multirow[b]{2}{*}{$\mathrm{K}_{\mathrm{s}, \mathrm{m}}(\mathrm{m} / \mathrm{s})$} & \multicolumn{5}{|c|}{$\begin{array}{l}\text { Parameters in } \\
\text { Lognormal } \\
\text { Distribution } \\
\text { (Eq. 25) }\end{array}$} & \multirow[b]{2}{*}{$\mathrm{K}_{\mathrm{s}, \mathrm{I}}(\mathrm{m} / \mathrm{s})$} \\
\hline & $\alpha(1 / m)$ & $\beta$ & $S_{r}$ & & & & $\mathbf{A}$ & $\mathrm{B}$ & $\mathrm{C}$ & $\mathrm{b}_{\text {mean }}(\mu \mathrm{m})$ & $\sigma$ & \\
\hline 43 & 0.00821 & 1.558 & 0.002 & 0.08 & $9.0 \times 10^{-5}$ & $9.7 \times 10^{-12}$ & 2.0 & 0.4 & 3.0 & 25 & 0.3 & $1.7 \times 10^{-5}$ \\
\hline 1158 & 0.00567 & 1.798 & 0.080 & 0.11 & $1.5 \times 10^{-4}$ & $1.9 \times 10^{-11}$ & 10.5 & 0.4 & 3.5 & 25 & 0.3 & $1.1 \times 10^{-5}$ \\
\hline 1299 & 0.00419 & 1.622 & 0.053 & 0.09 & $1.5 \times 10^{-4}$ & $4.5 \times 10^{-10}$ & 1.2 & 0.4 & 3.2 & 25 & 0.3 & $1.1 \times 10^{-5}$ \\
\hline 1548 & 0.00308 & 1.602 & 0.110 & 0.28 & $3.6 \times 10^{-4}$ & $2.0 \times 10^{-10}$ & 9.0 & 0.4 & 1.6 & 25 & 0.3 & $12.4 \times 10^{-5}$ \\
\hline
\end{tabular}

*The fitting parameters used in Eq. 15 for the fractures were kept constant for all cases, with only $\mathrm{K}_{\mathrm{z}, \mathrm{f}} \mathrm{varied}$. The parameters are: $\alpha=1.2851 \mathrm{~m}^{-1}$, $\beta=4.23, \mathrm{~S}_{\mathrm{r}}=0.0395$. 


\section{Summary}

The proposed repository zone at the Yucca Mountain site is in the unsaturated zone. The unsaturated zone contains tuffs that have both high- and lowconductivity matrix material and high- and lowfracture densities. Hydrologic calculations using models that explicitly include the fractures are not feasible because a very large number of fractures $\left(\sim 10^{10}\right)$ would be contained in a site-scale problem. A continuum approach to calculating water flow in the fractured media at Yucca Mountain was developed. The major assumption in this development was that the pressure head in the fractures and the matrix are identical in a direction perpendicular to flow. Calculations of small-scale problems that explicitly include the fractures show that this assumption is correct at Yucca Mountain. Evaluation of the coefficients in the fluid continuity equation using both macroscopic and microscopic approaches yields qualitatively and quantitatively similar results. The macroscopic approach is easily implemented if information on matrix and fracture porosities and representative curves for the unsaturated hydrologic properties of the matrix and fractures is available. Data for matrix properties are becoming available, and hydrologic data for fractures are expected as research in this field progresses. Until measurements of the characteristic curves of fractures have been made, assumptions must be made to estimate the shape of the curves. The approach presented in this report, which can be used as an initial approximation, is based upon capillary theory along with the assumption of a lognormal, fracture-aperture distribution. This macroscopic approach is, therefore, being used in current computer code calculations for which it is required to model hydrologic flow in a large volume of rock mass containing both matrix and fractures.

\section{References}

Aitchison, J., and J. A. C. Brown. 1957. "THE LOGNORMAL DISTRIBUTION,” Cambridge, University Press, New York, NY.

Barenblatt, G. I., Zheltov, Iu. P., and I. N. Kochina. 1960. "Basic Concepts in the Theory of Seepage of Homogeneous Liquids in Fissured Rocks [strata]," PMM, Vol. 24, No. 5, 852-864.

Barton, N., Bakhtar, K., and S. Bandis. 1983. "Rock Joint Description and Modeling for Prediction of NearField Repository Performance," Materials Res. Soc. Ann. Meeting 1983. Boston, MA, Proc. Symp. D - "Scientific Basis for Nuclear Waste Management."
Bixler, N. E. 1985. "NORIA: A Finite Element Computer Program for Analyzing Water/Vapor/Air/Energy Transport in Porous Media," SAND84-2057, Sandia National Laboratories, Albuquerque, NM.

Brooks, R. H., and A. T. Corey. 1966. "Properties of Porous Media Affecting Fluid Flow," J. of the Irrig. and Drainage Div., Proceedings of the Amer. Soc. of Civil Engrs., IR2, 61-88.

Burdine, N. T. 1953. "Relative Permeability Calculations from Pore Size Distribution Data," Petroleum Transactions, AIME, Vol. 198, T. P. 3519, 71-78.

Burdine, N. T., Gournay, L. S., and P. P. Reichertz. 1950. "Pore Size Distribution of Petroleum Rocks," Petroleum Transactions, AIME, Vol. 189, T. P. 2893, 195-204.

Campbell, J. E., Longsine, D. E., and R. M. Cranwell. 1981. "Risk Methodology for Geologic Disposal of Radioactive Waste: The NWFT/DVM Computer Code Users Manual," NUREG/CR-2081 (SAND81-0886), Sandia National Laboratories, Albuquerque, NM.

Childs, E. C. and N. Collis-George. 1950. "The Permeability of Porous Materials," Proc. Royal Soc., Ser. A, Vol. 201, 392-405.

DOE. 1984. "Draft Environmental Assessment - Yucca Mountain Site, Nevada Research and Development Area, Nevada," US Department of Energy, Washington, DC.

Dudley, A. L., Peters, R. R., Tierney, M. S., Klavetter, E. A., Gauthier, J. H. and M. Wilson. In Preparation. "Total Systems Performance Assessment Code (TOSPAC) Volume 1: Physical and Mathematical Bases," SAND85-0002, Sandia National Laboratories, Albuquerque, NM.

Duguid, J., and P. C. Y. Lee. 1973. "Flow in Fractured Porous Media," Research Report No. 73-WR-1, Dept. of Civil and Geological Engineering, Princeton University, Princeton, NJ.

Eaton, R. R., Gartling, D. K., and D. E. Larson. 1983. "SAGUARO - A Finite Element Computer Program for Partially Saturated Porous Flow Problems," SAND82-2772, Sandia National Laboratories, Albuquerque, NM.

Fatt, I., and H. Dykstra. 1951. "Relative Permeability Studies," Petroleum Transactions, AIME, Vol. 192, T. P. 3078, 249-256.

Freese, R. A., and J. A. Cherry. 1979. "GROUNDWATER," Prentice-Hall, Inc., Englewood Clifs, NJ.

Froment, G. F., and K. B. Bischoff. 1979. "CHEMICAL. REACTOR ANALYSIS AND DESIGN,” John Wiley and Sons, New York, NY.

Gale, J. E. 1975. “A Numerical Field and Laboratory Study of Flow in Rocks with Deformable Fractures," Ph.D. Dissertation, Univ. of California, Berkeley, CA.

Gringarten, A. C., and H. J. Ramey, Jr. 1974. "Unsteady State Pressure Distribution Created with a Single Horizontal Fracture, Partial Penetration or Restricted Entry," Soc. Pet. Eng. J., Vol. 14, No. 4, 413-426.

Haverkamp, R., Vauclin, M., Touma, J., Wierenga, P., and G. Vachaud. 1977. "A Comparison of Numerical Simulation Models for One-Dimensional Infiltration," Soil Sci. Am. J., Vol. 41, No. 2, 285-294.

Hillel, D. 1982. "INTRODUCTION TO SOIL PHYSICS,” Academic Press, New York, NY. 
Intera Environmental Consultants Inc. 1982. "NETFLO - A Network Ground-Water Flow Code," ONWI/E51202900/CD-01, Houston, TX.

Johnson, E. F., Bossler, D. P., and V. O. Naumann. 1959. "Calculation of Relative Permeability from Dispacement Experiments," Petroleum Trans., Vol. 216, T.N. 2027, 370-372.

Klavetter, E. A., Peters, R. R., and B. M. Schwartz. In preparation. "Experimental Plan for Investigating Water Movement Through Fractures," SAND84-0468, Sandia National Laboratories, Albuquerque, NM.

Kozeny, J. 1933. “Theorie ind Berechnung der Brunnen," Wasserkraft und Wassenwirtschaft, Vol. 28, 88-92.

Mansure, A. J., and T. S. Ortiz. 1984. "Preliminary Evaluation of the Subsurface Area Available for a Potential Nuclear Waste Repository at Yucca Mountain," SAND840175, Sandia National Laboratories, Albuquerque, NM.

Martinez, M. J. In preparation. "Capillary Driven Flow in a Fracture Located in a Porous Media," SAND84-1697, Sandia National Laboratories, Albuquerque, NM.

Mc'Tigue, D. F., Wilson, R. K., and J. W. Nunziato. 1984. "An Effective Stress Principle for Partially Saturated Media," SAND82-1977, Sandia National Laboratories, Albuquerque, NM.

Millington, R. J. and J. P. Quirk. 1961. "Permeability of Porous Solids," Trans. Faraday Society, Vol. 57, 1200-1206.

Montazer, P., and W. E. Wilson. 1984. "Conceptual Hydrologic Model of Flow in the Unsaturated Zone, Yucca Mountain, Nevada," Water-Resources Investigations Report 84-4345, US Geological Survey, Denver, CO.

Mualem, Y. 1976. "A New Model for Predicting the Hydraulic Conductivity of Unsaturated Porous Materials," Water Resources Research, Vol. 12, No. 3, 513-522.

Narasimhan, T. N. 1982. "Physics of SaturatedUnsaturated Subsurface Flow" in "Recent Trends in Hydrogeology" edited by T. N. Narasimhan, Special Paper 189, Geological Society of America, Boulder, CO.

Neuzil, C. E., and J. V. Tracy. 1981. "Flow Through Fractures," Water Res. Research, Vol. 17, No. 1, 191-199.

Nimick, F. B., Bauer, S. J., and J. R. Tillerson. 1984. "Recommended Matrix and Rockmass Bulk, Mechanical and Thermal Properties for Thermo-Mechanical Stratigraphy of Yucca Mountain," Keystone Doc. 6310-85-1, Sandia National Laboratories, Albuquerque, NM.

Odeh, A. S., 1965. "Unsteady Behavior of Mutually Fractured Reservoirs," Soc. Pet. Eng. J., Vol. 5, 60-65.

Ortiz, T. S., Williams, R. L., Nimick, F. B., Whittet, B. C., and D. L. South, 1985. "A Three-Dimensional Model of Reference Thermal/Mechanical and Hydrologic Stratigraphy at Yucca Mountain, Southern Nevada," SAND84-1076, Sandia National Laboratories, Albuquerque, NM.

Peters, R. R., Klavetter, E. A., Hall, I. J., Blair, S. C., Heller, P. R., and G. W. Gee. 1984. "Fracture and Matrix Hydrologic Characteristics of Tuffaceous Material from Yucca Mountain, Nye County, Nevada," SAND84-1471, Sandia National Laboratories, Albuquerque, NM.
Purcell, W. R. 1949. "Capillary Pressures-Their Measurement Using Mercury and the Calculation of Permeability Therefrom," Petroleum Transactions, AIME, T. P. 2544, 3948.

Reeves, M., and J. O. Duguid. 1975. "Water Movement Through Saturated-Unsaturated Porous Media: A FiniteElement Galerkin Model," ORNL-4927, Oak Ridge National Laboratory, Oak Ridge, TN.

Reisenauer, A. E., Key, K. T., Narasimhan, T. N., and R. W. Nelson. 1982. "TRUST: A Computer Program for Variably Saturated Flow in Multidimensional, Deformable Media," NUREG/CR-2360, US Nuclear Regulatory Commission, Washington, DC.

Richards, L. A. 1931. “Capillary Conduction of Liquids Through Porous Mediums” [sic], Physics, Vol. 1, 318-333.

Rose, W. 1949. "Theoretical Generalizations Leading to the Evaluation of Relative Permeability," Petroleum Transactions, AIME, T. P. 2563, 111-126.

Scott, R. B., Spengler, R. W., Lappin, A. R., and M. P. Chornack. 1983. "Geologic Character of Tuffs in the Unsaturated Zone at Yucca Mountain, Southern Nevada," in "Role of the Unsaturated Zone in Radioactive and Hazardous Waste Disposal," edited by J. Mercer, Ann Arbor Science, Ann Arbor, MI.

Sharp, J. C. 1970. "Fluid Flow Through Fissured Media," Ph.D. thesis, Imp. Coll. of Sci. and Technol., London, England.

Sinnock, S., Lin, Y. T., and J. P. Brannen. 1984. "Preliminary Bounds on the Expected Postclosure Performance of the Yucca Mountain Repository Site, Southern Nevada," SAND84-1492, Sandia National Laboratories, Albuquerque, NM.

Snow, D. T. 1970. "The Frequency and Apertures of Fractures in Rock," Int. J. Rock Mech. Min. Sci., Vol. 7, 2340.

Spengler, R. W., and M. P. Chornack. 1984. "Stratigraphic and Structural Characteristics of Volcanic Rocks in Core Hole USW G-4, Yucca Mountain, Nye County, Neva$\mathrm{da}$," with a section on geophysical logs by D. C. Muller and J. Kibler; OFR 81-1349, US Geological Survey, Denver, CO.

Travis, B. J., Hodson, S. W., Nuttal, H. E., Cook, T. L., and R. S. Rundberg. 1984. "Preliminary Estimates of Water Flow and Radionuclide Transport in Yucca Mountain," Mat. Res. Soc. Symp. Proc., Vol. 26, 1039-1047.

van Genuchten, R. 1978. "Calculating the Unsaturated Hydraulic Conductivity with a New Closed form Analytical Model," Water Resources Bulletin, Princeton University Press, Princeton University, Princeton, NJ.

Wang, J. S. Y. and T. N. Narasimhan. 1985. "Hydrologic Mechanisms Governing Fluid Flow in Partially Saturated, Fractured, Porous Tuff at Yucca Mountain," SAND84-7202, Sandia National Laboratories, Albuquerque, NM.

Wang, J. S. Y., and T. N. Narasimhan. In preparation. "Hydrologic Mechanisms Governing Partially Saturated Fluid Flow in Fractured Welded Units and Porous Nonwelded Units at Yucca Mountain," SAND85-7114, Sandia National Laboratories, Albuquerque, NM. 
Warren, J. E., and P. J. Root. 1963. "Behavior of Naturally Fractured Reservoirs," Soc. Pet. Eng. J., Vol. 9, 245-255.

Wheeler, A. 1955. "CATALYSIS," Reinhold, New York, NY, edited by P. H. Emmett, Vol. 2, 105.
Winograd, I. J., and G. C. Doty. 1980. "Paleohydrology of the Southern Great Basin, with Special Reference to Water Table Fluctuations Beneath the Nevada Test Site During the Late (?) Pleistocene," OFR80-569, US Geological Survey, Reston, VA.

Wyllie, M. R. J., and G. H. F. Gardner. 1958. "The Generalized Kozeny-Carman Equation," World Oil, Vol. $146,210-228$. 


\section{APPENDIX A}

\section{Derivation of the Flow Equation}

This appendix presents the full derivation of the macroscopic flow equation (Eq. 14 in the main body of the report). It shows how the assumptions concerning the relative importance of physical properties, processes, etc., are implemented mathematically. These assumptions are discussed in more detail in the main body of the report.

Many authors have discussed the dual-porosity approach to modeling fractured, porous media including personnel in the petroleum industry (Warren and Root, 1963; Odeh, 1965; Gringarten and Ramey, 1974) and those involved in hydrogeology (Barenblatt et al., 1960; Duguid and Lee, 1973). The following derivation draws upon the work just cited, especially that of Duguid and Lee. The fluid continuity equations in a dual-porosity equivalent continuum can be expressed as follows:

$\frac{\partial\left(\rho \mathrm{S}_{\mathrm{m}} \mathrm{n}_{\mathrm{m}}\right)}{\partial \mathrm{t}}+\nabla \cdot\left(\rho \overline{\mathrm{q}}_{\mathrm{m}}\right)+\nabla \cdot\left(\rho \mathrm{S}_{\mathrm{m}} \mathrm{n}_{\mathrm{m}} \overline{\mathrm{V}}\right)+\Gamma=0$,

$\frac{\partial\left(\rho \mathrm{S}_{\mathrm{t}} \mathrm{n}_{\mathrm{f}}\right)}{\partial \mathrm{t}}+\nabla \cdot\left(\rho \overline{\mathbf{q}}_{\mathrm{f}}\right)+\nabla \cdot\left(\rho \mathrm{S}_{\mathrm{f}} \mathrm{n}_{\mathrm{f}} \overline{\mathrm{V}}\right)-\Gamma=0$,

The subscripts " $m$ " and "f" refer to the matrix and fractures, respectively. The equations are identical in form to that of Eq. 1 except that they include a term $(\Gamma)$ for the transfer of fluid from the fracture system to the matrix. Many authors (e. g., Barenblatt, 1960) calculate the transfer of flux between the two systems as

$\Gamma=\omega\left(\psi_{1}-\psi_{\mathrm{m}}\right)$

The value of the transfer coefficient $\omega$ is difficult to determine experimentally, and estimates usually vary over many orders of magnitude.

Equations 8 and 9 may be added together, yielding a single equation in the two unknowns $\psi_{\mathrm{m}}$ and $\psi_{\mathrm{f}}$. Thus, we need a second equation or condition concerning the linkage between $\psi_{\mathrm{m}}$ and $\psi_{\mathrm{t}}$ to solve for the flow field in a fractured, porous medium. Calculations by Travis et al. (1984) and by Martinez (in preparation) indicate that periodic injections of water into the surface of Yucca Mountain above the main body of the repository region are not likely to penetrate the fractures to great depth and so the flux at depth is a slowly varying function of time (Wang and Narasimhan, in preparation). Calculations by Wang and Narasimhan (1985) indicate that in a drainage situation (or its equivalent, slow saturation), the fractures and matrix, along a direction perpendicular to flow have nearly identical pressure heads. Thus, except near the surface (where the fracture aperture is large) and near large-scale features (e.g., fault zones), it may be reasonable to assume that the pressure head in the fracture system is equal to that in the matrix. This topic is discussed in more detail in the main body of the report.

Summing Eqs. 8 and 9, setting equal $\psi_{\mathrm{m}}$ to $\psi_{\mathrm{t}}$, and calling this pressure head simply $\psi$ yields the following:

$$
\begin{aligned}
& \frac{\partial\left[\rho\left(\mathbf{S}_{\mathrm{m}} \mathbf{n}_{\mathrm{m}}+\mathrm{S}_{\mathrm{f}} \mathbf{n}_{\mathrm{f}}\right)\right]}{\partial \mathrm{t}}+\nabla \cdot \rho\left(\overline{\mathrm{q}}_{\mathrm{m}}+\overline{\mathrm{q}}_{\mathrm{f}}\right) \\
& +\nabla \cdot\left[\rho \overline{\mathrm{V}}\left(\mathbf{S}_{\mathrm{m}} \mathbf{n}_{\mathrm{m}}+\mathrm{S}_{\mathrm{f}} \mathbf{n}_{\mathrm{f}}\right)\right]=0
\end{aligned}
$$

Equation 11 may be expanded to begin evaluating the terms.

$$
\begin{aligned}
& \rho \frac{\partial \psi}{\partial t}\left\{\left[\mathrm{n}_{\mathrm{m}} \frac{\partial \mathrm{S}_{\mathrm{m}}}{\partial \psi}+\mathrm{n}_{\mathrm{f}} \frac{\partial \mathrm{S}_{\mathrm{f}}}{\partial \psi}\right]+\frac{1}{\rho} \frac{\partial \rho}{\partial \psi}\left(\mathrm{S}_{\mathrm{m}} \mathrm{n}_{\mathrm{m}}+\mathrm{S}_{\mathrm{f}} \mathrm{n}_{\mathrm{f}}\right)\right\} \\
& +\rho\left[\mathrm{S}_{\mathrm{m}} \frac{\partial \mathrm{n}_{\mathrm{m}}}{\partial \mathrm{t}}+\mathrm{S}_{\mathrm{f}} \frac{\partial \mathrm{n}_{\mathrm{f}}}{\partial \mathrm{t}}\right]+\nabla \cdot \rho\left(\overline{\mathrm{q}}_{\mathrm{m}}+\overline{\mathrm{q}}_{\mathrm{f}}\right) \\
& +\rho\left[\mathrm{S}_{\mathrm{m}} \mathrm{n}_{\mathrm{m}}+\mathrm{S}_{\mathrm{f}} \mathrm{n}_{\mathrm{f}}\right] \nabla \cdot \overline{\mathrm{V}} \\
& +\overline{\mathrm{V}} \cdot \nabla\left[\rho\left(\mathrm{S}_{\mathrm{m}} \mathrm{n}_{\mathrm{m}}+\mathrm{S}_{\mathrm{f}} \mathrm{n}_{\mathrm{f}}\right)\right]=0
\end{aligned}
$$

The discussion of the terms in Eq. 12 will proceed from left to right. The first set of terms (terms containing $\mathrm{n} \partial \mathrm{S} / \partial \psi$ ) represents the storage of water in the unit volume via a change in saturation of the matrix and the fracture system. The matrix saturation and its partial derivative with respect to pressure can be experimentally determined in a variety of ways. These are discussed in the main body of the report.

The second term in Eq. 12 (multiplied by 1/ $\rho$ $\partial \rho / \partial \psi)$ represents the storage of water in the unit 
volume due to the compressibility of water. The quantity $1 / \rho \partial \rho / \partial \psi$ is proportional to the water compressibility and is relatively constant. It will be denoted as $\beta_{n}$.

The third set of terms in Eq. 12 (terms containing $S \partial n / \partial t)$ represents the storage of water in the unit volume due to the net expansion of the matrix pores and the fracture apertures.

The fourth term (terms containing $\bar{q}$ ) represents the net change in flux of water which is withdrawn from the unit volume. The final two terms (terms containing $\bar{V}$ ) represent the movement of water out of the unit volume due to movement of the rock mass (e.g., compaction).

The continuity equation for the matrix grains can be applied to begin evaluation of terms in Eq. 12 concerned with compaction and movement of the rock mass.

$\frac{\partial\left(1-n_{m}-n_{f}\right)}{\partial t}+\nabla \cdot\left(1-n_{m}-n_{f}\right) \bar{V}=0$

Simplification of Eq. A.1 and rearrangement of terms yields the following:

$$
\begin{aligned}
& \frac{\partial \mathrm{n}_{\mathrm{m}}}{\partial \mathrm{t}}+\mathrm{n}_{\mathrm{m}} \nabla \cdot \overline{\mathrm{V}}=\nabla \cdot \overline{\mathrm{V}}-\overline{\mathrm{V}} \cdot \nabla\left(\mathrm{n}_{\mathrm{m}}+\mathrm{n}_{\mathrm{f}}\right) \\
& -\left[\frac{\partial \mathrm{n}_{\mathrm{f}}}{\partial \mathrm{t}}+\mathrm{n}_{\mathrm{f}} \nabla \cdot \overline{\mathrm{V}}\right]
\end{aligned}
$$

Collecting only those terms from Eq. 12 involving the deformation of the rock mass, moving them to the right side of the equation, and substituting the definition of $\beta_{\omega}$ yields

$$
\begin{aligned}
& \rho \frac{\partial \psi}{\partial \mathrm{t}}\left\{\mathrm{n}_{\mathrm{m}} \frac{\partial \mathrm{S}_{\mathrm{m}}}{\partial \psi}+\mathrm{n}_{\mathrm{f}} \frac{\partial \mathrm{S}_{\mathrm{f}}}{\partial \psi}+\beta_{\mathrm{w}}\left(\mathrm{S}_{\mathrm{m}} \mathrm{n}_{\mathrm{m}}+\mathrm{S}_{\mathrm{f}} \mathrm{n}_{\mathrm{f}}\right)\right\} \\
& +\nabla \cdot \rho\left[\overline{\mathrm{q}}_{\mathrm{m}}+\overline{\mathrm{q}}_{\mathrm{f}}\right] \\
& =-\rho\left[\mathrm{S}_{\mathrm{m}}\left(\frac{\partial \mathrm{n}_{\mathrm{m}}}{\partial \mathrm{t}}+\mathrm{n}_{\mathrm{m}} \nabla \cdot \overline{\mathrm{V}}\right)\right. \\
& \left.+\mathrm{S}_{\mathrm{f}}\left(\frac{\partial \mathrm{n}_{\mathrm{f}}}{\partial \mathrm{t}}+\mathrm{n}_{\mathrm{f}} \nabla \cdot \overline{\mathrm{V}}\right)\right] \\
& -\bar{V} \cdot \nabla\left[\rho\left(\mathrm{S}_{\mathrm{m}} \mathrm{n}_{\mathrm{m}}+\mathrm{S}_{\mathrm{f}} \mathrm{n}_{\mathrm{f}}\right)\right] .
\end{aligned}
$$

Substituting the right side of Eq. A.2 into the right side of Eq. A.3 yields the following expression for the right side of Eq. A.3:

$-\rho\left\{\mathrm{S}_{\mathrm{m}}\left[\nabla \cdot \overline{\mathrm{V}}-\overline{\mathrm{V}} \cdot \nabla\left(\mathrm{n}_{\mathrm{m}}+\mathrm{n}_{\mathrm{f}}\right)-\frac{\partial \mathrm{n}_{\mathrm{f}}}{\partial \mathrm{t}}\right.\right.$

$\left.\left.-n_{f} \nabla \cdot \bar{V}\right]+S_{f}\left[\frac{\partial n_{f}}{\partial t}+n_{f} \nabla \cdot \bar{V}\right]\right\}$

$-\overline{\mathrm{V}} \cdot \nabla\left[\rho\left(\mathrm{S}_{\mathrm{m}} \mathrm{n}_{\mathrm{m}}+\mathrm{S}_{\mathrm{f}} \mathrm{n}_{\mathrm{f}}\right)\right]$.

Collecting terms and neglecting the term $\overline{\mathrm{V}} \cdot\left[\mathrm{n}_{\mathrm{m}} \nabla\right.$ $\left.\left(\rho \mathrm{S}_{\mathrm{m}}\right)+\mathbf{n}_{\mathrm{f}} \nabla\left(\rho \mathrm{S}_{\mathrm{f}}\right)\right]$ as a higher-order effect, we obtain the following expression for A.4.

$-\nabla \cdot \overline{\mathrm{V}}\left(\rho\left[\mathrm{S}_{\mathrm{m}}-\mathrm{n}_{\mathrm{f}}\left(\mathrm{S}_{\mathrm{m}}-\mathrm{S}_{\mathrm{f}}\right)\right]\right)$

$+\rho \frac{\partial \mathrm{n}_{\mathrm{f}}}{\partial \mathrm{t}}\left(\mathrm{S}_{\mathrm{f}}-\mathrm{S}_{\mathrm{m}}\right)$.

If the three-dimensional bulk-rock consolidation equation is integrated and if the displacement is assumed to be vertical, the term $\nabla$. V may be evaluated as follows (see Reeves and Duguid (1975) for further discussion of the consolidation equation):

$\nabla \cdot \bar{V}=\alpha_{\text {lulk }} \frac{\partial \sigma^{\prime}}{\partial \mathrm{t}}=\alpha_{\mathrm{lulk}} \frac{\partial \psi}{\partial \mathrm{t}}\left(\frac{\mathrm{n}_{\mathrm{m}} \mathrm{S}_{\mathrm{m}}+\mathrm{n}_{\mathrm{f}} \mathrm{S}_{\mathrm{f}}}{\mathrm{n}_{\mathrm{m}}+\mathrm{n}_{\mathrm{f}}}\right)$,

where we have assumed that a unit change in the quantity "total saturation times the pressure head at a point" cause a unit change in the local stress field (see McTigue, Wilson, and Nunziato (1984)). The "total saturation" is defined as the term in parentheses in Eq. A.6, i.e., sum of the water contents of the fracture system and the matrix divided by the sum of the porosities of the fracture system and the matrix. The quantity $\alpha_{\text {bulk }}$ is defined in bulk rock properties as:

$\alpha_{\text {trulh }}=\frac{(1+\nu)(1-2 \nu)}{\mathrm{E}(1-\nu)}$

where $\mathrm{E}$ is the modulus of deformation and $\nu$ is Poisson's ratio. 
Expression A.5 may be rewritten using Eq. A.6 as follows:

$$
\begin{aligned}
& -\rho \frac{\partial \psi}{\partial t}\left\{\alpha_{\text {lulk }}\left(\frac{\mathrm{S}_{\mathrm{m}} \mathrm{n}_{\mathrm{m}}+\mathrm{S}_{\mathrm{f}} \mathrm{n}_{\mathrm{f}}}{\mathrm{n}_{\mathrm{m}}+\mathrm{n}_{\mathrm{f}}}\right)\left[\mathrm{S}_{\mathrm{m}}-\mathrm{n}_{\mathrm{f}}\left(\mathrm{S}_{\mathrm{m}}-\mathrm{S}_{\mathrm{f}}\right)\right]\right. \\
& \left.-\frac{\partial \mathrm{n}_{1}}{\partial \sigma^{\prime}}\left(\frac{\mathrm{S}_{\mathrm{m}} \mathrm{n}_{\mathrm{m}}+\mathrm{S}_{\mathrm{f}} \mathrm{n}_{\mathrm{f}}}{\mathrm{n}_{\mathrm{m}}+\mathrm{n}_{\mathrm{f}}}\right)\left(\mathrm{S}_{\mathrm{m}}-\mathrm{S}_{\mathrm{f}}\right)\right\} .
\end{aligned}
$$

where the previously assumed relationship between stress and pressure head has been applied to evaluate the quantity $\partial \sigma^{\prime} / \partial \psi$ as $\frac{\left(S_{m} n_{m}+S_{f} n_{f}\right)}{n_{m}+n_{f}}$. The term $\partial n_{f} / \partial \sigma^{\prime}$ can be determined by experimentally measuring the closure of a fracture (e.g., Peters et al. (1984)).

The final terms to be evaluated are specific discharge in the fracture system and the matrix, which may be assumed to be Darcian, especially if the total downward flux at Yucca Mountain is of the order of $1 \mathrm{~mm} /$ year or less (DOE, 1984).

$$
\begin{aligned}
& \overline{\mathrm{q}}_{\mathrm{m}}=-\overline{\mathrm{K}}_{\mathrm{mb}} \cdot \nabla(\psi+\mathrm{z}) \\
& \overline{\mathrm{q}}_{\mathrm{f}}=-\overline{\mathrm{K}}_{\mathrm{fb}} \cdot \nabla(\psi+\mathrm{z})
\end{aligned}
$$

The subscripts " $\mathrm{m}, \mathrm{b}$ " and " $\mathrm{f}, \mathrm{b}$ " indicate that the matrix and fracture conductivities are bulk values for a unit volume of the fractured, porous media. These values may be estimated as the conductivity for the material times its relative volume in bulk material.

Eqs. A.7, A.8, and A.9 may be substituted into Eq. A.3, which then may be rearranged to move all terms except the specific discharge term to the left of the equation, yielding the following expression.

$$
\begin{aligned}
& \rho \frac{\partial \psi}{\partial \mathrm{t}}\left\{\left(\mathrm{n}_{\mathrm{m}} \frac{\partial \mathrm{S}_{\mathrm{m}}}{\partial \psi}+\mathrm{n}_{\mathrm{f}} \frac{\partial \mathrm{S}_{\mathrm{f}}}{\partial \psi}\right)+\beta_{\mathrm{w}}\left(\mathrm{S}_{\mathrm{m}} \mathrm{n}_{\mathrm{m}}+\mathrm{S}_{\mathrm{f}} \mathrm{n}_{\mathrm{f}}\right)\right. \\
& +\alpha_{\text {thulk }}\left(\frac{\left(S_{m} n_{m}+S_{f} n_{f}\right)}{n_{m}+n_{f}}\right)\left(S_{m}-n_{f}\left(S_{m}-S_{f}\right)\right) \\
& \left.-\frac{\partial n_{f}}{\partial \sigma^{\prime}}\left(\frac{\left(S_{m} n_{m}+S_{f} n_{f}\right)}{n_{m}+n_{f}}\right)\left(S_{m}-S_{f}\right)\right\} \\
& =\nabla \cdot\left[\rho\left(\overline{\mathrm{K}}_{\mathrm{m} 1,}+\overline{\mathrm{K}}_{\mathrm{fl},}\right) \cdot \nabla(\psi+\mathrm{z})\right] \text {. }
\end{aligned}
$$

This is the result presented in the main body of the report.

The terms in Eq. 14 may be put into four groups representing distinct physical processes. These include

1) a group that represents the storage of water in the unit volume resulting from saturation of the matrix and the fracture system [terms containing $\mathrm{n} \partial \mathrm{S} / \partial \psi]$

2) a group that respresents the storage resulting from the compressibility of water contained in the fractured, porous media [the term multiplied by $\beta_{u}$ ],

3) a group that represents the storage resulting from dilation of the bulk rock [the remainder of the left side of Eq. 14], and

4) a group that represents the divergence of the total water flux moving through the unit volume [the terms on the right side of Eq. 14]. 


\section{APPENDIX B}

\section{Comparison of Several Models of Relative Hydraulic Conductivity}

Calculations for characterizing water movement in an unsaturated medium require knowledge of the medium's ability to transmit water under different saturation (or pressure head) conditions. It is necessary to know the magnitude of the matrix relative hydraulic conductivities as a function of saturation. It is also important to know the general shape of the matrix conductivity curve and its relationship to the relative conductivity curves for fractures. The matrix relative conductivities can be experimentally measured; however, these measurements are difficult (especially when the saturated conductivities are $10^{-10}$ $\mathrm{m} / \mathrm{s}$ or lower), and no experimental data are yet available. Current calculations, using codes such as TOSPAC (Total Systems Performance Assessment Code) (Dudley et al., in preparation) and NORIA (Bixler et al., 1985), compute relative conductivities on the basis of theoretical considerations and data describing saturation versus pressure-head (i.e., the method developed by Mualem, 1976). There are a variety of formulations that may be used to compute relative hydraulic conductivities as a function of saturation or pressure head. The method of Mualem is used because of its success in predicting relative conductivity curves for a number of soils and also because no other method has been shown to have a distinct advantage in accurately predicting hydraulic conductivities in unsaturated, consolidated rocks, such as tuff. The purpose of this appendix is to compare various models used to predict matrix relative conductivities with the currently used Mualem model in order to determine the relative consistency of predictions between the models.

The models used for predicting hydraulic conductivities can be split into two general groups (Mualem, 1976). The first is based upon a generalization of Kozeny's (Kozeny, 1933) approach for saturated and unsaturated porous media, whereby the relative con- ductivity is a power function of the effective saturation. The formulation of Brooks and Corey is representative of this group with the exponent dependent upon the pore structure of the medium under consideration. The Brooks-Corey formulation (Brooks and Corey, 1966) for the wetting phase relative conductivity is given by:

$\mathrm{K}_{\mathrm{r} \epsilon \mathrm{l}}=\mathrm{K}(\mathrm{s}) / \mathrm{K}_{\mathrm{sat}}=\left(\mathrm{S}_{\mathrm{et} 1}\right)^{\epsilon}=\left(\frac{\mathrm{S}-\mathrm{S}_{\mathrm{r}}}{1-\mathrm{S}_{\mathrm{r}}}\right)^{\epsilon}$

$\mathrm{K}_{\mathrm{rel}}$ is the relative hydraulic conductivity, $\mathrm{K}(\mathrm{S})$ is the hydraulic conductivity at saturation $\mathrm{S}, \mathrm{K}_{\mathrm{sat}}$ is the saturated hydraulic conductivity, $S_{e ! l}$ is termed the effective saturation, $S_{r}$ is the residual saturation, and $\epsilon$ is the Brooks-Corey constant.

Various values of the exponent $\epsilon$ have been suggested, generally ranging from 3-4 for soils. For a consolidated material such as tuff, which often has a narrow pore size distribution, the exponent may be greater.

The second group of models makes use of the capillary pressure (negative suction) head-water content curve to derive the unsaturated hydraulic conductivities. Models in this group which will be examined here are those of Mualem (1976), Fatt and Dykstra (1951), Burdine (1953), and Burdine et al. (1950). There are a variety of other models available to compute relative conductivity curves (such as those by Millington and Quirk (1961), Childs and CollisGeorge (1950), and Wyllie and Gardner (1958)). The models listed above are considered to be representative of this group of models. The models of Mualem and Fatt and Dykstra make direct use of the curve relating pressure head to water content, whereas Burdine (1953) suggests a more fundamental approach, using pore size distribution data, which can in turn be 
converted to the needed curve (see, for example, Purcell, 1949). The formulations for the above three models are given below:

$\mathrm{K}_{\mathrm{rel}}=\mathrm{S}_{\mathrm{et1}}^{0}\left[\frac{\int_{0}^{\mathrm{eet}^{\mathrm{j}}} \frac{\mathrm{dS}_{\mathrm{ett}}}{\psi}}{\int_{0}^{1} \frac{\mathrm{dS}_{\mathrm{ett}}}{\psi}}\right]^{2}$,

(Mualem) (B.2)

$K_{\mathrm{rel}}=\frac{\int_{11}^{h} \mathrm{dS} / \psi^{2\left(1+b^{\prime}\right)}}{\int_{0}^{1} \mathrm{dS} / \psi^{2\left(1+b^{\prime}\right)}}$

(Fatt \& Dykstra) (B.3)

$\mathrm{K}_{\mathrm{r} \mathrm{t}}=\frac{\mathrm{n}}{8 \mathrm{k}_{\mathrm{s}}} \sum_{i=0}^{\mathrm{r}_{\mathrm{max}}} \frac{\mathrm{v}_{1} \mathbf{r}_{1}^{2}}{\chi_{1}^{2}}\left(\frac{\mathrm{S}-\mathrm{S}_{\mathrm{r}}}{1-\mathrm{S}_{\mathrm{r}}}\right)^{2}$

(Burdine) (B.4)

$\psi$ is the capillary pressure head, b is a parameter related to the tortuosity distribution of the medium, $v_{1}$ is the incremental, fractional pore volume, $r$ is the pore radius, $n$ is the porosity, and $\chi$ is the tortuosity distribution as a function of radius (where $\chi=5 \exp (-0.4 \mathrm{r})+1.83)$. All other symbols are as previously defined.

It is best, of course, to experimentally determine relative conductivity curves for tuff samples. As mentioned, these measurements are difficult and timeconsuming. If it can be determined that one of the above models can accurately predict the relative conductivity curve using more easily determined data (such data on pore size distribution or pressure head as a function of water content) then the need for extensive measurements of relative conductivity as a function of saturation can be substantially reduced.

The data required by the models presented include porosity, pore size distribution, and pressure head as a function of water content. These data are fairly easy to acquire for consolidated materials such as tuff. Porosity can be determined from grain and bulk density measurements, pore-size distribution data from mercury-intrusion measurements, and pressure head as a function of water content from thermocouple psychrometer and pressure-plate-apparatus measurements. The latter data have been measured by Peters et al. (1984) for a number of samples from drill holes USW GU-3 and USW G-4 and fitted to an equation of a form suggested by van Genuchten (1978). This equation is given by

$S=\left(1-S_{r}\right)\left[\frac{1}{1+|\alpha \psi|^{\beta}}\right]^{\lambda}+S_{r}$,

where $\alpha$ and $\beta$ are curve-fitting parameters and $\lambda$ is equal to $1-1 / \beta$.

The parameters used to fit the data describing pressure head as a function of moisture content to the van Genuchten equation are given in Table B.1. Mercury-intrusion data have been measured by Micromeritics, Inc. on samples from approximately the same depths in USW G-4 as tested by Peters et al. (1984). For this study, six samples, from different stratigraphic units, have been selected for use in comparing the models. The samples selected were from drill hole USW G-4 at depths of 43, 208, 1158, 1299,1548 , and $1899 \mathrm{ft}$.

\section{Table B.1 Mualem and Brooks-Corey Fitting Parameters}

\begin{tabular}{clrcrrr}
$\begin{array}{c}\text { Sample Depth } \\
\text { (USW G-4) }\end{array}$ & Unit & $\mathrm{S}_{\mathrm{r}}$ & $\alpha(1 / \mathrm{m})$ & $\beta$ & $\lambda^{\prime}$ & $\epsilon$ \\
\hline $43 \mathrm{ft}$ & TCw & 0.0020 & $0.821 \times 10^{-2}$ & 1.558 & 0.53 & 6.8 \\
$208 \mathrm{ft}$ & PTn & 0.1053 & $0.158 \times 10^{-1}$ & 10.563 & 7.97 & 3.3 \\
$1158 \mathrm{ft}$ & TSw2 & 0.0801 & $0.567 \times 10^{-2}$ & 1.799 & 0.79 & 5.5 \\
$1299 \mathrm{ft}$ & TSw3 & 0.0517 & $0.419 \times 10^{-2}$ & 1.622 & 0.61 & 6.3 \\
$1548 \mathrm{ft}$ & CHnz & 0.1095 & $0.308 \times 10^{-2}$ & 1.602 & 0.58 & 6.4 \\
$1899 \mathrm{ft}$ & PPw & 0.0658 & $0.141 \times 10^{-1}$ & 2.639 & 1.50 & 4.3 \\
\hline
\end{tabular}


The curve relating relative conductivity to pressure head, using the Brooks-Corey model (Eq. B.1), can be determined by calculating relative conductivity as a function of saturation and converting the saturation into its corresponding pressure head through manipulation of Eq. B.5. The exponent $\epsilon$ is a parameter that depends upon the water-retention characteristics (and thus the pore structure) of the porous material under consideration. The exponent can be determined from capillary-pressure-versussaturation data. The exponent $\epsilon$ is related to the pore size distribution index $\lambda^{\prime}$ by

$\epsilon=\left(2+3 \lambda^{\prime}\right) / \lambda^{\prime}$

where $\lambda^{\prime}$ is large for media having a narrow range of pore sizes and small for media with a wide range of pore sizes. By experimentally determining $\psi$, the capillary pressure, versus $S$, the pore size distribution index $\lambda^{\prime}$ can be determined (if the residual saturation is known). Brooks and Corey suggest plotting the logarithm of the effective saturation, $S_{\mathrm{et}}$, versus the logarithm of $\psi$ observing that the equation

$\ln \left(\mathrm{S}_{\mathrm{ef} 1}\right)=-\lambda^{\prime} \ln (\psi)+\lambda^{\prime} \ln \left(\psi_{\mathrm{b}}\right)$

was found to be generally valid for the cores analyzed in their studies. The equation is one of a straight line of slope $-\lambda^{\prime}$ and intercept $\lambda^{\prime} \ln \left(\psi_{\mathrm{b}}\right)$, where $\psi_{\mathrm{h}}$ is the bubbling pressure. Using the van Genuchten curve fits for the $\psi$-versus-S data (experimentally determined; see Peters et al., 1984), $\lambda$ and $\epsilon$ were determined for the six samples mentioned previously. These values are shown in Table B.1. The values of $\epsilon$ range from 3.3 for the sample from depth $208 \mathrm{ft}$ to 6.8 for the sample from depth $43 \mathrm{ft}$. This wide range of values indicates the necessity of determining the parameters $\lambda^{\prime}$ and $\epsilon$ from experimental data for all media under consideration if the Brooks-Corey formulation for predicting relative hydraulic conductivities is used. It can be seen that significant errors in predicting relative conductivities could result if a constant value was used for the exponent $\epsilon$ for tuffs with considerably different pore structures.

Mualem (1976) proposes an analytic model that predicts the relative hydraulic conductivity curves by using the curve relating moisture content (or saturation) to capillary pressure, with assumptions made concerning the hydraulic conductivity of the pore sequence. The expression for determining relative conductivity as a function of pressure head, when determined by the method of Mualem (substitute Eq. B.5 into Eq. B.2 and integrate) is

$\mathrm{K}_{\mathrm{r}}=\left[1+|\alpha \psi|^{\beta}\right]^{-\mathrm{N} / 2}\left\{1-\left[\frac{|\alpha \psi|^{\beta}}{1+|\alpha \psi|^{\beta}}\right]^{\lambda}\right\}^{2}$,

where the parameters are defined in the van Genuchten formulation. Like the method of Brooks and Corey (1966), it requires no other parameters or data than those provided by the S-versus- $\psi$ data.

The model of Fatt and Dykstra (1951) is derived by assuming that a porous medium is analogous to a bundle of capillary tubes, with a term included to correct between core length and fluid path length (tortuosity). The tortuosity is assumed to be inversely proportional to the pore radius raised to the $b^{\prime}$ power. The curve relating relative conductivity to pressure head determined by this method is calculated using Eq. B.5 with the appropriate parameters in Eq. B.3 and numerically performing the integration. Although the method has shown success in predicting water-oil relative permeabilities, it does require the determination of the parameter $b^{\prime}$ by either experimental or theoretical means. For the sands studied by Fatt and Dykstra, $b^{\prime}$ appeared to be in the range from 0 to 1 . For the tuff samples chosen for this study, a value for $b^{\prime}$ of 0.1 was used. Fatt and Dykstra compared measured data with calculated data for $b^{\prime}=0.5$ and found that $b^{\prime}$ varies for different materials. They suggest that the value used for $b^{\prime}$ should be chosen for each medium to give the best fit between calculated curves and experimental data. Therefore, the value used here is somewhat arbitrary.

The relative-conductivity versus pressure-head curve of Burdine (1953) is calculated by using the mercury-intrusion data, along with capillary-bundle theory, to sum up indivdual contributions of the pores to the relative conductivity. Since water is a wetting fluid, pores fill from the smallest pore radius to the largest. The relative conductivity is calculated at desired saturations, with the wetting phase saturation determined by calculating the ratio of the pore volume occupied by the wetting phase fluid to the total pore volume. The tortuosity, as in Fatt and Dykstra's model, is assumed to be a function of the pore radius. Burdine also makes assumptions concerning the difference between the wetting-phase and non-wetting-phase tortuosity distributions, as well as an assumption on the distribution of capillary pore length. The tortuosity distribution used is one empirically determined by Rose (1949). 
The results of the five model predictions for the six samples studied are shown in Figures B.1 through B.6. Although the six samples selected show wide variations in degree of welding and mineralization, for each particular sample the model predictions of Brooks and Corey, Fatt and Dykstra, Mualem, and Burdine show very good agreement. The model predictions of Brooks, Corey, and Mualem show excellent agreement for all six samples. The predictions of Fatt and Dykstra and Burdine also show good agreement although both models require parameters describing the tortuosity distribution. With no tortuosity distribution available for the tuff samples selected, these parameters were estimated and are undoubtedly in error to some degree. Because the methods of both Brooks, Corey, and Mualem do not require determination of parameters, other than the available saturationcapillary pressure data, and since all four methods appear to give consistent results for a wide variety of tuff samples, it is suggested that either the model of Brooks and Corey, or that of Mualem is a reasonable method for calculating relative conductivities. Because the method of Brooks and Corey involves the determination of the exponent $\epsilon$, the method of Mualem is considered slightly more straightforward. It also appears that the functional nature of the van Genuchten curve fit when used with the method of Mualem will give it more flexibility in fitting the data than the method of Brooks and Corey, when relative hydraulic conductivity data become available. At present, both methods are reasonable alternatives for determining the matrix relative hydraulic conductivity curves.

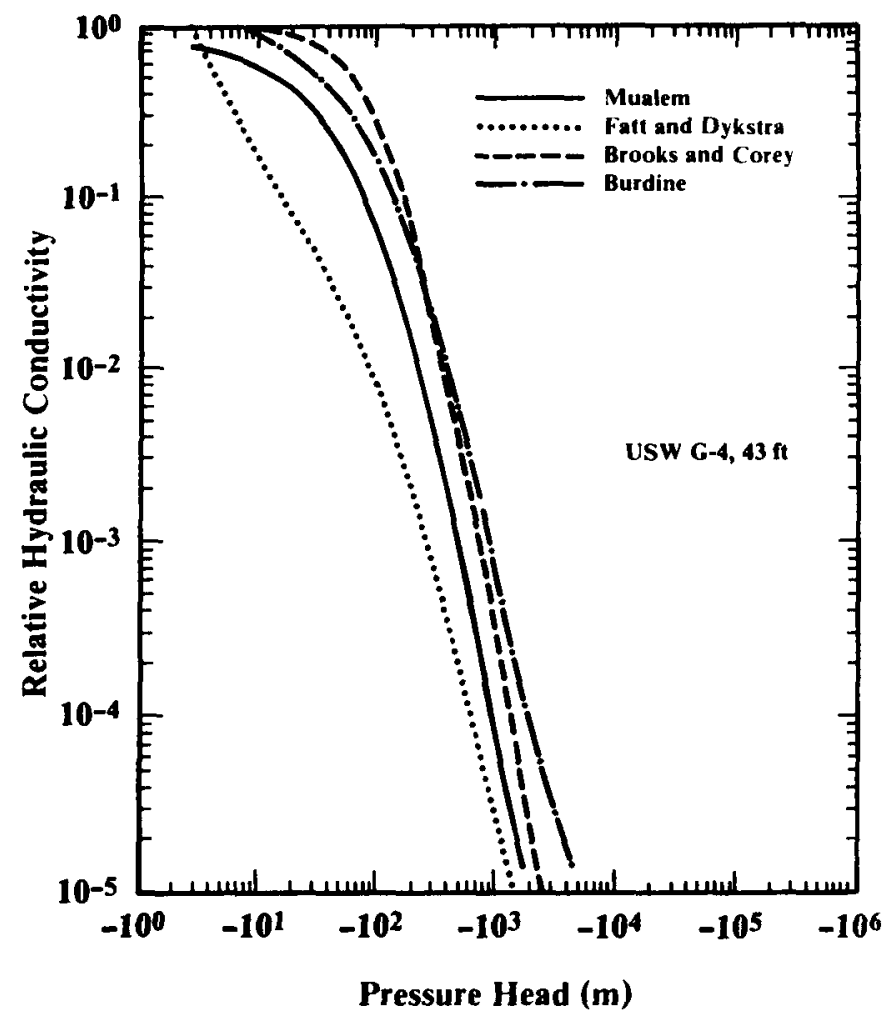

Figure B.1. Relative Hydraulic Conductivity Model Comparison for Rock Mass Material of Unit TCw

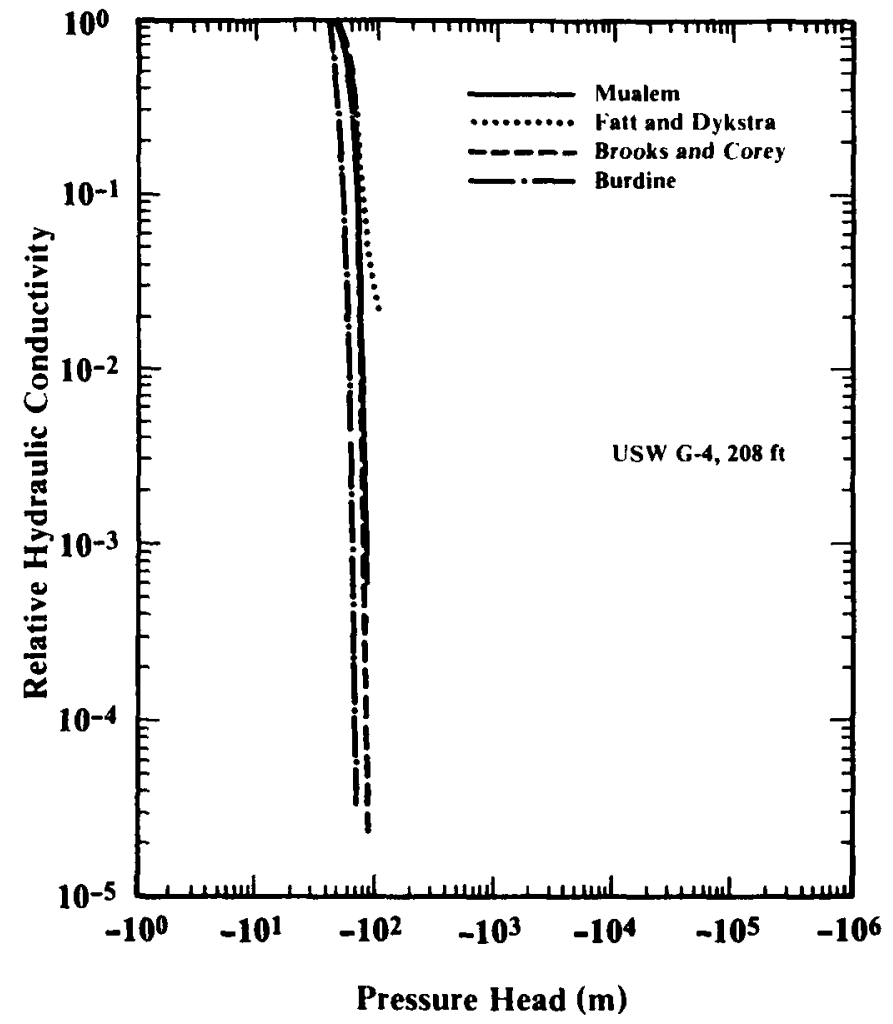

Figure B.2. Relative Hydraulic Conductivity Model Comparison for Rock Mass Material of Unit PTn 


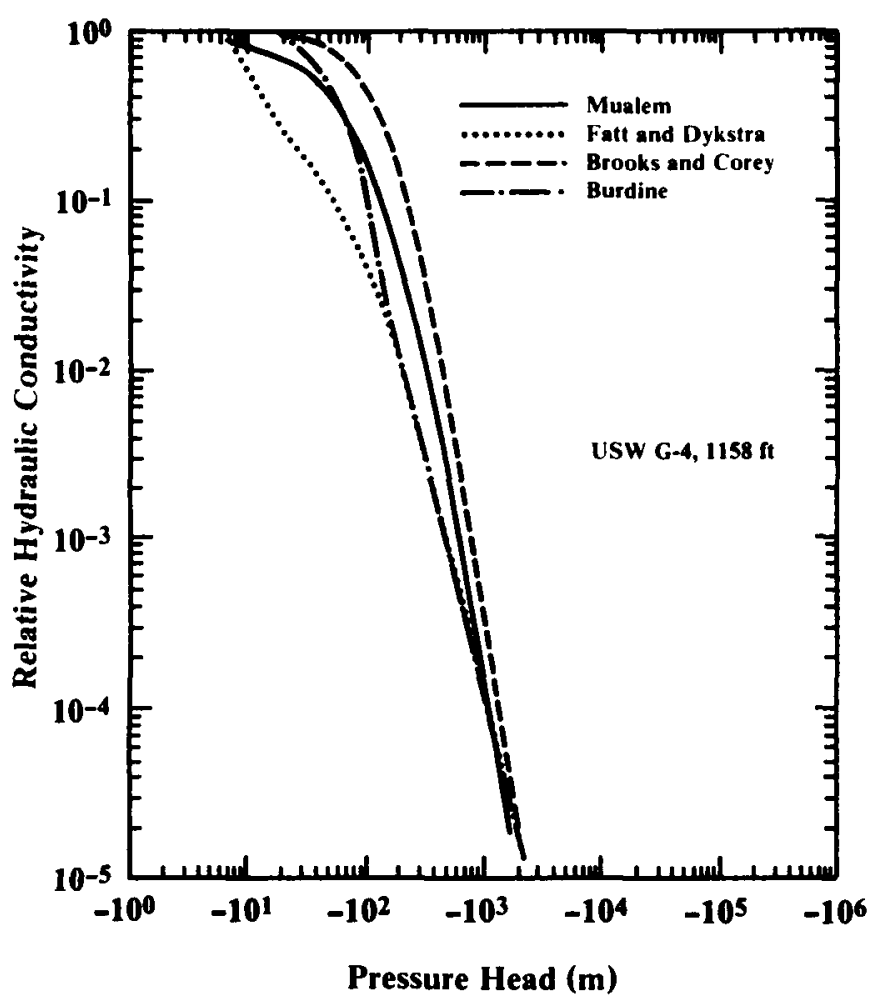

Figure B.3. Relative Hydraulic Conductivity Model Comparison for Rock Mass Material of Unit TSw2

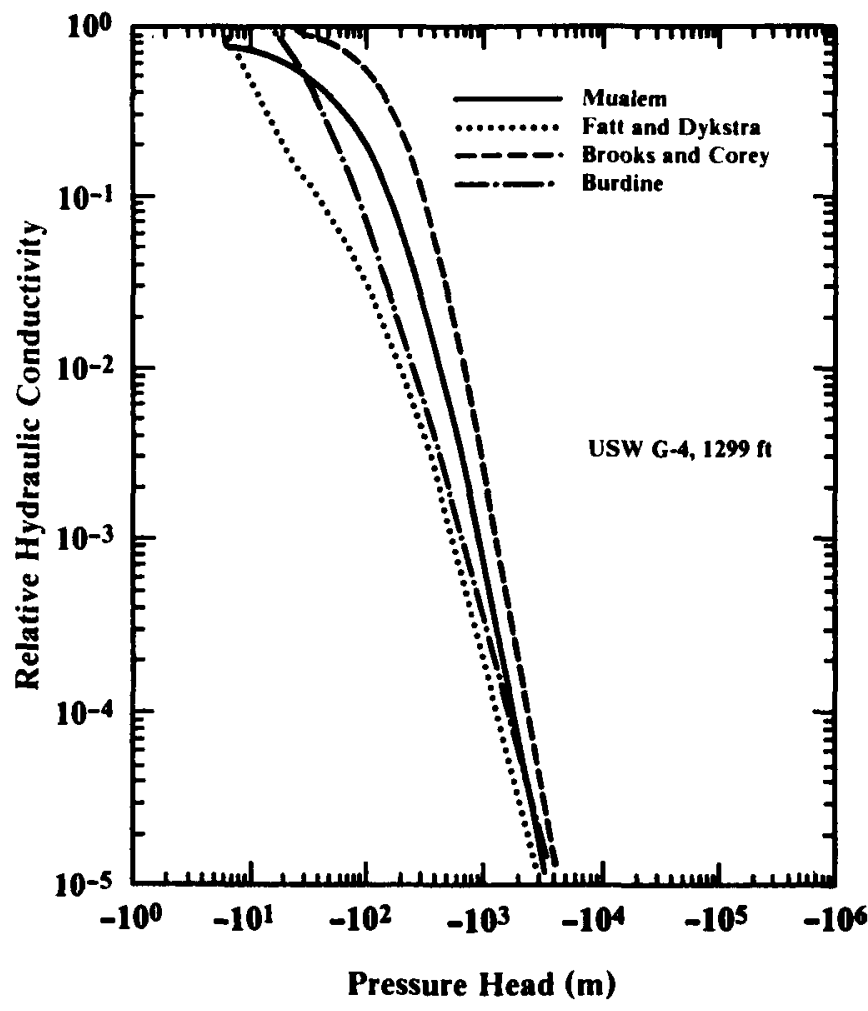

Figure B.4. Relative Hydraulic Conductivity Comparison for Rock Mass Material of Unit TSw3

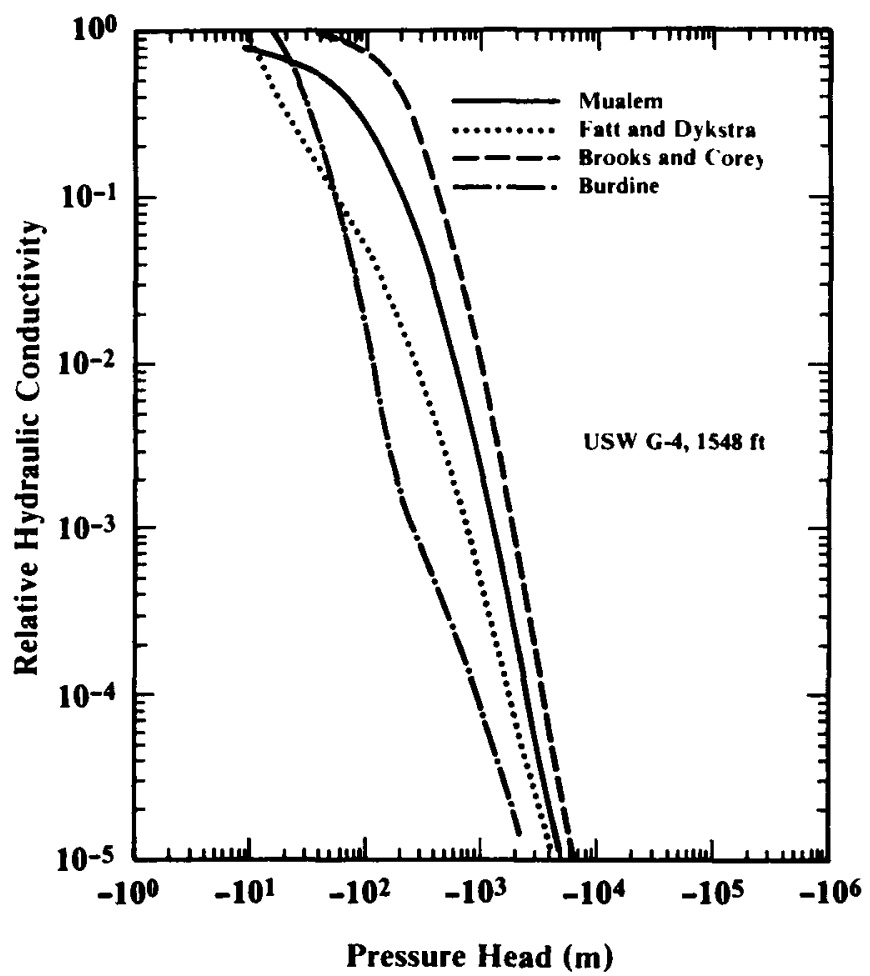

Figure B.5. Relative Hydraulic Conductivity Model Comparison for Rock Mass Material of Unit CHnz

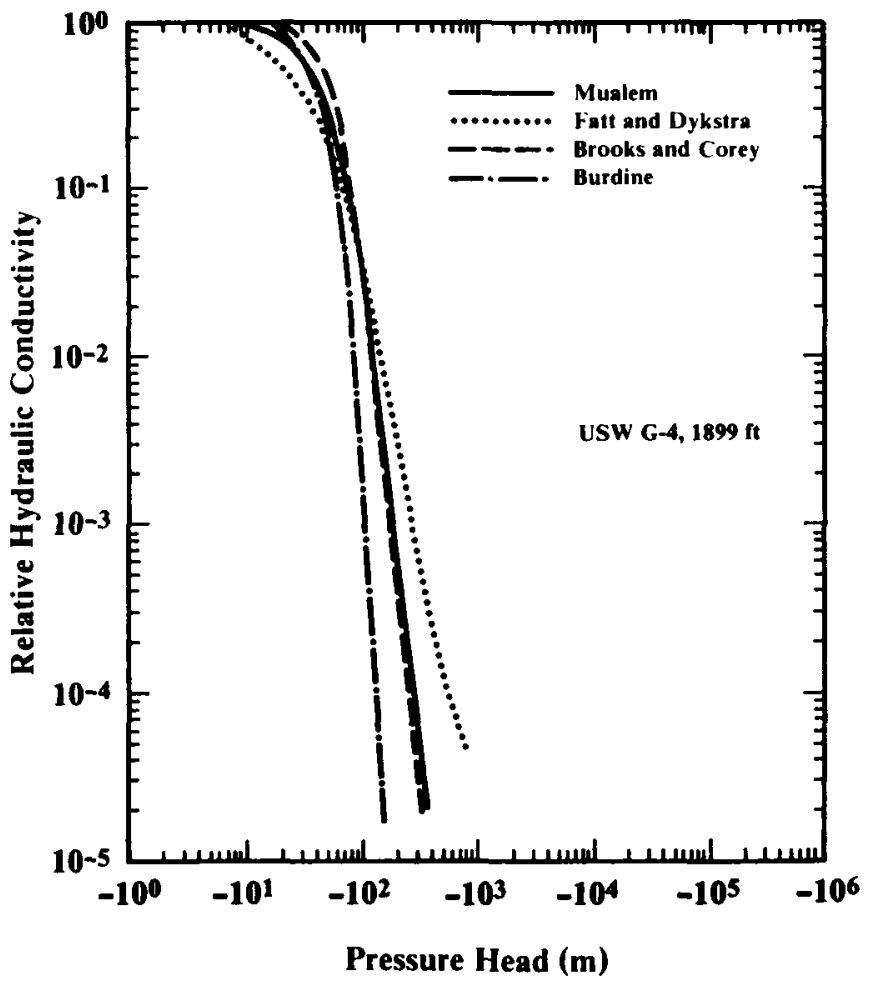

Figure B.6. Relative Hydraulic Conductivity Model Comparison for Rock Mass Material of Unit PPw 


\section{DISTRIBUTION:}

US Department of Energy

Office of Civilian Radioactive Waste Management

Attn: B. C. Rusche (RW-1), Director

Forrestal Building

Washington, DC 20585

US Department of Energy

Office of Geologic Repositories

Attn: Ralph Stein (RW-23)

Forrestal Building

Washington, DC 20585

US Department of Energy

Program Management Division

Office of Geologic Repositories

Attn: J. J. Fiore, (RW-22)

Forrestal Building

Washington, DC 20585

US Department of Energy

Engineering \& Licensing Division

Office of Geologic Repositories

Attn: M. W. Frei (RW-23)

Forrestal Building

Washington, DC 20585

US Department of Energy

Siting Division

Office of Geologic Repositories

Attn: E. S. Burton (RW-25)

Forrestal Building

Washington, DC 20585

US Department of Energy

Geosciences \& Technology Division

Office of Geologic Repositories

Attn: C. R. Cooley (RW-24)

Forrestal Building

Washington, DC 20585

US Department of Energy

Office of Geologic Repositories

Attn: V. J. Cassella (RW-22)

Forrestal Building

Washington, DC 20585

US Department of Energy

Program Management Division

Office of Geologic Repositories

Attn: T. P. Longo (RW-25)

Forrestal Building

Washington, DC 20585
US Department of Energy

Geosciences and Technology Division

Office of Geologic Repositories

Attn: Cy Klingsberg (RW-24)

Forrestal Building

Washington, DC 20585

US Department of Energy

Siting Division

Office of Geologic Repositories

Attn: B. G. Gale (RW-25)

Forrestal Building

Washington, DC 20585

US Department of Energy

Program Management Division

Office of Geologic Repositories

Attn: R. J. Blaney (RW-22)

Forrestal Building

Washington, DC 20585

US Department of Energy

Office of Policy, Integration, and Outreach

Attn: R. W. Gale (RW-40)

Forrestal Building

Washington, DC 20585

US Department of Energy

Outreach Programs

Office of Policy, Integration, and Outreach

Attn: J. E. Shaheen (RW-44)

Forrestal Building

Washington, DC 20585

US Department of Energy

Salt Repository Project Office

Attn: J. O. Neff, Manager

505 King Avenue

Columbus, $\mathrm{OH} 43201$

US Department of Energy

Engineering \& Licensing Division

Office of Geologic Repositories

Attn: D. C. Newton (RW-23)

Forrestal Building

Washington, DC 20585

US Department of Energy

Basalt Waste Isolation Project Office

Richland Operations Office

Attn: O. L. Olson, Manager

PO Box 550

Richland, WA 99352 
DISTRIBUTION (continued):

US Department of Energy (4)

Waste Management Project Office

Attn: D. L. Vieth, Director

PO Box 14100

Las Vegas, NV 89114

US Department of Energy

Office of Public Affairs

Attn: D. F. Miller, Director

PO Box 14100

Las Vegas, NV 89114

US Department of Energy (12)

Office of Public Affairs

Attn: P. M. Bodin

PO Box 14100

Las Vegas, NV 89114

US Department of Energy

Health Physics Division

Attn: B. W. Church, Director

PO Box 14100

Las Vegas, NV 89114

US Nuclear Regulatory Commission

Chief, Repository Projects Branch

Division of Waste Management

Washington, DC 20555

US Department of Energy

Crystalline Rock Project Office

Attn: S. A. Mann, Manager

9800 South Cass Avenue

Argonne, IL 60439

Lawrence Livermore National Laboratory

Attn: K. Street, Jr.

Mail Stop L-209

PO Box 808

Livermore, CA 94550

Lawrence Livermore National Laboratory (3)

Technical Project Officer for NNWSI

Attn: L. D. Ramspott

Mail Stop L-204

PO Box 808

Livermore, CA 94550

US Department of Energy

Office of Geologic Repositories

Attn: W. J. Purcell (RW-20)

Forrestal Building

Washington, DC 20585
Los Alamos National Laboratory (4)

Technical Project Officer for NNWSI

Attn: D. T. Oakley

Mail Stop F-619

PO Box 1663

Los Alamos, NM 87545

US Geological Survey (3)

Technical Project Officer for NNWSI

Attn: W. W. Dudley, Jr.

418 Federal Center

PO Box 25046

Denver, CO 80225

US Nuclear Regulatory Commission

Division of Waste Management

Repository Project Branch

Attn: NTS Section Leader

Washington, DC 20555

US Nuclear Regulatory Commission

Division of Waste Management

Document Control Center

Washington, DC 20555

P. T. Prestholt

NRC Site Representative

1050 East Flamingo Road

Suite 319

Las Vegas, NM 89109

Science Applications International Corporation

Technical Project Officer for NNWSI

Attn: M. E. Spaeth

Suite 407

101 Convention Center Drive

Las Vegas, NV 89109

Science Applications International Corporation (2)

SAIC-T\&MSS Library

Suite 407

101 Convention Center Drive

Las Vegas, NV 89109

Science Applications International Corp.

Attn: W. S. Twenhofel, Consultant

820 Estes Street

Lakewood, CO 89215 
DISTRIBUTION (continued):

Holmes \& Narver, Inc.

Energy Support Division

Attn: A. E. Gurrola, General Manager

PO Box 14340

Las Vegas, NV 89114

Fenix \& Scisson, Inc.

Las Vegas branch

Attn: J. A. Cross, Manager

PO Box 15408

Las Vegas, NV 89114

US Geological Survey

Attn: V. M. Glanzman

PO Box 25046

913 Federal Center

Denver, CO 80225

Westinghouse Electric Corporation

Waste Technology Services Division

Attn: J. S. Wright

Technical Project Officer for NNWSI

Nevada Operations

PO Box 708

Mail Stop 703

Mercury, NV 89023

Battelle Columbus Laboratory

Office of Nuclear Waste Isolation

ONWI Library

505 King Avenue

Columbus, OH 43201

Roy F. Weston, Inc.

Attn: W. M. Hewitt, Program Manager

2301 Research Blvd., 3rd Floor

Rockville, MD 20850

Reynolds Electrical \& Engineering Co., Inc. Attn: H. D. Cunningham, General Manager

Mail Stop 555

PO Box 14400

Las Vegas, NV 89114

Office of the Governor

State of Nevada

Attn: T. Hay, Executive Assistant

Capitol Complex

Carson City, NV 89710
Nevada Agency for Nuclear Projects (3)

Nuclear Waste Project Office

Attn: R. R. Loux, Jr., Director

State of Nevada

Capitol Complex

Carson City, NV 89710

US Department of Energy

Office of Policy, Integration, and Outreach

Attn: Neal Duncan (RW-44)

Forrestal Building

Washington, DC 20585

Desert Research Institute

Water Resources Center

Attn: John Fordham

PO Box 60220

Reno, NV 89506

Clark County

Department of Comprehensive Planning

225 Bridger Avenue, 7th Floor

Las Vegas, NV 89155

Lincoln County

Lincoln County Commission

PO Box 90

Pioche, NV 89043

Community Planning and Development

City of North Las Vegas

PO Box 4086

North Las Vegas, NV 89030

City Manager

City of Henderson

Henderson, NV 89015

Bechtel National Inc.

Attn: N. A. Norman

Project Manager

PO Box 3965

San Francisco, CA 94119

Los Alamos Technical Associates

Attn: Flo Butler

1650 Trinity Drive

Los Alamos, NM 87544 
DISTRIBUTION (continued):

Nevada Agency for Nuclear Projects

Nuclear Waste Project Office

Attn: C. H. Johnson, Technical Program Manager

State of Nevada

Capitol Complex

Carson City, NV 89710

Desert Research Institute

Water Resources Center

Attn: Dr. Martin Mifflin

Suite 1

2505 Chandler Avenue

Las Vegas, NM 89120

Nye County

Planning Department

PO Box 153

Tonopah, NV 89049

City of Las Vegas

Economic Development Department

400 East Stewart Avenue

Las Vegas, NV 89101

City of Boulder City

Director of Community Planning

PO Box 367

Boulder City, NV 89005

Commission of the European Communities

200 Rue de la Loi

B-1049 Brussels

BELGIUM

Roy F. Weston, Inc.

Technical Information Center

2301 Research Boulevard, Third Floor

Rockville, MD 20850

Parsons Brinckerhoff Quade \& Douglas, Inc.

Attn: R. Harig

1625 Van Ness Ave.

San Francisco, CA 94109-3678

Science Applications International Corporation

Attn: Timothy G. Barbour

1626 Cole Boulevard, Suite 270

Golden, CO 80401
Lawrence Berkeley Laboratory

Attn: E. P. Binnall

Field Systems Group Leader

Building 50B/4235

Berkeley, CA 94720

U. of Waterloo

Groundwater Research Inst.

Dept. of Earth Sciences

Attn: J. E. Gale

N2L 3G1

Waterloo, Ontario

CANADA

D. Hodgkinson

Theoretical Physics Div.

AERE Harwell

Oxfordshire OX11 ORA

UNITED KINGDOM

Atomic Energy of Canada, Ltd.

Attn: R. B. Lyon

Acting Dir., Nuclear Fuel Waste Management

Pinawa, Manitoba ROE 1L0

CANADA

P. Raimbault

CEA/PSH

SAED/SASICC-DAS

CEN FAR BP.6

92260 Fontencey aux Roses

FRANCE

US NRC

Attn: R. Codell

Washington, DC 20555

U. of California

Dept. of Mech. and Env. Engineering

Attn: G. Dagen

Santa Barbara, CA 93106

Engineers International, Inc.

Attn: Dr. Madan M. Singh, President

90 East Naperville Road

Westmont, IL 60559-1595

Itasca Consulting Group, Inc.

Attn: Roger Hart

PO Box 14806

Minneapolis, MN 55414 
DISTRIBUTION (continued):

\section{A. Herbert AERE Harwell \\ Oxfordshire OX11 ORA \\ UNITED KINGDOM}

\section{A. Larsson \\ Swedish Nuclear Power Inspectorate \\ Box 27106 \\ S-102 52 Stockholm \\ SWEDEN}

\section{Neretnieks}

Dept. Chemical Engineering

Royal Institute of Technology

S-10044 Stockholm

SWEDEN

D. Alexander

RW24 OCRWM

7F088 Forrestal Building

Washington, DC 20585

Pacific Northwest Laboratory

Attn: C. Cole

PO Box 999

Richland, WA 99352

U. of Arizona

Dept. of Hydrology and Water Res.

Attn: S. Davis

Tucson, AZ 85719

Pacific Northwest Laboratory

Attn: F. H. Dove

PO Box 999

Richland, WA 99352

U. of Arizona

Dept. of Hydrology and Water Res.

Attn: D. Evans

Tucson, AZ 85719

Massachusetts Institute of Technology

Attn: D. R. F. Harleman

Ford Professor of Engineering

Cambridge, MA 02139

$\mathrm{Re} / \mathrm{Spec}$ Inc.

Attn: S. Key

Box 1984

3815 Eubank NE

Albuquerque, NM 87191
P. Montazer

USGS-WRD, Mail Stop 416

Federal Center

Denver, CO 80225

U. of Arizona

Dept. of Hydrology and Water Res.

Attn: S. Neuman

Tucson, AZ 85719

W. W. Owens

502 Via Cisco

San Clemente, CA 92672

Princeton University

Civil Engineering Dept.

Attn: G. Pinder

Princeton, NJ

Disposal Safety Inc.

Attn: B. Ross

1211 Conn. Ave. NW

Suite 610

Washington, DC 20036

NM Tech.

Dept. of Soil Sciences

Attn: D. Stevens

Socorro, NM 87801

Lawrence Livermore National Laboratories

Attn: K. Eggert

PO Box 808 L206

Livermore, CA 94550

Pacific Northwest Laboratory

Attn: G. W. Gee

PO Box 999

Richland, WA 99352

IT Corporation

Attn: P. Kelsall

2340 S. Alamo

Albuquerque, NM 87106

OTHA, Inc.

Attn: J. A. Lieberman

PO Box 651

Glen Echo, MD 20812 
DISTRIBUTION (continued):

U. of California

Lawrence Berkeley Laboratories

Attn: T. N. Narasimhan

Berkeley, CA 97420

Earth Sci. Branch

Attn: T. J. Nicholson

USNRC Mail Stop 1130-55

Washington, DC 20815

U. of California

Dept. of Nuclear Engineering

Attn: T. R. Pigford

Berkeley, CA 94720

Lawrence Berkeley Laboratories

Attn: J. Rulon

Berkeley, CA 97420

Science Applications International Corporation

Valley Bank Center

Attn: M. Teubner

101 Convention Center Dr.

Suite 407

Las Vegas, NV 89109

Los Alamos National Laboratory

Attn: B. J. Travis

PO Box 1663

Los Alamos, NM 87545

Earth Science Division

Lawrence Berkeley Laboratories

Attn: J. S. Y. Wang

Berkeley, CA 97420

US Geological Survey

Attn: D. T. Hoxie

MS 416, Box 25046

Denver Federal Center

Denver, CO 80255

\section{DRI}

Attn: S. Tyler

2505 Chandler Ave., Suite 1

Las Vegas, NV 89120

USGS-WRD

Attn: W. E. Wilson

Mail Stop 416

Federal Center

Denver, CO 80225
Lawrence Berkeley Laboratories

Attn: G. S. Bodvarsson

Berkeley, CA 97420

1511 N. E. Bixler

1511 R. R. Eaton

6300 R. W. Lynch

6310 T. O. Hunter

6310 CF 72-12144-1.6/NQ

6311 L. W. Scully

6311 C. Mora

6312 G. E. Barr

6312 F. W. Bingham

6312 A. L. Dudley

6312 J. H. Gauthier

6312 B. S. Langkopf

6312 W. B. Miller

6312 R. R. Peters (20)

6312 A. C. Peterson

6312 N. K. Prindle

6312 R. W. Prindle

6312 M. S. Tierney

6312 M. Wilson

6312 J. G. Yeager

6313 T. E. Blejwas

6313 E. A. Klavetter (20)

6313 F. B. Nimick

6313 R. M. Zimmerman

6314 J. A. Fernandez

6314 J. R. Tillerson

6315 M. J. Eatough

6315 P. C. Kaplan

6315 Y. T. Lin

6315 S. Sinnock

6331 A. R. Lappin

6332 WMT Library (20)

6430 N. R. Ortiz

6431 E. J. Bonano

6431 R. M. Cranwell

6431 R. Guzowski

7223 R. G. Easterling

7223 F. W. Spencer

7223 I. J. Hall

8024 P. W. Dean

3141 S. A. Landenberger (5)

3151 W. L. Garner (3)

3154-1 C. H. Dalin (28)

For DOE/OSTI (Unlimited Release) 